University of New Hampshire

University of New Hampshire Scholars' Repository

Spring 2015

\title{
Examining Situations Involving Intimate Partner Aggression: A Dyadic Study of Agreement on Behaviors, Attributions, and Emotional Effects
}

Angela Marie Neal

University of New Hampshire, Durham

Follow this and additional works at: https://scholars.unh.edu/dissertation

\section{Recommended Citation}

Neal, Angela Marie, "Examining Situations Involving Intimate Partner Aggression: A Dyadic Study of Agreement on Behaviors, Attributions, and Emotional Effects" (2015). Doctoral Dissertations. 2182. https://scholars.unh.edu/dissertation/2182

This Dissertation is brought to you for free and open access by the Student Scholarship at University of New Hampshire Scholars' Repository. It has been accepted for inclusion in Doctoral Dissertations by an authorized administrator of University of New Hampshire Scholars' Repository. For more information, please contact Scholarly.Communication@unh.edu. 
EXAMINING SITUATIONS INVOLVING INTIMATE PARTNER AGGRESSION:

A DYADIC STUDY OF AGREEMENT ON BEHAVIORS, ATTRIBUTIONS, AND

EMOTIONAL EFFECTS

\author{
BY \\ ANGELA M. NEAL \\ Elmira College, B.A., 2010 \\ University of New Hampshire, M.A., 2012 \\ DISSERTATION \\ Submitted to the University of New Hampshire \\ in Partial Fulfillment of \\ the Requirements for the Degree of \\ Doctor of Philosophy \\ in
}

Psychology

May, 2015 


\section{DISSERTATION COMMITTEE PAGE}

This thesis/dissertation has been examined and approved in partial fulfillment of the requirements for the degree of Doctorate of Philosophy in Psychology by:

Dissertation Director, Dr. Katie Edwards, Assistant Professor of Psychology

Dr. Victoria Banyard, Professor of Psychology

Dr. Rebecca Warner, Professor of Psychology

Dr. Lisa Jones, Research Associate Professor of Psychology

Dr. Sharyn Potter, Associate Professor of Sociology

On April 7, 2015

Original approval signatures are on file with the University of New Hampshire Graduate School. 


\section{ACKNOWLEDGEMENTS}

First, I would like to thank the funders of this project. This research was supported by the Grant-in-Aid Program of the American Psychological Association's Society for the Psychological Study of Social Issues, as well as the Department of Psychology at the University of New Hampshire. This research literally could not have been done without them.

I would also like to express gratitude to my graduate advisers Dr. Katie Edwards and Dr. Edward Lemay for all of their support during the last several years. During the beginning of my graduate career, Dr. Lemay's constant assistance and willingness to share his breadth of statistical knowledge helped paved the way for my development into a scholar of the field. During the second half of my graduate career, the unwavering support and dedication of Dr. Edwards, as well as the extensive opportunities she has given me, have expanded my understanding of the field, as well as given me experience with more applied psychology. In addition, I would like to thank my committee members: Drs. Victoria Banyard, Rebecca Warner, Lisa Jones, and Sharyn Potter for all of their feedback and advice throughout the dissertation process.

In addition, I would like to show appreciation to the numerous undergraduate research assistants that have given their time and energy to this project. Without their continual efforts, this project would not be possible.

Finally, I would like to thank my family for their unconditional love and support. Each stage of my career, from childhood to now and beyond would surely be difficult if not impossible without their kindness. Their encouragement has been a perpetual stream of help that has made the entire process leading up to and completing the $\mathrm{PhD}$ seem far less laborious than it probably could have been. 


\section{List of Tables}

$\underline{\text { Table }} \quad \underline{\text { Page }}$

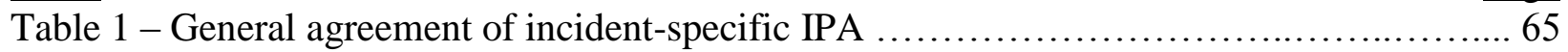

Table 2 -Comparing couples with one or two partners indicating aggression .................. 66

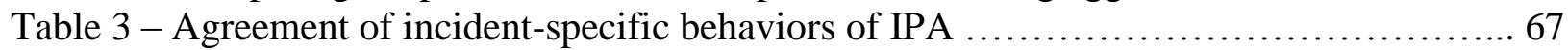

Table 4 -Correlates of agreement on specific IPA-related behaviors...................... 70

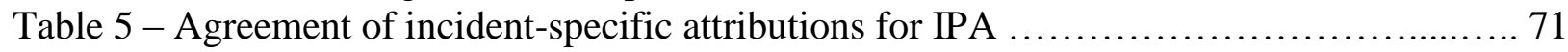

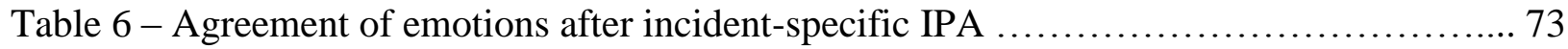

Table 7 - Correlates of agreement on IPA emotional effects.............................. 74 


\section{List of Figures}

Table

$\underline{\text { Page }}$

Figure 1 - Breakdown of participants in current study . 


\begin{abstract}
EXAMINING SITUATIONS INVOLVING INTIMATE PARTNER AGGRESSION:

A DYADIC STUDY OF AGREEMENT ON BEHAVIORS, ATTRIBUTIONS, AND

EMOTIONAL EFFECTS

by
\end{abstract}

Angela M. Neal

University of New Hampshire, May, 2015

There is a growing body of literature investigating agreement of partners on instances of intimate partner aggression (IPA) well as attributions for why people engage in IPA. Although our understanding has increased, there remains a major gap in the literature: the utilization of only one member of a couple's reports of the aggression and attributions (i.e., partners' perceptions of why an event of IPA occurred). Using a dyadic study, romantic couples were asked to independently discuss the same psychological, physical, and sexual IPA incidents in their relationship. Seeking to bridge the two bodies of literature of both perpetrators' and victims' perceptions of the same IPA incidents, the current study found that while there was moderate agreement on whether or not aggression even happened in an instance of IPA, as well as agreement on the general type of aggression that occurred (e.g., psychological), there was little to no agreement otherwise (i.e., Kappa statistics indicating agreement ranging from nonexistent agreement to poor agreement on specific behaviors, attributions, and emotional effects). Partners typically disagreed on most behaviors that were enacted during instances of aggression, the attributions for the aggression (with the exception of alcohol), as well as the emotional outcomes related to IPA. In addition, disagreement on specific behaviors of aggression were related to various correlates (i.e., hypergender ideology, emotion dysregulation, controlling behavior, 
perceptions that one/one's partner will perpetrate in the future, past year physical IPA victimization/perpetration, past year psychological IPA victimization/perpetration, and any past year IPA victimization/perpetration), whereas disagreement on emotional effects was only related to past-year psychological IPA perpetration. These findings and area of research are imperative to understanding the complexities of conflict in the realm of romantic relationships, as well as being vital for the development and success of IPA prevention and treatment programs. 


\section{TABLE OF CONTENTS}

DISSERTATION COMMITTEE PAGE ................................................................... ii

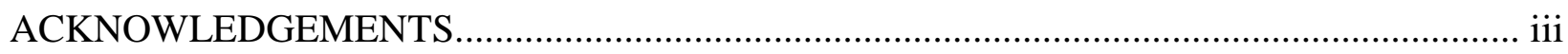

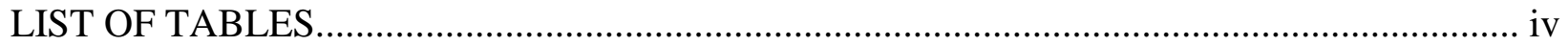

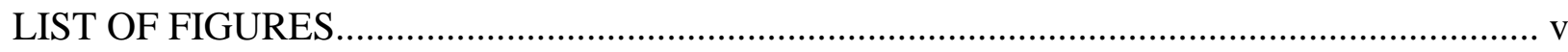

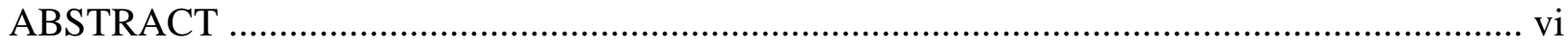

CHAPTER $\quad$ PAGE

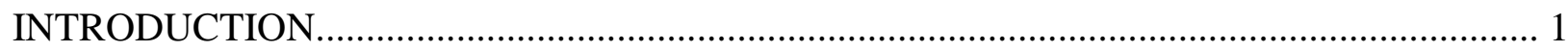

I. PERCEPTIONS OF AGGRESSIVE BEHAVIORS WITHIN IPA INCIDENTS................... 1

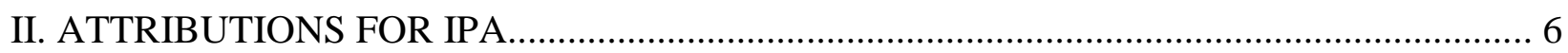

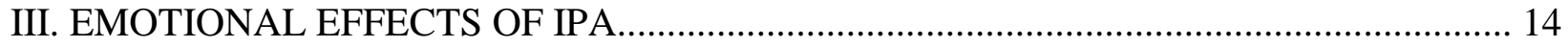

IV. CORRELATES OF AGREEMENT/DISAGREEMENT .............................................. 16

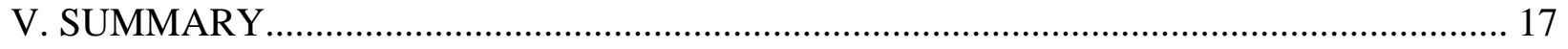

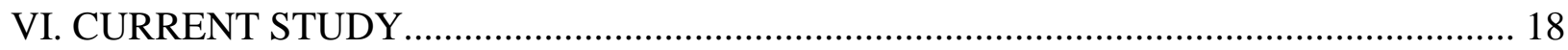

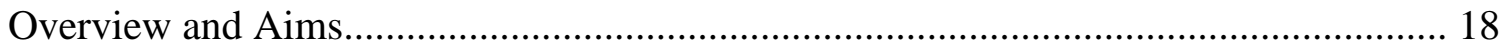

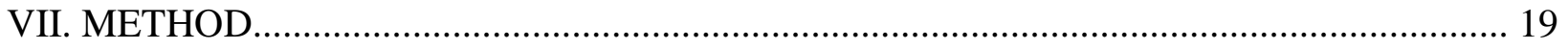

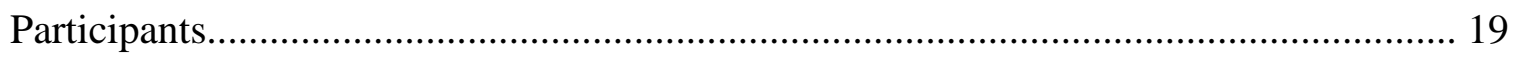

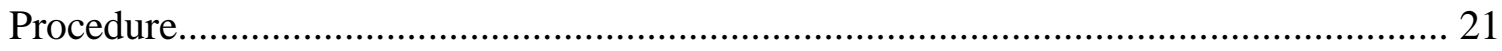

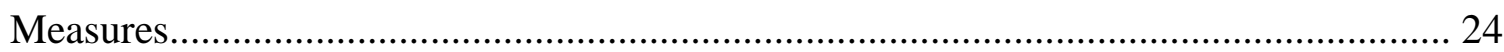

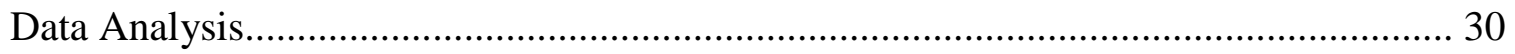

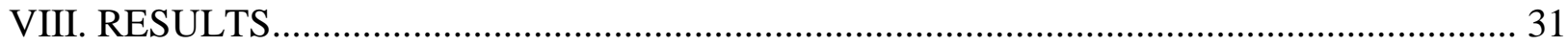

General Description of Specific Incidents of IPA ............................................. 31

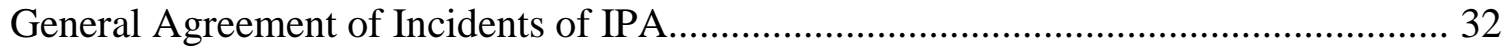


Agreement on Specific Aggressive Behaviors within an IPA Incident................ 34

Agreement on Attributions for the Aggression within an IPA Incident......................... 35

Agreement on Emotional Effects Following an IPA Incident.................................. 36

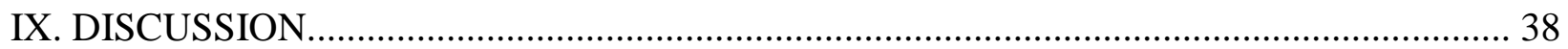

A Conceptual Understanding of Specific Instances of Relationship Conflict................. 38

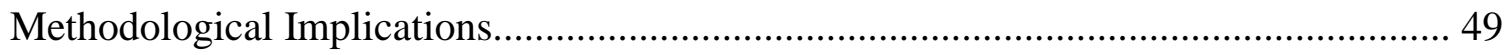

Implications for Policy and Practice ............................................................... 50

X. LIMITATIONS AND FUTURE DIRECTION ........................................................ 53

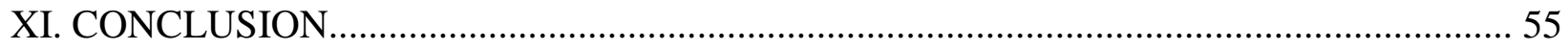

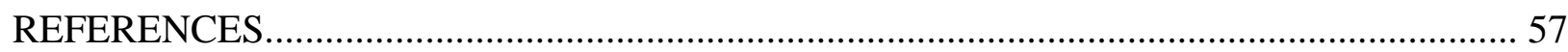

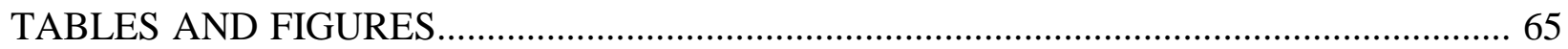

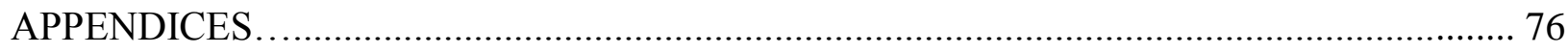

IRB APPROVAL LETTER.................................................... 77

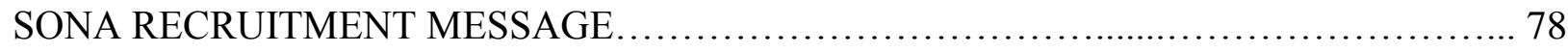

PARTICIPANT RECRUITMENT FLIER ........................................... 79

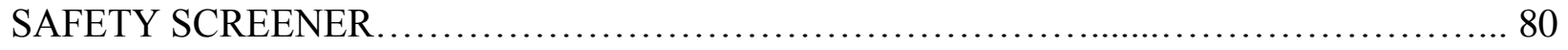

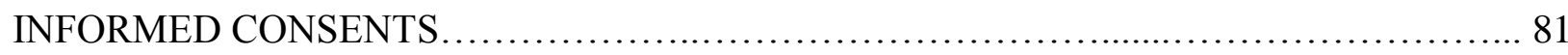

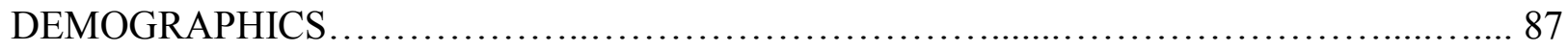

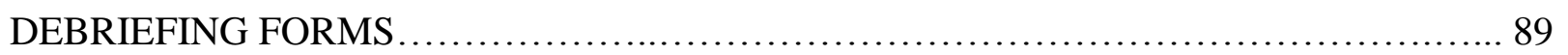

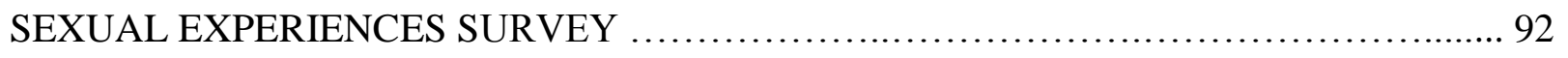

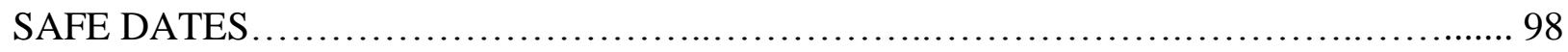

EVENT-SPECIFIC IPA.................................................... 102

ATTRIBUTIONS FOR IPA..................................................... 105 


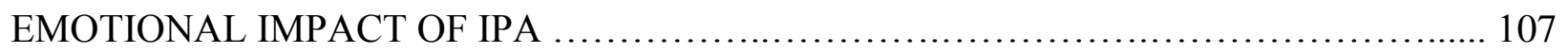

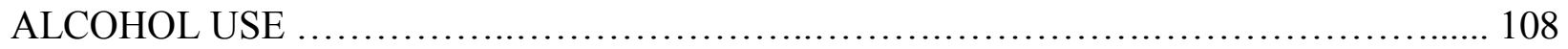

ATTACHMENT ANXIETY....................................................... 109

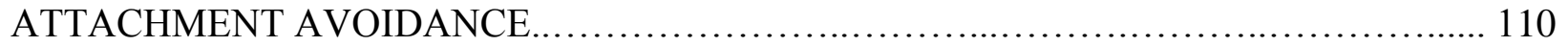

CONTROLLING BEHAVIOR ......................................................... 111

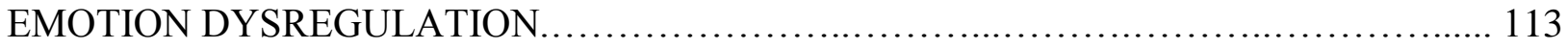

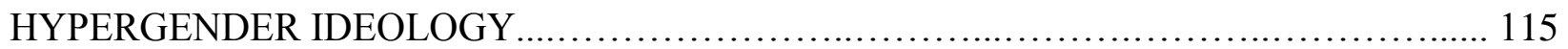

INVESTMENT MODEL SCALE.................................................. 116

PROPENSITY AND PERCEIVED PARTNER PROPENSITY FOR FUTURE IPA............ 118

SELF-ESTEEM............................................................. 119 
Examining Situations Involving Intimate Partner Aggression:

A Dyadic Study of Agreement on Behaviors, Attributions, and Emotional Effects

Intimate partner aggression (IPA), including physical, psychological, and sexual abuse of one's partner, is both a common and substantial problem in our society, with about $13 \%$ of relationships consisting of physical IPA (e.g., hitting, pushing), 23\% sexual IPA (e.g., coercing or forcing sexual activity), and 15-71\% psychological IPA (e.g., insulting, threatening) (Edwards, Desai, Gidycz, \& VanWynsberghe, 2009; Coker et al., 2002). Research also suggests that a great deal of IPA is mutual (i.e., both partners engage in IPA perpetration) (for review, see Archer, 2000). Thus, understanding both partners' perceptions of the behaviors that occur within instances of partner aggression, their perceptions of why the IPA perpetration occurs, as well as the emotional outcomes of IPA, are vital to our understanding of these aggressive behaviors. People tend to explain events by incorporating their role in the event into what actually happened (Fisk \& Taylor, 1991). Thus, when asking perpetrators and victims what behaviors occurred during an instance of partner aggression, why the aggression occurred, or even how the event emotionally impacted the partners involved, there are biases that can distort what people report as what really happened, as well as why it occurred (e.g., Fincham, Beach, \& Baucom, 1987; Fletcher, Fitness, \& Blampied, 1990). Thus, each incident of partner aggression can be examined from the perpetrator, as well as the victim, and their reports may not be identical, which has important methodological and practice implications.

\section{PERCEPTIONS OF AGGRESSIVE BEHAVIORS WITHIN IPA INCIDENTS}

Previous research has investigated the perceptions that people have of the aggressive behaviors that occur within their relationship. Much of this research, however, has investigated rates of IPA using only victims' or perpetrators' perceptions of IPA incidents. However, the 
problem with using only one partner's accounts of an incident of IPA is that, on average, couples agree only about $48 \%$ of the time on general behaviors enacted, even those occurring within the last 24-hours (e.g., watching TV together, going to a bar together, having a humorous conversation with each other) (Jacobson \& Moore, 1981). More specific to IPA, research has shown that agreement rates on whether or not IPA has ever happened are low to moderate (for review, see Armstrong, Wernke, Medina, \& Schafer, 2002), with kappa statistics ranging from about .00 to .58 (Caetano, Schafer, Field, \& Nelson, 2002; Cunradi, Bersamin, \& Ames, 2009; Moffitt et al., 1997; Schafer, Caetano, \& Clark, 1998), indicating low to moderate agreement (Landis \& Koch, 1977). Consistent with this, Margolin (1987) found that, reports of only one partner increase reports of IPA $100 \%$ from reports where both partners report the IPA. Put differently, if only one partner's reports are used, depending on which partner's report it is, the rates could differ greatly. Thus, one partner does not necessarily give the best estimation of the aggression that may occur within a couple.

According to Armstrong and colleagues (2002), determining the amount that romantic partners agree about the incidence of IPA is vital for obtaining IPA prevalence rates that are accurate. In a review of the present literature on IPA couple agreement, Armstrong et al. (2002) found that, in general, couples tend to disagree on the extent of IPA within their relationship. Perry and Fromuth (2005) used a dyadic sample in which at least one partner was a student, investigating aggression across the course of the relationship. They found that, when using only one partner's report of the aggression, $60 \%$ of couples could be labeled as physically aggressive, while only $28 \%$ of couples would be labeled as such if agreement between partners was needed for classification. Using data from a nationally representative sample of 4,088 married romantic couples, Szinovacz and Egley (1995) found that couples tended to agree on the occurrence of 
IPA in their relationships in general, as well as when asked to report on past-year aggression (using percent agreement, they agreed $88 \%$ of the time). However, they acknowledge that this strength in agreement was really inflated by agreement on the lack of aggression, as opposed to the presence of aggression. When investigating couples in which at least one partner reported aggression, this agreement dropped to about $25 \%$ of couples agreeing on the relationship's total aggression.

Moffitt and colleagues (1997) have also investigated types of IPA separately (e.g., psychological, physical), using a nationally representative sample of 360 romantic couples in New Zealand. When participants were asked to report on past-year aggression, Moffitt et al. (1997) found poor to fair agreement between partners (psychological IPA Kappa statistics ranging from .31 to .32 and physical IPA Kappa statistics ranging from .34 to .46). Cunradi, Bersamin, \& Ames (2009) also found that, among 897 union workers and their spouses, agreement in reports of any physical aggression within the past year ranged from .36 to .40 , indicating poor agreement. These findings were also supported in a clinical sample of 54 couples in which the male partner was recruited from a treatment center for substance use (Freeman, Schumacher, \& Coffey, 2015). In their study, they found that agreement on past-year physical IPA ranging from .44 to.59, psychological IPA ranging from .43 to .47 , and sexual IPA ranging from .03 to .19 , with no agreement on women's perpetration of sexual IPA within the past year (Freeman et al., 2015). These results suggest that, while agreement is generally low to moderate, there is typically more agreement on physical and psychological IPA than sexual IPA (i.e., fair agreement for physical and psychological aggression compared to none to slight agreement for sexual aggression).

Whereas the previous studies reviewed examined IPA agreement in general or collapsed 
across subscales of IPA (e.g., psychological, physical), researchers have also examined agreement of specific behaviors of IPA. When considering physical and psychological IPA items individually, agreement begins to be less consistent and drops further than when comparing these types of IPA at the subscale level. Using a sample of 897 union workers and their spouses, Cunradi et al. (2009) found that agreement statistics on specific behaviors of physical IPA within the past year ranged anywhere from .06 (him slamming her against a wall) and .36 (him slapping her). Past-year Kappa agreement statistics in Moffitt et al.'s (1997) nationally representative sample of $360 \mathrm{New}$ Zealand romantic couples ranged from .00 (e.g., her choking him) to .58 (e.g., her beating him up) for physical IPA and .03 (e.g., him telling his partner she cannot work or study) to .54 (e.g., her damaging something in the home out of anger) for psychological IPA. Using a nationally representative sample of 1,635 mostly married couples, Schafer, Caetano, and Clark (1998) estimated that partners tended to agree that aggression occurred during the previous year about $8-21 \%$ of the time. However, this study primarily investigated physical IPA, with only one item (i.e., forced sex) measuring sexual IPA, and one item (i.e., threatened with a knife or gun) measuring psychological IPA. Furthermore, there was low agreement for forced sex, with their Kappa statistics ranging from .15-.16, indicating only slight agreement (for discussion of Kappa strength, see Freeman, Schumacher, \& Coffey, 2015; Landis \& Koch, 1977). Additionally, the one item of psychological IPA (i.e., threatened with a knife or gun) was reported at rates too low for a Kappa statistic to even be reported. The agreement statistics for individual items of physical IPA, however, ranged from .00 (her burning or scalding him; her beating him up) to .49 (him pushing, grabbing, or shoving her), with the highest agreement items being only fair agreement (see Freeman, Schumacher, \& Coffey, 2015; Landis \& Koch, 1977). Thus, while there was some agreement on types of IPA enacted when 
investigating them more in general, depending on the type of aggression being explored, agreement on its enactment varies drastically.

Indeed, some research has found moderate agreement between couples on the enactment of IPA, albeit typically with IPA in general or when investigating specific forms of IPA in general (e.g., physical, psychological) (e.g., Cunradi et al., 2009; Freeman et al., 2015; Moffitt et al., 1997), however there are limitations with these studies. To date, the agreement literature has focused on non-college samples (e.g., representative samples, clinical samples). While these methods of sampling have their merits, agreement on aggression in college students has largely been ignored. In light of the fact that the vast majority of IPA research is conducted with this population, not just due to convenience, but because they consist of one of the highest at-risk age groups for IPA (e.g., Edwards, Desai, Gidycz, \& VanWynsberghe, 2009), it is important that we examine agreement among college students. Understanding if and when partners agree on what actually occurs during these instances of aggression is vital for developing successful treatment and prevention efforts tailored to this population and can also provide important light on methodological considerations when conducting IPA research.

In addition to sampling limitations, in order to investigate agreement on IPA, studies typically examine the relationship as a whole, or over the past year, as opposed to investigating specific instances of IPA (e.g., Coker et al., 2002; Schafer, Caetano, \& Clark, 1998). This type of methodology, in which individuals are asked to consider long periods of time, may increase recall bias and could help explain why there is such low agreement in behaviors reported by each partner. In other words, it is possible that couples (especially those in which the relationship is rather aggressive) may agree that specific behaviors of aggression (e.g., hitting, threatening) have occurred at some point, but they may not necessarily agree that the behavior occurred during any 
specific instance of aggression. Thus, past research may really tapping into general agreement of aggressive behaviors, as opposed to whether or not partners tend to agree on whether or not different forms of IPA occur at any given point in time. By investigating how much partners agree on what actually occurs within instances of partner aggression, we can develop an understanding for why there may be a disconnect between partners' interpretations of why the aggression occurred and what each partner was feeling after the event. If partners generally cannot agree on what happened during an incident of IPA, then their justifications for the aggression, as well as their perceptions of the aggression's effects will likely be biased toward those initial interpretations. In other words, treatment aimed at developing a mutual understanding of the reasons and effects of partner aggression may not be fruitful if the partners cannot agree on what actually happened.

Additionally, in order to aid in prevention and intervention efforts, it is important to obtain more situational and contextual information on specific incidents of IPA. Understanding what led up to aggression, why that aggression occurred, and specifically what sorts of behaviors (e.g., insulting, pushing) were actually performed in a specific IPA incident can give researchers a better understanding of why people aggress, as well as how to diminish and eradicate that aggression. Thus, it is important to investigate how people make sense of the aggression within their relationships in order to determine what methods would be most successful at ending that aggression.

\section{ATTRIBUTIONS FOR IPA}

In addition to understanding if couples agree on acts of IPA within a relationship, another important area to examine is agreement on attributions for IPA, or how both partners make sense of the aggression within their relationship. Although there is a growing body of research 
examining attributions, they have historically been examined only from one partner's perspective. Over the past few decades our understanding of reasons for IPA perpetration has increased; however, there remain some issues with the body of research. One issue with the literature is the conceptualization of what is being investigated. As it stands, the literature refers to the reasons why people engage in IPA perpetration as their "motives." However because research on why people perpetrate never uses prospective or concurrent reports inquiring about why IPA will occur or is occurring, researchers focus on why people believe an IPA event happened. Thus, it could be argued that the retrospective reports used by the IPA literature are tapping into attributions (i.e., individuals' explanations or reasoning for why the aggression occurred), as opposed to motives (i.e., what drives perpetrators to engage in aggression).

While it is reasonable to assert that people may accurately report their partners' or their own reasons for perpetrating IPA, the IPA literature has mainly asked participants the reasons why they/their partner were aggressive (e.g., Stuart et al., 2006), presuming both an absence of recall bias and that the individuals involved consciously know why they/their partner perpetrated. Thus, "attributions" may more accurately describe each partner's perceptions of IPA perpetration than "motives." In addition, researchers have consistently acknowledged that subjective perceptions are typically more robust predictors of psychological adjustment and health than objective reality (see Sarason, Sarason, \& Pierce, 1995). In other words, it is not necessarily actual events in one's relationship, but rather it is the perceptions of events, that are important for relational outcomes (e.g., Lemay \& Neal, 2014). Similarly, it is reasonable to presume that the importance of perceptions, independent of accuracy, can be extended to IPA perpetration. In other words, people's perceptions of why perpetration occurs may act as better predictors of future IPA perpetration and the emotional effects of the perpetration than accurate 
descriptions of why perpetration occurs, having implications for IPA prevention and intervention efforts (discussed below). Therefore, due to potential recall bias and the robust prediction value of perceptions as opposed to accuracy, it may be more appropriate to temper the term "motives" to "attributions" when examining self-reported, retrospective reasons for engaging in IPA towards a partner.

While research has examined both perpetrator and victim attributions for why IPA occurred, these literatures are rarely investigated within the same study and when they are, they include IPA victims and perpetrators from different relationships (e.g., Bograd, 1988; Cascardi, \& Vivian, 1995; Follingstad, Wright, Lloyd, \& Sebastian, 1991). Victims and perpetrators are more often investigated independently (i.e., examining only perpetrator's or victims' attributions) (e.g., Caldwell, Swan, Allen, Sullivan, \& Snow, 2009; Christopher, Owens, \& Stecker, 1993; Hamberger, Lohr, \& Bonge, 1994; Jones, 1993). In addition to this, there is also a variety of ways in which attributions for IPA are measured. While some studies utilize various “check all that apply” scales of attributions for IPA (e.g., Follingstad et al., 1991), others use scales to indicate one's most-endorsed attribution (e.g., Whitaker, 2014). In addition, these scales do not always include the same attributions as selection options (for examples, see Follingstad et al., 1991; Henning, Jones, \& Holdford, 2005). Furthermore, other studies utilize a more qualitative methodology, using open-ended prompts (e.g., Bograd, 1988; Cascardi \& Vivian, 1995). Thus, there is a great deal of variability within the literature regarding how attributions for IPA are measured, which makes synthesizing the extant literature difficult.

Within the studies investigating attributions for perpetration, a recent review by Neal and Edwards (2015) determined that 88 such attributions have been documented in previous research. Across studies, women have been found to perpetrate physical IPA out of anger 
(Caldwell, Swan, Allen, Sullivan, \& Snow, 2009; Downs, Rindels, \& Atkinson 2007; Hettrich \& O’Leary, 2007; Walley-Jean \& Swan, 2009), an inability to express themselves verbally (Hettrich \& O’Leary, 2007; Walley-Jean \& Swan, 2009), retaliation, and self-defense (DeKeseredy, Saunders, Schwartz, \& Alvi, 1997; Fiebert \& Gonzalez, 1997; Follingstad, Wright, Lloyd, \& Sebastian, 1991; Foshee et al., 2007; Kernsmith \& Tolman, 2011; Leisring, 2012; Makepeace, 1986; Shorey, Meltzer, \& Cornelius, 2010). Furthermore, women have also been consistently shown to endorse attributions, related to their own perpetration, of a desire to harm or punish their partner (Foshee et al., 2007; Kernsmith, 2005; Makepeace, 1986), jealousy (Flemke \& Allen, 2008; Harned, 2001; Leisring, 2012; Olson \& Lloyd, 2005), to get attention (Fiebert \& Gonzalez, 1997; Leisring, 2012; Olson \& Lloyd, 2005; Shorey et al., 2010), control/influence (Follingstad et al., 1991; Whitaker, 2014), and their IPA being in play (Foshee et al., 2007; Perry \& Fromuth, 2005). Research using male only samples has found that men's attributions specific to their own perpetration are less consistent, with different studies finding dissimilar results (see Neal \& Edwards, 2015; e.g., attributions of losing control and to express anger have been documented as common attributions in some studies with men, but not others). However, being drunk or high has been consistently found for men's physical IPA perpetration (Carrado, George, Loxam, Jones, \& Templar, 1996; Cascardi \& Vivian, 1995; Epstein-Ngo et al., 2013; Hamberger et al., 1994).

Other researchers have conducted studies with both male and female samples. These studies have found a variety of attributions that both men and women report. These similar attributions consist of those such as anger, retaliation, jealousy/control, and self-defense for psychological IPA (Perry \& Fromuth, 2005), and self-defense, inability to express themselves verbally, to get control, and to get attention for physical IPA (Fernandez-Fuertes \& Fuertes, 
2010; Harned, 2001; Makepeace, 1986). Research directly comparing men and women's attributions for IPA has found that men's perpetration is more often attributed to substance use/abuse (Henning et al., 2005), retaliation for being hit first (Follingstad et al., 1991), and intimidation (Makepeace, 1986) than women's perpetration, however women's perpetration tends to be attributed more to self-defense (Makepeace, 1986) and retaliation for emotional hurt (Follingstad et al., 1991).

Whereas most of the research has focused on perpetrators' self-reported attributions for IPA perpetration, studies have also begun to investigate victims' attributions for their partners' perpetration. However, research on victims' ascriptions is more lacking. In fact, in a recent review of victims' attributions for their partner's aggression, only 13 such articles were found (Neal \& Edwards, 2015). These studies often include only victims and utilize scales similar to those discussed above (e.g., Epstein-Ngo et al., 2013; Walley-Jean \& Swan, 2009) or open-ended prompts (e.g., Jones, 1993; Olson \& Lloyd, 2005). Male and female victims of IPA have both attributed their partners' physical IPA to anger (Cascardi \& Vivian, 1995; Epstein-Ngo et al., 2013; Follingstad et al., 1991; Jackson et al., 2000), trying to make them do something/stop doing something (e.g., Bograd, 1988; Carrado et al., 1996; Follingstad et al., 1991; Jones, 1993; Olson \& Lloyd, 2005), and their partner being provoked/threatened (Carrado et al., 1996; Cascardi \& Vivian, 1995). Male and female victims of IPA have also consistently attributed their partners' physical IPA perpetration to jealousy and retaliation (Follingstad et al., 1991; Jackson et al., 2000). Research on victims' attributions for their partners' perpetration has also consistently found attributions made specifically by female victims for their male perpetrators. Female victims have attributed their partners' perpetration to the men's expectations of the wives' duties (Dobash \& Dobash, 1984; Pahl, 1985), him losing control (Bograd, 1988; Jones, 
1993), and him being under the influence of drugs and/or alcohol (Carrado et al., 1996; EpsteinNgo et al., 2013; Jones, 1993; Olson \& Lloyd, 2005; Pahl, 1985), while these attributions have not been given by male victims to explain their partners' perpetration.

Perpetrators' and victims' attributions for their perpetration are generally varied throughout different studies and samples, though some consistency has been found. Several attributions (e.g., anger, control, self-defense, retaliation, to get attention) have been endorsed by perpetrators as well as by victims. However, studies indicating perpetrator attributions and studies indicating victims' attributions utilize non-dyadic methodologies. In other words, there are no studies to date that have asked members of the same relationship their attributions for why the same IPA incident occurred. Perpetrators' attributions have also been found that are not found in the victims' literature (see Neal \& Edwards, 2015; e.g., punish partner, relationship decline, response to something said/threatened).

One partner does not necessarily give the best estimation of the aggression (e.g., presence of IPA, and thus attributions for IPA and outcomes of IPA) that may occur within a couple. Although not directly tested, preliminary evidence of lack of agreement in attributions is evident in the literature, as male and female victims have attributed their partners' perpetration to factors not acknowledged by perpetrators (e.g., relationship dissolution, their being under the influence of alcohol, their partners' jealousy, their own jealousy, and the woman's refusal of sexual advances). In particular, there are several attributions endorsed by female perpetrators that male victims do not attribute to their partners (e.g., anger, an inability to express themselves verbally, self-defense, retaliation, stress, and losing control). In fact, female victims tend to attribute these to their perpetrating partners; put another way, female perpetrators and victims oftentimes 
attribute perpetration to anger, stress, etc., but men tend not to acknowledge these attributions for their perpetration.

According to attribution theory, people tend to differentially attribute the behavior of others and themselves (Jones \& Nisbett, 1972). Thus, attributions for perpetration can be examined from two points of view - self-reported attributions of perpetrators and attributions as described by victims. Given the growing body of literature on attributions for IPA perpetration from the aggressors' perspective, the next logical stage in understanding the dynamics of IPA is to investigate victims' attributions for their partners' IPA perpetration. While this next step seems reasonable enough, little research has actually explored victims' assessments of a partner's aggression, which is an important factor in understanding the context of IPA perpetration. This is important because it is not only the accurate evaluations of one's partner that determines relationship wellbeing, but the perceptions of one's partner are also imperative, independently of accuracy (e.g., Murray, Holmes, \& Griffin, 1996). Specific to IPA perpetration, the attributions given for a partner's or one's own aggression may be stronger predictors of relationship variables (e.g., satisfaction) than accurately identifying why the aggression occurred. In their study on accuracy and positive illusions of romantic partners, Murray et al. (1996) compared perceptions of one's partner compared to that partner's perceptions of himself/herself. In doing this, they found that individuals were, in general, more satisfied in their relationship when their partner viewed them in a generally more positive light than they viewed themselves. Thus, not only is accuracy important in understanding relationship events, but the perceptions of those events are also important, as those perceptions may better predict other relational variables, which underscores the importance of both partners' perceptions of relationship events. Similar to this idea, attributions give individuals justification or explanations for the behavior of themselves 
and others, so victims' perceptions, or attributions for their partners' IPA perpetration, may predict other relational variables (e.g., satisfaction, how well couples may respond to therapy). Thus, it is vital for researchers to combine research on victims' and perpetrators' perceptions of, or attributions for, IPA perpetration within one study.

Understanding agreement in attributions for IPA perpetration is imperative when creating and implementing interventions for couples experiencing IPA. Treating couples who experience IPA is controversial (Greene \& Bogo, 2002; Jacobson \& Gottman, 1998; Stith, Rosen, McCollum, \& Thomsen, 2004), and it is believed that couple's therapy inherently leads to blaming the victim (Babcock \& Taillade, 2000). However, according to Jacobson and Gottman (1998), couple's therapy is beneficial in certain circumstances (i.e., when the perpetration is not fueled by control, dominance, and coercion) or when the IPA is mutual. Thus, if the victims' and perpetrators' attributions for IPA can be determined, couples that experience IPA for reasons other than control, dominance, and coercion (e.g., because of substance use, stress, anger, selfdefense, retaliation, losing control) may benefit from couple's treatment. Research that examines similarities and differences in attributions of IPA can help determine the extent to which victims and perpetrators agree on the primary reasons for IPA, as it may be difficult to focus on changing aggressive behaviors if the reasons for why they occur are not agreed upon.

Furthermore, once couples begin taking part in therapy, therapists focus on increasing perpetrators' responsibility for using aggression and ceasing IPA perpetration via conflict resolution skills and anger management (see La Taillade, Epstein, \& Werlinich, 2006). By understanding why each partner believes IPA occurs, therapists can fine-tune their efforts to increase perpetrator responsibility, as well as decrease victim blaming. In addition, it can be determined how effective anger management and conflict resolution skills may be. If 
perpetrators and victims attribute IPA in their relationship to anger-related reasons, then anger management would likely be beneficial. If, instead, partners attribute IPA to other things, such as substance use, then anger management may not be the appropriate focus of treatment. Thus, being able to ascertain both partners' attributions for IPA within the relationship has important implications for treatment.

In addition to clinical applications, understanding the differences between the attributions made by each partner may have implications for intervention efforts. Being able to show couples that both partners may not have the same interpretation of the events (both peaceful and aggressive) that occurs within their relationship could aid in partners' efforts to understand each other and work on their relationship/avoid engaging in aggression in the future (Jacobson \& Moore, 1981). Through understanding that both partners have different perspectives of what goes on in their relationship (Fisk \& Taylor, 1991), each partner can learn to acknowledge that these differing perspectives could lead to conflict.

\section{III.EMOTIONAL EFFECTS OF IPA}

In addition to the limitations of the IPA behaviors and attributions literature, research has largely ignored the emotional outcomes of IPA on both partners, and whether or not agreement exists between their accounts. While research has found that women tend to experience worse outcomes than men (e.g., Archer, 2000; Koss et al., 2007), the literature does not focus much on perceptions of emotional outcomes. In other words, research has largely neglected to investigate and report on the extent to which partners agree on the emotional outcomes of IPA perpetration for both the victim and perpetrator.

While victimization has been linked to psychological distress, such as anxiety, depression, and PTSD symptoms (see Golding, 1999; Stets \& Straus, 1990), this focus is 
generally on how many victims have these symptoms, compared to non-victims, as opposed to trying to link the symptoms up with the actual abuse. For instance, using a national sample of 6,002 people, Stets and Straus (1990) found that, 825 people reported aggression, and the more severe aggression they experienced, the more likely they were to have psychosomatic symptoms. While this shows a relationship between IPA and emotional distress, it does not tap into whether or not the distress is perceived to be a cause of the IPA. While research has begun to examine the perceptions of the effects that IPA has on each partner, this research is few and far between. In fact, Perry and Fromuth (2005) used a college sample of 50 couples, and investigated the agreement on psychological effects of the IPA occurring throughout the entire duration of a relationship. This study reported that there were no significant differences between the accounts of both partners on emotional effects; however the researchers neglect to discuss these findings further in the report (Perry and Fromuth, 2005). It is quite possible that the power of using 50 couples was too low for significant differences to emerge. It is also possible that, when reporting on IPA throughout the entire duration of the relationship may lead to greater agreement on how IPA impacts the victim, as the more incidents being considered, the more likely one may be to understand how the victim was impacted.

In addition to the limited findings above, using a sample of 295 college students asked to report on physical IPA occurring throughout the entire duration of a dating relationship, Follingstad et al. (1991) investigated the effects of IPA perceived by both perpetrators and victims. They found that the most common emotional effects perceived by perpetrators for their victims consisted of feeling anger and emotionally hurt, while many men also reported that their partners likely felt fear, anxiety, sadness, and depression. Victims were more likely to report feeling emotionally hurt, sadness, depression, and anger, while female victims specifically 
reported feeling fear, anxiety, and wanting to get away (Follingstad et al., 1991). While there are similarities between both accounts (e.g., feeling emotionally hurt and anger were highly reported by both perpetrators and victims), there were also differences (e.g., only male perpetrators tended to report that their partner felt sad or depressed). However, these findings report on perpetrators and victims who were not in the same relationship.

The current study investigated the extent to which perpetrators and victims similarly perceive how IPA incidents emotionally impact both partners. In other words, the current study examined the extent to which perpetrators/victims perceive the effect that perpetration has on their partners. If perpetrators are unaware of how their partner is emotionally impacted by their actions, they may not understand the extent to which their perpetration negatively impacted their partner.

\section{IV.CORRELATES OF AGREEMENT/DISAGREEMENT}

In addition to recall bias, there may be other reasons that members of a dyad disagree on IPA incidents. Some correlates of this disagreement might be past year IPA, time since the IPA event, perceptions that one/one's partner will perpetrate in the future, controlling behavior, emotion dysregulation, attachment anxiety, attachment avoidance, investment, commitment, satisfaction, qualities of alternatives, alcohol use, self-esteem, hypergender ideology, social desirability, socioeconomic status, age, and relationship length.

Regarding these correlates for agreement/disagreement, because of the exploratory nature of the current study, we primarily examined common correlates of IPA in association with IPA agreement. In addition, a correlate whose relationship to agreement may be more complicated is social desirability. Social desirability involves answering questions, particularly those with potential negative implications, in ways that appear socially acceptable (Edwards, 1957). 
Researchers have long used social desirability as a potential catch-all to explain low agreement between partners, as perpetrators tend to under-report the IPA in the relationship (e.g., Moffit et al., 1997), though research has also explicitly tested social desirability and found it to generally not be related to reports of men's reports of their perpetration of IPA (Freeman et al., 2015). It is also possible that, when investigating IPA using a dyadic sample, that one partner may show social desirability, while the other does not. This would lead one partner to report IPA events accurately, while the other would report in way that make them and their relationship "look good." Thus, social desirability could be related to disagreement, or it could be unrelated altogether.

\section{SUMMARY}

Because other studies do not include members of the same couple, we can really only speculate on whether or not victims and perpetrators form similar perceptions of IPA events, of the behaviors that occur, the attributions for perpetration, as well as similar perceptions of the emotional outcomes of IPA. There may, indeed, be agreement in the perceptions of IPA incidents for some couples, while other couples may be lacking in agreement of IPA. Understanding what differentiates these couples requires studying perpetrators' and victims' recollections of the behaviors occurring instances of IPA, the attributions for the aggression, and the emotional outcomes of that aggression using members of the same couple. Examining both partners of a couple can help us ascertain, not only how perceptions differ between partners, but also why they do so. To do this, in addition to documenting if partners agree on the various qualities of specific incidents of relationship conflict, examining the correlates of these behaviors, attributions, and outcomes (i.e., self-esteem, attachment, history of IPA) is also important in order to understand the factors that discriminate couples who agree and those who 
do not agree on what and why aggression occurs, as well as the outcomes of the IPA. With everything considered, psychological and individual variables (e.g., length of relationship, severity of aggression, type of aggression, jealousy, emotional dysregulation, alcohol use, etc.) may also be related to agreement in attributions for and emotional effects of IPA.

\section{CURRENT STUDY}

\section{Overview and Aims}

Research has examined both perpetrators' perceptions of specific behaviors of IPA and attributions for IPA perpetration, and to a lesser extent, victims' perceptions of behaviors of IPA and attributions for their partner's perpetration. Previous research has also yet to investigate the emotional effects IPA has on both partners. Using an empirical study investigating both perpetrators' and victims' perceptions of IPA (i.e., specific behaviors occurring during the event, attributions for the event, emotions after the event), the current study examined these concepts simultaneously, using both members of romantic couples.

Aim and Hypothesis \#1: Examine how the perceptions of specific behaviors of IPA perpetration may differ between the accounts of both members of romantic couples. Since no study has investigated the specific behaviors within an IPA incident using both members of a romantic couple, hypotheses regarding levels of discrepancies between partners' accounts are predicted due to general disagreement rates in whether IPA even occurs (Caetano, Schafer, Field, \& Nelson, 2002; Cunradi, Bersamin, \& Ames, 2009; Moffitt et al., 1997; Schafer, Caetano, \& Clark, 1998). Thus, it was hypothesized that the majority of couples would disagree on the behaviors that occur within a specific incident of IPA although we generally expected agreement to be higher than studies which utilized longer periods of time when measuring IPA agreement assessment. The current study also aimed to investigate how agreement/disagreement on 
behaviors enacted during each IPA incident relates to various psychological (e.g., satisfaction, self-esteem) and demographic (e.g., age, relationship length) correlates for agreement, however there were no a priori hypotheses for these correlates.

Aim and Hypothesis \#2: Examine how the perceptions of IPA perpetration may differ between the accounts of both members of romantic couples. Since no study has investigated the attributions for an IPA incident using both members of a romantic couple, hypotheses regarding levels of discrepancies between partners' accounts were predicted due to general disagreement rates in whether IPA even occurs (Caetano, Schafer, Field, \& Nelson, 2002; Cunradi, Bersamin, \& Ames, 2009; Moffitt et al., 1997; Schafer, Caetano, \& Clark, 1998). Thus, it was hypothesized that the majority of couples would disagree on attributions for IPA. The current study also aimed to investigate how agreement/disagreement on attributions relates to various psychological (e.g., satisfaction, self-esteem) and demographic correlates (e.g., age, relationship length), however there were no a priori hypotheses for these correlates.

Aim and Hypothesis \#3: Examine how the perceptions of emotional effects of IPA may differ between the accounts of both members of romantic couples and how that disagreement relates to various psychological (e.g., satisfaction, self-esteem) and demographic correlates (e.g., age, relationship length) for agreement. It was hypothesized that the majority of couples would disagree on emotional effects following incidents of IPA. The current study also aimed to investigate how agreement/disagreement on emotional effects relates to various relational (e.g., unidirectional versus bidirectional IPV) and demographic correlates (e.g., age, relationship length) for agreement, however there were no a priori hypotheses for these correlates.

\section{METHOD}

\section{Participants}


Romantic couples $(N=151)$ were recruited from both the university as well as the community for a study entitled “A Study of Romantic Couples." Same-sex couples were excluded from analyses due to there being so few in the sample $(N=5)$, and, as such, it would be difficult to compare them to heterosexual couples, leaving 146 couples. Of the sample of 146 heterosexual couples, 84 couples came up with the same incident of conflict (i.e., when probed further, they answered further questions based on the same event), as agreed upon by two independent raters (discussed in more detail below). These 84 couples were used for all analyses (e.g., behaviors, emotional effects) aside from attribution agreement analyses, in which 42 couples were used because, in order to test agreement of attributions, both partners needed data indicating aggression occurred in order to provide attributions for why it occurred. Thus, only the 42 couples where both partners indicated aggression were retained for attribution agreement analyses, whereas the 84 couples were used for behaviors and emotional effects. See Figure 1 for visual representation of this breakdown.

The participants in the resulting 84 couples, where both partners were reporting on the same conflictual incident, had an average age of $19.68(S D=1.81)$, and their ages ranged from 18-27 years old. In addition, 128 participants (76.2\%) indicated that their relationship was serious, whereas 40 (23.8\%) indicated that it was a casual dating relationship. The average relationship length was 15.76 months $(S D=19.21$, Range $=1-90$ months). Participants were mostly Caucasian $(N=158 ; 94.0 \%)$ and current students in college $(N=159 ; 94.6 \%)$, and $69.5 \%$ of the participants' annual family income was above $\$ 50,000,49.7 \%$ above $\$ 75,000,32.9 \%$ above $\$ 100,000$, and $19.8 \%$ above $\$ 150,000$.

The participants in the resulting 42 couples in which both indicated aggression had an average age of $19.75(S D=1.62)$, and their ages ranged from 18-25 years old. In addition, 67 
participants $(79.8 \%)$ indicated that their relationship was serious, whereas $17(20.2 \%)$ indicated that it was a casual dating relationship. The average relationship length was 16.55 months $(S D=$ 19.36, Range $=1-84$ months $)$. Participants were mostly Caucasian $(N=78 ; 92.9 \%)$ and current students in college $(N=78 ; 92.9 \%)$, and $73.8 \%$ of the participants' annual family income was above $\$ 50,000,48.8 \%$ above $\$ 75,000,34.5 \%$ above $\$ 100,000$, and $20.2 \%$ above $\$ 150,000$.

\section{Procedure}

Upon approval by the University's IRB (see Appendix A for approval letter), college students were recruited via the SONA (Psychology Department participant pool) website (see Appendix B for SONA recruitment message). At the time of consent, participants were informed of the study criteria, which included that participants be at least 18 years old and currently involved in a romantic relationship with someone who they would bring to the laboratory study session. Community participants were recruited through fliers around the New Hampshire Seacoast region (see Appendix C for flier).

Both members of the couple arrived at the laboratory, were separated, and completed a safety screener to determine if they were safe to participate in the study (consisting of asking “Are you afraid of your partner?" If at least one partner answer yes to either question, they would not have qualified for the study, and both partners would complete an alternative study unrelated to IPA). See Appendix D for the Safety Screener. No couples failed the safety screener. Following the safety screener, participants complete informed consents (see Appendix E), followed by demographics (see Appendix F), a series of questionnaires aimed at investigating the conflicts that occurred within the last year their relationship.

First, the Sexual Experiences Survey and Safe Dates Psychological and Physical Scales (Foshee et al., 1998; SES; Koss et al., 2007) (described in detail in the Measures section) were completed to assess the frequency and severity of IPA within the past year of the relationship, as 
well as to prime participants to discuss conflict. Next, participants were asked to indicate, by writing on sheets of paper, their relationship's 10 most recent instances of physical, psychological, and sexual IPA (presented behaviorally to participants) in which either they, their partner, or both of them were aggressive. They indicated these with estimated dates and descriptions (e.g., the behaviors of each partner) of the incidents to increase certainty of matching events. Participants were provided with definitions of aggression, described below. If they were unable to think of any instances of IPA, they were asked to write about times in which they had an argument or disagreement with their partner. After completing the sheet, participants gave it, in a brown envelope, to the researcher and proceeded to complete additional measures.

While participants were completing additional measures assessing risk factors that are generally tied to IPA perpetration (i.e., satisfaction, alcohol use, controlling behavior, emotion dysregulation) that were used for additional analyses aimed at determining what characteristics are related to partner agreement, two researchers independently reviewed both partners' lists and, using the descriptions provided by both partners, selected incidences that matched. The researchers then compared their selections, and noted any discrepancies (83.08\% agreement), which were then discussed until a mutual agreement was met, either that the two partners were or were not describing the same event. Most discrepancies focused on the dates that participants indicated and researchers initially disagreeing on whether the incidents each partner was discussing were different incidents or the same incident and one/both partners misremembering the date or location. Other discrepancies were due to perceived location differences indicated by the participants that, upon discussion, were determined to actually be the same location (e.g., one partner states the general term "dorm" while another indicates it by name). Then, incidents that both researchers select as being the same for both partners were highlighted (using different 
colors for each incident to be discussed and the same color for both participants). A maximum of three IPA incidents were selected.

Following selection, the incident sheets were returned to the correct partner, saying: "The highlighted items were selected for you to describe in further detail." If none of the incidents matched between partners, the most similar incidents were selected for the participants to elaborate on. However, only the first (if applicable) matching incidents were used in the analyses reported herein. Participants then completed the SES and Safe Dates Psychological and Physical Scales (Foshee et al., 1998; Koss et al., 2007) for each incident. Then, participants completed a questionnaire regarding their own attributions for perpetrating and/or attributions for their partner's aggression (Follingstad et al., 1991; Stuart, Moore, Hellmuth, Ramsey, \& Kahler, 2006) for each IPA incident, whichever is applicable. After indicating attributions for each incident, participants were then asked regarding their emotional responses following the incident, as well as their perceptions of their partners' emotional responses, in order to see if couples agree on how relationship aggression impacts both partners. While some couples matched on more than one incident, the current study only analyzed the first incident that matched between partners.

Once participants finished completing their questionnaires, they were individually debriefed (see Appendix G for debriefing forms). They were asked if they had questions, if they wanted to connect with resources, and if they felt safe to be reunited with their partner. No participants felt unsafe to be reunited. They were then compensated and reunited with their partner. For student participants, if both members of the couple require course credit, each participant received two (2) course credits for completing the study. If only one member of the couple required course credit, he or she received two (2) course credits and the other received 
$\$ 20$ for completing the study. For community participants, each member received $\$ 20$ for participating. Because of the novel methodology of the current study, two weeks later, we sent a short follow-up optional survey to make sure participating did not negatively impact their relationship, which was completed by 72 participants (23.84\% of the total sample of 151 couples, 302 individuals). Due to the anonymity required by the approved IRB protocol, participants' follow-up data could not be linked with their original study data. Thus, there is no way to determine how many of the 72 follow-up participants were in each set of analyses. Participants' responses to the two-week follow-up were generally neutral and positive. For example, most responses mentioned that they felt closer to their partners upon finishing the survey (e.g., "I feel stronger and closer to my partner because we talked and compared the results which opened up our connection."), while some responses were more neutral (e.g., "We talked about the conflicts we thought of."). A few participants indicated that they were upset during the survey $(N=9 ; 12.5 \%)$, due to the survey content (e.g., aggression focus) but there was no indication of long-term distress or harm resulting from study participation. Thus, while some reported some transient unpleasant emotions, the vast majority of participants indicated that they either were not distressed by the study or they actually benefited from participation.

\section{Measures}

Past year IPA frequency and severity. IPA victimization and perpetration were assessed using items from the Sexual Experiences Survey and Safe Dates Psychological and Physical Scales (Foshee et al., 1998; SES; Koss et al., 2007). Using a 4-point Likert scale ranging from 0 (Never) to 3 (More than 10 times), participants indicated how many times they and their partner have engaged in psychological (12 items; e.g., "My partner told me that I wasn't good enough"), physical (15 items; e.g., "I slapped my partner"), and sexual (7 items; 
e.g., "I used threats to make my partner have sex") IPA in the past year within their current relationship. Participants' answers were summed to create two indexes, one of total IPA perpetration, and one of total IPA victimization. See Appendix H for the SES and Appendix I for Safe Dates.

IPA Event details. Participants indicated the 10 most recent instances of IPA: "Please describe the ten most recent instances in which only you/your partner were physically aggressive (for example, pushing or shoving partner), sexually aggressive (for example, verbally pressuring sex when partner did not want to), psychologically aggressive (for example, insulting or swearing at partner), or controlling (for example, using looks, actions, and/or gestures to change the other's behavior). If you cannot think of an instance of aggression, then you can describe the most recent times when you and your partner had an argument, disagreement, or conflict."

For each IPA event, participants were asked a series of questions to determine the context of the event so that the researcher could ensure that both members of the couple were discussing the same event. These questions consisted of the date, time, and place of the incident, as well as whether there were any people around who may have witnessed the incident, who the primary perpetrator/victim was, and a description of what happened.

Event-specific IPA. The SES and Safe Dates Psychological and Physical Scales (Foshee et al., 1998; SES; Koss et al., 2007) were completed on a yes/no scale regarding each incident of IPA that was selected for further investigated, including a box to indicate any other behaviors that either partner may have done during the IPA incident. For incident-specific agreement analyses at the item level, the yes/no responses were used. For agreement analyses at the subscale level, all behaviors within the subscale were summed to create a single score that was then dichotomized $(0=$ no behaviors indicated; $1=$ any behaviors indicated $)$. For agreement 
analyses to measure overall agreement on whether or not any aggression occurred during the incident, all behaviors were summed to create a single score that was then dichotomized $(0=$ no behaviors indicated; $1=$ any behaviors indicated). See Appendix J.

Perpetrator-endorsed attributions for IPA. The Motivation and Effects Questionnaire (Follingstad et al., 1991) scale was used to assess IPA attributions. This scale includes 13 attributions for perpetration (e.g., to feel more powerful, to show anger). This original scale, which was a "check all that apply" scale was modified to be asked using 9-point scales $(1=$ Extremely disagree, $9=$ Extremely agree) because prior research suggests that larger scales, specifically 9-point scales, result in greater reliability of measurements than scales with less response options (e.g., Preston \& Colman, 2000; Weng, 2004). Further, it is possible that adjusting this to be a larger range for agreement for participants could lead participants who slightly agree with an attribution to select such, as opposed to possibly just selecting "no" on a yes/no dichotomy. In addition to these attributions, 15 attributions based on the Reasons for Violence Scale (Stuart et al., 2006) were included in order to be more inclusive of attributions cited in the literature. In order to keep agreement analyses consistently using Kappa, each attribution was then dichotomized $(0=$ Extremely disagree through neutral; $1=$ Slightly agree through extremely agree) for agreement analyses. Attributions were initially asked on 9-point scales to give the researchers the opportunity to investigate them both dichotomously and continuously. In addition, they were asked using a continuous scale, as a dichotomous scale potentially limited participants' responses (e.g., if given a yes/no response, someone who believes an attribution slightly applied may select "no," when they really agree with the attribution, albeit slightly. Slightly agree was selected for the cut-off for agreement, as it is the lowest option for stating that an attribution applied. See Appendix K. 
Victims' attributions for IPA perpetration. A mirrored version of the PerpetratorEndorsed Attributions for IPA measure was used to assess victims' attributions for their partners' perpetration. See Appendix K.

Perceptions of IPA initiation and primary perpetrator. Participants were asked to complete two dichotomous items: "Who was the primary aggressor during this incident?" and "Who initiated the incident?"

Own emotional reaction to the IPA incident. A 14-item scale was created for this study to ascertain the emotional impact that the IPA incident had on them after it took place (e.g., angry, aroused, afraid), using a 9-point scale ( $1=$ not at all; $9=$ extremely). The items were selected based on research regarding victims' most common self-reported emotional reactions to IPA (e.g., Follingstad et al., 1991). Each emotion was then dichotomized $(0=$ Not at all; $1=$ somewhat through extremely) for agreement analyses. See Appendix L.

Perceptions of partner's emotional reaction to the IPA incident. A mirrored version of the Own Emotional Reaction to the IPA Incident measure was used to assess perceptions of partner emotions. See Appendix L.

Alcohol use. The 10-item Alcohol Use Disorders Identification Test (AUDIT; Saunders et al., 1993) was used to measure frequency and quantity of alcohol use. Consistent with scoring instructions of the AUDIT, eight questions were asked on a 5-point scale $(1=$ Never; $5=$ Daily $)$. Example items include: "How often do you have a drink containing alcohol?" and "How often during the last year have you been unable to remember what happened the night before because you were drinking?" Two questions were asked on a 5-point scale $(1=$ Never; $5=$ Yes, during the last year). These consisted of: "Have you or someone else been injured as a result of your drinking?" and "Has a relative or friend, or a doctor or other health care worker been concerned 
about your drinking or suggested you cut down?" A summed average score of all items was created for each participant, where higher scores indicate greater alcohol use and abuse $(\alpha=.85)$. See Appendix M.

Attachment anxiety. The 18-item Experiences in Close Relationships Questionnaire Revised (ECR-R; Fraley, Waller, \& Brennan, 2000) Anxiety Subscale was used to measure attachment anxiety. Questions (e.g., "I often worry that my partner will not want to stay with me.”) were asked on a 9-point Likert scale $(1=$ extremely disagree; $9=$ extremely agree $)$. A summed average score was calculated so that higher scores indicated greater attachment anxiety $(\alpha=.89)$. See Appendix N.

Attachment avoidance. The 18-item Experiences in Close Relationships Questionnaire Revised (ECR-R; Fraley et al., 2000) Avoidance Subscale was used to measure attachment avoidance. Questions (e.g., "I prefer not to show a partner how I feel deep down.") were asked on a 9-point Likert scale $(1=$ Extremely disagree $; 9=$ Extremely agree $)$. A summed average score was calculated so that higher scores indicated greater attachment avoidance $(\alpha=.91)$. See Appendix O.

Controlling behavior. The Controlling Behaviors Scale (Graham-Kevan \& Archer, 2003) was used to measure controlling behavior and was asked on a 9-point Likert scale $(1=$ Never $; 9=$ Always). The five subscales (economic, threats, intimidation, emotional, and isolation) were summed and averaged to create a single score indicating controlling behavior, so that higher scores indicated greater controlling behavior $(\alpha=.63)$. See Appendix P.

Emotion dysregulation. The Difficulties in Emotion Regulation Scale (DERS; Gratz \& Roemer, 2004) was used to examine emotion dysregulation. These questions were asked on a 9point scale $(1=$ Never $; 9=$ Always $)$. The six subscales (i.e., non-acceptance of emotional 
responses, difficulties engaging in goal-directed behavior, impulse-control difficulties, lack of emotional awareness, lack of access to emotion regulation strategies, and lack of emotional clarity) were averaged to create a single score of emotion dysregulation $(\alpha=.93)$. See Appendix Q.

Hypergender ideology. The 19-item Hypergender Ideology Scale (Hamburger, Hogben, McGowan, \& Dawson, 1996) was used to measure hypergender ideology, or adherence to strict gender roles (e.g., "A true man knows how to command others."; "Effeminate men deserve to be ridiculed.”). These questions were asked on a 9-point scale $(1=$ Extremely disagree; $9=$ Extremely agree), and items were averaged to create a single score of hypergender ideology $(\alpha=$ .90). See Appendix R.

Investment model variables. The Investment Model Scale (IMS; Rusbult, Martz, \& Agnew, 1998) was used to examine investment model variables: satisfaction (e.g., "Our relationship makes me very happy"), quality of alternatives (e.g., "My alternatives are attractive to me (dating another, spending time with friends or on my own, etc.”), investment (e.g., ". I have put a great deal into our relationship that I would lose if the relationship were to end"), and commitment (e.g., "I want our relationship to last forever"). These questions were asked on a 9point Likert scale $(1=$ Do not agree at all; $9=$ Agree completely). Items for each subscale were averaged to create a single subscale score $(\alpha \mathrm{s}=.95, .95, .90$, and .88 for satisfaction, alternatives, investment, and commitment, respectively). See Appendix S.

Propensity and perceived partner propensity for future IPA. Propensity for future IPA victimization was assessed using four items (e.g., "I will be physically aggressive (e.g., push my partner, slap my partner)") and Perceived partner propensity for future IPA was assessed using four analogous questions (e.g., "My partner will be physically aggressive (e.g., push me, 
slap me)"). Participants' answers for perpetration and victimization items were each summed and averaged to create an index of future IPA perpetration and future IPA victimization. See Appendix T.

Self-esteem. The 10-item Rosenberg Self-Esteem Scale (1965) was used to measure selfesteem. These questions (e.g., "On the whole, I am satisfied with myself”) were asked on a 9point Likert scale $(1=$ Extremely disagree $; 9=$ Extremely agree $)$. A summed average score was calculated so that higher scores indicated greater self-esteem $(\alpha=.89)$. See Appendix U.

Time since incident. Each participant was asked to estimate when the IPA incident occurred. The duration of time that had passed from the incident to the date of reporting was determined, and the average was taken between both partners' accounts to create a single score for each couple. Of the 84 incidents in which both partners were reporting on the same event, couples tended to report on events that occurred 2.26 months ago $(S D=4.34$; Range $=0-24$ months).

\section{Data Analysis}

In order to link partners' responses, each partner was dummy coded, the dataset was copied, variables were renamed to indicate they were partner data (i.e., "self-esteem" became self-esteem_p"), and the partners' dummy codes were substituted for each other. The datasets were then merged, adding the new partner variables. This allowed each partner to have data assigned to them that was relevant to their partner. For example, Partner A then had Partner B's perceptions of Partner A's aggression. This allowed comparisons to be made directly between partners. Thus, due to the study's dyadic design regarding IPA incidents, each participant may provide data relevant to both of the roles of victim and perpetrator (i.e., both partners may be perpetrating in any given incident). Therefore, data from both members of each dyad were 
considered in the analyses for each role. Because both partners are indicating times in which they perpetrated/were victimized, data from participants with some missing data were retained for analyses. In addition, couples with any missing correlational measures (e.g., satisfaction, propensity for future IPA) were retained for agreement analyses.

For all agreement analyses reported herein, a Kappa statistic was created comparing dichotomous variables. Kappa statistics show, beyond chance, the agreement between partners on various items. According to standard Kappa interpretations (e.g., Freeman et al., 2015; Landis $\&$ Koch, 1977), there are five basic levels of agreement: slight $(\kappa=0-.20)$, poor $(\kappa=.21-.40)$, fair $(\kappa=.41-.60)$, substantial $(\kappa=.61-.80)$, and almost perfect $(\kappa=.81-1.00)$. In other words, a significant Kappa statistic in these ranges indicates that agreement between dichotomous variables is significantly better than chance, at the level specified by the strength of the statistic. The current study utilizes these standard Kappa interpretations in the reporting of the results that follow.

\section{RESULTS}

\section{General Description of Specific Incidents of IPA}

There were several trends within the incidents described by the couples in which at least one partner indicated that aggression occurred. Of the 60 couples (or 120 individuals) in which someone indicated aggression, $42 / 120$ individuals (35.0\% of individuals) indicated that the aggression was mutual; however agreement of mutual aggression was only present in 12 couples (20.0\% of couples). Of the couples where at least one partner indicated aggression $(N=60$ couples), most incidents involved aggression that was psychological in nature (90/120 participants reported; 75.0\%), and physical and sexual IPA were reported at lower frequencies (39 participants [32.5\%] indicated that some form of physical aggression occurred, and only 9 
[7.5\%] participants indicated that sexual aggression occurred). In addition, while it is possible that some couples simply did not mention these characteristics, about one-third of the couples indicated that the aggression discussed involved alcohol and/or parties or bars. In addition, the majority of the couples (around 2/3) also indicated that the aggression took place in the late evening/night. Finally, the majority of the couples stated that the aggressive incidents took place outside of the view of any potential bystanders (only about $23 \%$ of couples agreed that there were people around when the incident took place).

\section{General Agreement of Incidents of IPA}

Of the sample of couples in which both partners were discussing the same conflictual incident $(N=84$ couples), partners' agreement on the aggression during the incident was generally poor. While partners only tended to slightly agree on the presence of any past-year aggression $(\kappa=.18)$, agreement on aggression occurring during specific instances of conflict was also low. If one partner indicated that either they or their partner perpetrated some form of IPA, regardless of type, their partner did not typically agree $(\kappa=.30)$. Agreement at the overall scale level for psychological IPA specifically was also poor $(\kappa=.25)$. In addition, there was only slight agreement on physical IPA at the scale level $(\kappa=.18)$, and sexual IPA yielded cell sizes that were too small for Kappa to be conducted. See Table 1 for a breakdown of the agreement between partners on event-specific IPA in general.

When investigated further, there was no agreement between partners on who initiated the incident of IPA $(\kappa=.06)$, however there was fair agreement on who was the primary perpetrator $(\kappa=.47)$. Thus, members of a couple may not agree on how an incident of IPA starts, but they tend to have fair agreement on who the main person was who was engaging in the aggression. 
Exploratory independent samples $t$-tests were conducted in order to ascertain if there were differences between couples in which only one partner vs. both partners indicated that aggression occurred during the incident of IPA. In general, compared to couples in which there was not agreement on aggression, couples in which both partners indicated aggression occurring scored higher on alcohol use $(t=3.02, p<.01, d=.61)$, emotion dysregulation $(t=3.56, p<$ $.001, d=.55)$, controlling behavior $(t=4.23, p<.001, d=.66)$, attachment anxiety $(t=2.04, p<$ $.05, d=.32)$, investment $(t=2.31, p<.05, d=.36)$, perceptions that one will perpetrate in the future ( $t=4.26, p<.001, d=.67)$, perceptions that one's partner will perpetrate in the future ( $t=$ $4.38, p<.001, d=.69)$, past year sexual IPA perpetration $(t=2.04, p<.05, d=.32)$, past year physical IPA victimization $(t=3.26, p<.01, d=.51)$, past year physical IPA perpetration $(t=$ $3.10, p<.01, d=.48)$, past year psychological IPA victimization $(t=4.49, p<.001, d=.70)$, past year psychological IPA perpetration $(t=4.80, p<.001, d=.75)$, any past year IPA victimization $(t=4.68, p<.001, d=.73)$, and any past year IPA perpetration $(t=5.21, p<.001$, $d=.80$ ). In addition, couples in which both partners indicated aggression occurring, compared to couples in which only one partner indicated aggression, generally scored lower on self-esteem $(t$ $=2.63, p<.01, d=.41)$. There was no significant difference between groups of couples on age, relationship length, socioeconomic status, attachment avoidance, hypergender ideology, commitment, satisfaction, quality of alternatives, social desirability, time since the incident, and past year sexual IPA victimization $(p s>.05)$. See Table 2 for a means and standard deviations of all differences between couples in which one or both partners indicated that aggression occurred.

Because these results contradict the findings regarding agreement at the item level (reported next), binary logistic regressions were conducted to understand the relationships more, and to determine whether these relationships were actually being driven by the couples in which 
both members of the couple simply having more relationship aggression in general. When controlling for total relationship aggression, the relationship between one or both partners indicating that aggression occurred and all significant variables (e.g., alcohol use, emotion dysregulation, attachment anxiety/avoidance, perceptions that one/one's partner will be aggressive in the future) became non-significant ( $p s>.05)$. In other words, couples in which both partners indicated that aggression occurs within a specific incident are more likely to be couples in which there is simply generally more aggression that occurs (and more alcohol use, emotion dysregulation, etc.). Thus, this generally higher level of relationship aggression is the underlying predictor of whether both partners agree that aggression has occurred within a specific event.

\section{Agreement on Specific Aggressive Behaviors within an IPA Incident}

Of the sample of couples in which both partners were discussing the same incident $(N=$ 84 couples), partners' agreement on the presence or absence of specific behaviors ranged from nonexistent to poor, with agreement slight for the perpetrator saying things to hurt their partner's feelings on purpose $(\kappa=.17)$, and significant although poor for the perpetrator doing something just to make them jealous $(\kappa=.26)$, telling them they could not talk to someone of the opposite sex $(\kappa=.36)$, and blaming their partner for the bad things they had done $(\kappa=.39)$. See Table 3 for a depiction of the agreement of specific aggressive behaviors within incidents.

In order to examine how (dis)agreement on accounts of specific behaviors within IPA incidents relates to possible correlates, difference scores were created between each partner's accounts of each of the behaviors occurring within the incident of IPA and summed to create a single score for each partner (higher scores meaning more disagreement at the item level). These summed difference scores were then correlated with various correlates of interest. In general, 
disagreement on behaviors within an incident of IPA was related to emotion dysregulation $(r=$ $.18, p<.05)$, hypergender ideology $(r=.17, p<.05)$, controlling behavior $(r=.36, p<.001)$, perceptions that one will perpetrate in the future $(r=.26, p<.01)$, perceptions that one's partner will perpetrate in the future $(r=.17, p<.05)$, past year physical IPA victimization $(r=.22, p<$ $.01)$, past year physical IPA perpetration $(r=.26, p<.01)$, past year psychological IPA victimization $(r=.31, p<.001)$, past year psychological IPA perpetration $(r=.42, p<.001)$, any past year IPA victimization $(r=.32, p<.001)$, and any past year IPA perpetration $(r=.44, p<$ .001). There was no correlation between level of agreement/disagreement and age, relationship length, socioeconomic status, alcohol use, attachment anxiety, attachment avoidance, commitment, satisfaction, investment, quality of alternatives, social desirability, self-esteem, time since the incident, and past year sexual IPA victimization/perpetration $(p s>.05)$. See Table 4 for these correlates.

\section{Agreement on Attributions for the Aggression within an IPA Incident}

In order to test agreement of attributions, both partners needed data indicating aggression occurred. Thus, Kappa agreement analyses were conducted regarding the attributions made by these 42 couples. Within these couples, commonly endorsed attributions for both one's own and one's partner's perpetration consisted of showing anger ( $66.7 \%$ own; $53.6 \%$ partner), retaliation for emotional hurt (53.0\% own; $43.5 \%$ partner), and stress (51.5\% own; $45.6 \%$ partner). Least commonly endorsed attributions consisted of retaliation for being hit first (4.5\% own; $0 \%$ partner), to make partner scared or afraid ( $0 \%$ own; $1.4 \%$ partner), because the perpetrator wanted to have sex and the victim did not ( $0 \%$ own; $1.4 \%$ partner), because it was sexually arousing (0\% own; $2.9 \%$ partner), self-defense (7.6\% own; $2.9 \%$ partner), get away from partner (10.6\% own; $2.9 \%$ partner), and because they were cheated on (12.1\% own; $2.9 \%$ partner). 
The hypothesis that the majority of couples would disagree on the presence or absence of specific attributions for IPA was generally supported. Agreement between partners on the attributions for instances of IPA ranged from nonexistent to substantial. In particular, there was poor agreement on the perpetrator wanting to punish their partner for wrongdoing $(\kappa=.28)$, the perpetrator not believing their partner cared $(\kappa=.30)$, and the perpetrator acting out of jealousy $(\kappa=.30)$. There was also marginally significant $(p=.05)$ poor agreement on the perpetrator being afraid their partner was going to leave them $(\kappa=.25)$. Thus, while there was agreement on these various attributions, one partner's attributions are only a poor indicator of the other's attributions. There was substantial agreement, however, in the IPA being attributed to the perpetrator being under influence of drugs or alcohol $(\kappa=.67)$. In other words, if one partner attributed the aggression to drugs or alcohol, the other likely did as well. See Table 4 for a depiction of the agreement of specific attributions for IPA. Possible correlates for agreement on attributions not investigated due to the low number of couples in which both partners indicated that aggression occurred ( $N=42$ couples, with only 58 total participants with attribution data for both partners, as some couples consisted of partners who both indicated that aggression occurred disagreed on who was aggressive).

\section{Agreement on Emotional Effects Following an IPA Incident}

Commonly endorsed emotional effects of IPA incidents include both oneself and one's partner feeling unhappy (69.74\% own; 71.24\% partner), uncertain about things (56.25\% own; $50.31 \%$; partner), confused (55.63 own; $50.62 \%$ partner), and tense ( $46.95 \%$ own; $50.31 \%$ partner). Least common emotions endorsed consist of feeling aroused (8.43\% own; $9.70 \%$ partner) and afraid (17.18\% own; $19.88 \%$ partner). 
Of the sample of couples in which both partners were discussing the same incident $(N=$ 84 couples), partners' reports on general feelings of being upset (i.e., all negative affect emotions collapsed: unhappy, depressed, helpless, worthless, ashamed, confused, emotionally hurt, uncertain about things, tense, on edge, afraid, and angry) were correlated, in that both partners tended to report similar levels of negative emotions (i.e., if Partner A reported being upset, Partner B reported that Partner A was upset), $r=.23 p<.001$. However, when dichotomized for Kappa agreement analyses, one partner reporting the presence of any negative emotional effect (i.e., somewhat agreeing to extremely agreeing on at least one item of negative affect), there was no significant agreement between partners' reports $(p=.24)$. When broken down into specific emotions, however, agreement on the specific emotions occurring after the event ranged from nonexistent to slight. Agreement was slight for uncertain about things $(\kappa=.20)$ and on edge $(\kappa=$ .16). There was marginally significant, yet slight, agreement for unhappy $(p=.07 ; \kappa=.15)$ and tense $(p=.07 ; \kappa=.15)$. There was no agreement between partners for the other eight emotions (e.g., worthless, helpless). See Table 6 for a depiction of the agreement of specific emotions after incidents.

In order to examine how (dis)agreement on emotional effects (i.e., emotions following an incident of IPA) of IPA incidents relates to possible correlates, difference scores were created between each partner's endorsed emotions and their partner's perceptions of their emotions after the incident of IPA and summed to create a single score for each partner. These summed difference scores were then correlated with the various correlates described above. Only past year psychological IPA perpetration was significant, in that higher frequencies of psychological IPA perpetration was related to higher degrees of disagreement on emotional effects, while all other possible correlates of interest (e.g., relationship satisfaction, relationship investment, 
quality of alternatives, commitment, attachment anxiety, attachment avoidance, likelihood of future aggression, age, socioeconomic status, length of relationship, etc.) were not statistically significant predictors of agreement on emotions following an incident of IPA. See Table 7 for these correlates.

\section{IX.DISCUSSION}

\section{A Conceptual Understanding of Specific Instances of Relationship Conflict}

Previous research has documented the presence of bias in perceptions of others, stating that people oftentimes see romantic partners in a biased and positive light (e.g., Agnew, Loving, \& Drigotas, 2001; Murray et al., 1996), with these positive illusions predicting wellbeing (Murray et al., 1996). However, researchers have also found that, at times, partners can have very accurate views of their partners, such as when evaluating their spouse's commitment (e.g., Adams \& Jones, 1997). Fletcher and Kerr (2010) stated that one of the primary goals in romantic relationships is to build and sustain high levels of relationship quality, which leads to viewing partners in a positively biased way. Being in a deliberative mindset is when you are trying to decide whether or not to pursue some goal, while an implemental mindset is when you are trying to decide how to attain the goal. Previous research suggests that people in deliberative mindsets (e.g., should we be together?) are oftentimes more accurate than implemental mindsets (e.g., we should definitely be together, so how do I make that work?) (e.g., Gagne \& Lydon, 2001). Couples in the current study were all currently in their relationships, and even signed up to participating in a couple's study. Thus, these participants were likely experiencing implemental mindsets. In fact, the average relationship satisfaction score was a $7.90(\mathrm{SD}=1.04)$, indicating that the average participant ranged from agree to extremely agree on the satisfaction items, with the average being strongly agree. Thus, the sample's relationship satisfaction scores were 
positively inflated. Because of this, they were likely experiencing positive illusions of their partners, seeing them in a more positive light than accuracy may imply (e.g., Murray et al., 1996). Thus, the more inconsistent the relationship was to a "typical" happy, healthy relationship, the more likely participants would be to disagree with each other on their accounts, as the accounts would be clouded in bias, trying to perceive their partners in the best possible way to ensure the continuation of the relationship.

General description of specific incidents of IPA. The current study found that most incidents of aggression were psychologically based. This is consistent with previous research indicating the greater prevalence of psychological IPA than physical or sexual IPA (Edwards, Desai, Gidycz, \& VanWynsberghe, 2009; Coker et al., 2002). In addition, a large number of incidents involved alcohol and or parties or bars, and occurred in the late evening/night. This is consistent with previous research findings that aggression is more likely on nights (Vazquesz, Stohr, \& Purkiss, 2005) with alcohol consumption (e.g., Fals-Stewart, 2003) and more likely for hazardous, or binge drinking (e.g., Stuart, Moore, Ramsey, \& Kahler, 2004). Finally, the current study found that most instances of aggression occurred away from the public eye, with no onlookers. In other words, while some aggression took place in the presence of potential bystanders, a large amount went unnoticed by others. If there is oftentimes no one witnessing the aggression external to the relationship, the need to ensure that we are receiving an accurate portrayal of events, should we ask one or both partners, is only heightened.

General agreement of incidents of IPA. Regarding the first aim of the study, within a specific conflict incident, romantic partners typically only agreed (albeit slight to poor) on IPA in general. When asked about whether any IPA occurred during the incident, while men and women typically reported similar levels of aggression $(p=.59)$, partners only had slight agreement. This 
is consistent with previous research suggesting that couples tend to disagree on the IPA that occurs in their relationship (Armstrong et al., 2002), with their agreement on whether or not IPA even happens as low to moderate (Caetano, Schafer, Field, \& Nelson, 2002; Cunradi, Bersamin, \& Ames, 2009; Moffitt et al., 1997; Schafer, Caetano, \& Clark, 1998). This agreement, or lack thereof, while seemingly lower than what may be expected may be a result of participants being able to remember their relationship aggression more when it comes to IPA in general (i.e., IPA occurring over the duration of an entire year), whereas participants may not be able to formulate accurate recollections of specific incidents of aggression. In other words, it is possible that, when trying to remember if IPA has happened more in general, participants can remember times when aggression occurred, so they are less inclined to hesitate to indicate in the affirmative. However, when asked to report on a specific instance of IPA, they may be more hesitant to agree that aggression occurred, for fear of inaccurately reporting the event. It is possible that many couples experienced high amounts of aggression within their relationship. Previous research suggests that, if attempting to remember something that occurs frequently, as opposed to using more episodic memory skills, people tend to use more general memory skills (e.g., Burton \& Blair, 1991).

In addition, regarding the disagreement in whether or not IPA actually occurred in the reported conflicts, participants may be cautious to confirm a specific instance of aggression, as it could work as a salient indicator of an unhealthy relationship, whereas reporting on more distant or general experiences could be interpreted differently (e.g., "occasionally things get out of hand, but we are usually happy"). Research has speculated that there are various relational processes that help enhance one's feelings for one's partner. One of these biases is seeing one's partner through "rose-colored" glasses, or in a generally positive light (e.g., Murray et al., 1996). 
Perhaps a specific instance of one or both of the partners acting in ways that are not positive provided a relationship threat that was much too salient.

The current study also found that, while there was fair agreement on which partner was the primary perpetrator, there was no agreement on who initiated the incident. This discrepancy could help explain why there are inconsistencies between partners' perspectives of the behaviors that occur within an instance of IPA. For instance, if Partner A says something that appears to be an insult to Partner B, and Partner B reacts with physical aggression, which then leads to more aggression, they may have different perspectives of the incident, while still both retaining memory of the actions of both partners. In this instance, both partners may agree that Partner B was the primary perpetrator, but disagree on how the aggression began. Perhaps Partner A's comment was not meant to be insulting, but Partner B perceived it to be so. Thus, Partner A may perceive the physical aggression as the initiation of the aggression, while Partner B perceives the negative comments to be what started it. It is possible that both partners may actually have accurate perceptions of what happened, but simply do not consider portions to be a part of the actual instance of IPA.

The current study also investigated types of IPA, using aggression subscales. While reports of sexual IPA were too low to conduct agreement analysis, previous research suggests that there is little to no agreement on sexual IPA, at least when asked about the past year (Freeman et al., 2015; Schafer et al., 1998). Future research should perhaps pull samples from populations with larger portions of sexual IPA perpetrators to determine if there is agreement on the extent of sexual IPA within a relationship. In addition, the current study found that there was only slight agreement on physical IPA and poor agreement on psychological IPA. This is similar, but somewhat lower, than reported in previous research reporting poor to fair agreement in past 
year physical IPA (Cunradi et al., 2009; Freeman et al., 2015; Moffitt et al., 1997) and psychological IPA (Freeman et al., 2015; Moffitt et al., 1997). The lower reports found in the current study could be attributed to the inflated agreement statistics of prior research. The current study's agreement analyses depended on at least one partner indicating aggression, thus removing the potential for inflated agreement analyses due to high agreement on the lack of aggression (for discussion see Armstrong et al., 2002).

The current study found various correlates related to whether one or both partners reported aggression. Specifically, couples where both partners indicated aggression also reported more alcohol use, emotion dysregulation, controlling behavior, attachment anxiety, investment, perceptions that one/one's partner will perpetrate in the future, past year sexual IPA perpetration, past year physical IPA victimization/perpetration, past year psychological IPA victimization/perpetration, any past year IPA victimization/perpetration. In addition, couples in which both partners reported aggression generally scored lower on self-esteem. However, when controlling for total past year relationship aggression, all of these relationships disappeared. In other words, these various correlates are also typically correlates of experiencing relationship aggression in general, and couples that experience more aggression were more likely to have both partners report aggression during a specific instance of IPA than have just one partner report the aggression. Thus, contrary to the hypothesis that past year IPA would be related to disagreement, agreement that there was in fact aggression within an instance of IPA depends largely on how aggressive the couple typically is, in that more relationship aggression predicts the likelihood that both partners will acknowledge that aggression in a given IPA incident. However, when investigating specific types of aggressive behaviors enacting during the incidents, past year IPA was related to disagreement (as described in the next section). 
The current study did not find a relationship between how many partners indicated aggression and age, relationship length, socioeconomic status, attachment avoidance, hypergender ideology, commitment, satisfaction, quality of alternatives, social desirability, and past year sexual IPA victimization. In particular, is possible that age, relationship length, and socioeconomic status were not significantly related to IPA agreement due to the restricted sample. Nearly all of the participants in the sample were college students, with similar incomes and ages. In addition, while the average relationship ranged from 1-90 months, the average relationship was just over a year. Thus, most relationships represented in the study were relatively new, leaving little variability to result in significant differences. Participants also generally reported low levels of hypergender ideology and past year sexual IPA victimization, as well as very high levels of commitment and satisfaction, with little variability of each. It is possible that, with more variability, these variables may demonstrate differences between couples in which one partner indicates aggression and couples where they both do.

Agreement on specific aggressive behaviors within an IPA incident. Regarding the first aim of the study, when investigating IPA incidents more specifically, partners generally agreed on behaviors such as saying things to hurt their partner's feelings on purpose, doing something just to make them jealous, telling them they could not talk to someone of the opposite sex, and blaming their partner for the bad things they had done. Thus, psychologically aggressive behaviors were the only behaviors in which there was at least some agreement between partners. It is possible that these are simply commonly endorsed behaviors occurring in their relationships, so both partners were more likely to indicate that they happened. Several of these are also related to relationship maintenance and jealousy, and thus they may feel less shame in reporting them. It may also be that, because they are related to the condition of the relationship, they may be very 
salient factors in relationships for both partners to remember occurring. For instance, a partner doing something to make another jealousy, or not letting one's partner talk to the opposite sex are related to relationship threat. Research has speculated that some cognitive processes (e.g., memory) tend to be adaptively attuned to stimuli that meet certain goals (e.g., McArthur \& Baron, 1983). As stated above, people in implemental mindsets tend to see their partner in a more positive light, however, when the goal being implemented is the successful continuation of the relationship (see Maner. Gailliot, Rouby, \& Miller, 2007), partners may become specifically attuned to aggression that is relationship-relevant (Maner et al., 2007). In other words, being aware of these behaviors would aid in the implementation of the relationship-protective goal. In being more attuned to relationship-relevant behaviors, couples may form perceptions of the events that are more in agreement of each other.

Furthermore, disagreement on the specific behaviors enacted within instances of aggression was related to hypergender ideology (i.e., adherence to traditional gender roles), emotion dysregulation, controlling behavior, perceptions that one/one's partner will perpetrate in the future, past year physical IPA victimization/perpetration, past year psychological IPA victimization/perpetration, and any past year IPA victimization/perpetration. Thus, the more they adhere to strict gender roles and the less people can regulate their emotions, the more likely they are to disagree on what happened during a given IPA incident. Adherence to strict gender roles may be related to disagreement on what happens during instances of IPA because believing in these roles may support different forms of IPA (e.g., real men are dominant and physical, while women are subservient and manipulative). While the sample in the current study did not have much variability in hypergender ideology, and there was a marginally positive correlation between own and partner's reports of hypergender ideology $(p=.05)$, it is possible that even 
small differences between partners on adhering to traditional gender roles could predict disagreement. Thus, if one partner is high in hypergender ideology, then he or she may see aggressive behaviors consistent with these traditional roles as "normal" (and less likely to endorse it on a measure), while his or her partner may not.

Researchers have also found that emotion dysregulation may not be related to IPA in and of itself, but rather it is related to IPA specifically with regard to IPA returned on, or retaliated against, an aggressive partner. In a study of 72 newlywed couples, McNulty and Hellmuth (2008) found that, when investigating simply the relationship between emotion dysregulation and perpetration against an unperpetrating partner, there was no relationship. However, variability in emotion dysregulation was related to IPA perpetration, if the perpetrator was also a victim. Considering the high correlation between IPA perpetration and victimization in general (across subscales) in the current study $(r=.85, p<.001)$, the current study was clearly a sample consisting of a large proportion of couples who experience situational couple aggression, which exists when aggression results from escalated conflicts, as opposed to one partner exercising control over their partner (Johnson, 1995). Thus, the current study's results regarding emotional dysregulation are consistent with McNulty and Hellmuth (2008).

Relationships that are generally higher in aggression (e.g., controlling behavior, perceptions of future perpetration by either partner, past IPA) also tended to have higher degrees of disagreement than relationships with less aggression. This is likely due to participants conflating aggressive incidents, as described above. Research on eyewitness testimonies has shown that details of one event can sometimes encroach on reports of other events (e.g., Lindsay, Allen, Chan, \& Dahl, 2004). In other words, the more aggression there is in a relationship (regardless of when the aggression being reported took place, as evident by time since the 
aggression being unrelated to agreement on IPA behaviors within the current study), the less likely partners are to agree on what happened during a specific incident of aggression, due to them likely confusing events.

Agreement on attributions for the aggression within an IPA incident. Regarding the second aim of the study, partners generally did not agree on why the IPA occurred during the specific instances of aggression. The attributions in which there was some agreement consisted of the perpetrator wanting to punish their partner, not believing their partner cared, jealousy, and being afraid their partner was going to leave them. There was also substantial agreement on attributing the aggression to drugs or alcohol. Thus, while previous research using a single partner finds countless attributions for aggression (e.g., desire to harm or punish their partner, losing control, retaliation; e.g., Foshee et al., 2007; Jones, 1993; Follingstad et al., 1991), when both partners are considered, only a few attributions were agreed upon by both partners. With regard to the substantial agreement on substance use attributions, alcohol/drug use is likely a salient factor involved in instances of aggression. Not only is substance use a risk factor for IPA perpetration (e.g., Stuart et al., 2013), but it is also an activity in and of itself and leads to impaired thinking. Furthermore, substance use is often paired with specific locations and situations (e.g., bars, parties). In addition, substance use is more external and observable, whereas other attributions are more internal and likely more difficult to really identify. Thus, if substance use was involved, the high agreement on aggressive behaviors being the result of alcohol or drug use should be expected. Consistent with this theorizing, general alcohol use was related to attributing IPA to substance use $(r=.53, p<.001)$. Furthermore, the current study utilized a college sample, and given the high rates of alcohol use in college populations (about 
85\% of students; e.g., Presley, Meilman, Cashin, \& Lyerla, 1993), reports of alcohol and alcoholrelated attributions are likely inflated.

The attributions found in this study to have high inter-relationship agreement, aside from substance use, may be very salient factors in relationships for both partners. All four attributions (i.e., wanting to punish their partner, not believing their partner cared, jealousy, and being afraid their partner was going to leave them) could signify a significant relationship threat, and potentially the dissolution of the relationship. Research has speculated that some cognitive processes (e.g., attention) tend to be adaptively attuned to stimuli that meet certain goals (e.g., McArthur \& Baron, 1983). As stated above, one such goal is attaining and keeping a mate (see Maner et al., 2007). Thus, being specifically attuned to aggression that stems from relationshiprelevant reasons may provide partners who wish to remain in the relationship, and especially those who actively work to keep their partner (e.g., Gagne \& Lydon, 2001) with the tools they need to be aware of relationship issues.

Agreement on emotional effects following an IPA incident. Regarding the third aim of the study, there was slight agreement for being uncertain about things and being on edge, while there was marginal agreement for feeling unhappy and tense, and there was no agreement between romantic partners for any other emotion. These relationships may tie into the stress of one partner being worried that the other may stray. As noted, popular attributions for aggression consisted of substance use, punishing their partner, not believing the partner cared, jealousy, and being afraid their partner was going to leave them. It is possible that these are very relatable and observable emotions. It is also possible, tying into the attributions, that partners in relationships where there is a lot of jealousy may be more inclined to be uncertain about the relationship, unhappy with it, and on edge and tense about the potential alternatives that one's partner may be 
interested in. This supports the concept discussed above, that people attempting to keep their relationship are especially attuned to experiences that could signify relationship threat, and potentially the dissolution of the relationship - in this case, how one partner's behaviors make the other partner feel. For instance, being particularly attuned (e.g., Maner et al., 2007; McArthur \& Baron, 1983) to instances in which one's partner may be on edge and tense, or unhappy and uncertain of the relationship, could signify that they are stressed out about the relationship may inform them of their partner's worry. As a result, one can respond in reassuring ways to ease their tension.

With regard to disagreement on emotional effects, perhaps partners tend to disagree on emotions felt following IPA instances as a result of perspective biases, or the actor-observer effect (see Jones \& Nisbett, 1972). This effect states that people often have different perspectives of a given situation (e.g., emotions), because their attention is focused on different things. In addition, perpetrators or victims of IPA they may have knowledge unique to themselves (e.g., past experiences, what led up to a behavior, how they feel about their behavior, etc.), while their partner may not have that knowledge (Storms, 1973). Thus, people may simply perceive differing emotional effects due to their different roles within the incidents of IPA.

The current study found that, while participants reported similar levels of emotional effects for themselves and their partners, they are generally unaware of how instances of IPA impact their partners. In addition, in the current study, past year psychological IPA perpetration was related to disagreement on emotional effects, though no other correlates were related. The lack of significant correlates may be a result of people simply not knowing how their partners feel as a result of IPA. However, the more psychological IPA perpetration that partners report, the less likely they are to agree on how a given incident impacted each partner. One possible 
reason for this is that most instances reported on were psychologically based, and psychological IPA typically occurs more frequently than other forms of IPA, which is evident by $62.5 \%$ of participants reporting some form of psychological victimization or perpetration IPA in the past year, with the average person indicating $10.08(S D=16.25)$ instances of aggression. Thus, it is possible that these partners may simply be conflating various IPA events when trying to understand the emotional effects of a single IPA incident. In other words, the more psychological IPA a couple tends to experience, the less distinct a specific incident is (regardless of when the psychological aggression reported actually took place, as evident by the time since the aggression being unrelated to agreement on emotional effects within the current study), and the more likely they are to confuse the emotional effects of any single instance of it. Future research should investigate emotion in the more general sense, in order to see if partners agree on the degree of positive and negative affect experienced. In other words, the present study indicates that people typically do not understand the specific emotions felt by their partners as a result of incidences of IPA. Future research should research affect in the broader sense to determine if people are able to acknowledge the degree to which their partners feel more global feelings of positive or negative emotions.

\section{Methodological Implications}

It is clear from the current study that partners typically give differing perspectives of the conflicts that occur within their relationships. Considering most research on IPA behaviors, attributions, and emotional effects consist of non-dyad methodologies, or asking one partner to report on the IPA (e.g., Bograd, 1988; Caldwell et al., 2009; Cascardi, \& Vivian, 1995; EpsteinNgo et al., 2013; Follingstad et al., 1991), the current research has methodological implications to consider. The current study shows that both partners' perspectives are vital to our 
understanding of IPA. Due of this, the validity of IPA literature comes into question. Regardless of which partner has been included, their agreement with what their partner would report is low. Because one partner does not necessarily give an accurate portrayal of the aggression in the relationship, researchers should critically examine the findings reported thus far in the IPA literature. In addition, the effectiveness of programs and policies are largely based on selfreported IPA. The results of the current study have implications suggesting that even the validity of these reports of effectiveness come into question. Thus, reports should integrate both partners' perspectives of IPA. From there, when it comes to conflicting data between partners, it would be best to take a conservative approach and count any IPA reported by either partner as indication of IPA within the relationship, regardless of whether it is a report by a victim or perpetrator, as it is likely more typical for someone to not admit aggression has occurred than to misreport something as happening that never took place. Taken altogether, in light of the findings reported herein, findings using one partner's reports of frequencies, attributions, and emotional effects of IPA should be considered with caution.

\section{Implications for Intervention and Prevention}

The current study's results suggest that agreement (on IPA behaviors, attributions and emotional effect) was not related how long it had been since the incident. However, past year IPA experiences were the most consistent correlates for agreement, with more IPA aggression being related to less agreement. This has implications for treatment. While, it does not matter how long it has been since an incident occurred for accurate reporting on both partners, how much aggression the couple tends to experience does matter. In other words, how long it has been since the aggression may be less important for interventions than the general frequency of 
IPA within the couple. Using these findings, clinicians should tailor some of their intervention efforts specifically toward couples who have just begun to experience aggression.

Considering the finding that partners tend to disagree on who initiated an instance of aggression, though agreed on the primary perpetrator, clinicians and intervention programmers should teach partners to incorporate behaviors they believe to be peripheral to IPA into their perceptions of the aggression that takes place in their relationships. Partners may have an accurate memory of the aggression; however, they may simply not connect all behaviors to the aggression. Consistent with this, previous research suggests that recollections of emotional events are oftentimes highly accurate, but they are inclined to be incomplete (Smeets, Candel, \& Merckelbach, 2004). Applying this to instances of IPA, perhaps both partners' accounts of the incidents are actually accurate, and instead are just incomplete. By considering behaviors beyond what they think took place during instances of aggression (i.e., what they believed occurred right before the incident), people may be able to better understand their partners' perspectives of the events, and thus develop a greater understanding of their partners.

Understanding the extent to which romantic partners form similar attributions for, as well as perceptions of, various instances of aggression is vital for the success of IPA intervention and prevention programs. The current study found that couples typically agree (albeit sometimes only slightly) on attributions of the perpetrator wanting to punish their partner, not believing their partner cared, jealousy, being afraid their partner was going to leave them, and the aggression being attributed to drugs or alcohol. Thus, prevention programs should aim their efforts at developing an understanding that partners oftentimes disagree on what goes on in their relationship (Jacobson \& Moore, 1981), as well as focusing on educating young partners on the dangers of jealousy and promote relationship wellbeing. In addition, due to such a high amount 
of the instances if IPA involving alcohol, educating people of the risks of alcohol use and its link to aggression is imperative. Furthermore, with respect to intervention programming specifically, it is believed that couple's therapy is counterproductive if the perpetration is fueled by control, dominance, or coercion (Jacobson \& Gottman, 1998). Thus, if either partner indicates any of those attributions, then couple's therapy should be avoided. Unfortunately, the current study found that those are not the attributions that are typically agreed upon by partners. In fact, there were several attributions that did not reach significant agreement (e.g., get control over partner, make partner agree with them, stress, feel more powerful). Thus, it would seem that both partners' perspectives of the aggression within the relationship should be utilized when screening couples for therapy. Furthermore, the current study highlights the different views that partners have of the aggressive events that take place in their relationship.

In addition to behaviors and attributions, the current study's findings on emotional effects are important for treatment and prevention efforts. In order to reduce and eradicate IPA from a relationship, fostering an understanding of how each partner's aggression impacts the other may be imperative. If perpetrators do not know the extent to which their actions are detrimental to their partners, they may not fully understand the consequences of their behaviors. In light of the current study's findings, intervention and prevention efforts should focus efforts on perspective taking. Previous research suggests that learning to take one's partner's perspective during conflict interactions leads to enacting less destructive behaviors (e.g., Arriaga \& Rusbult, 1998). Thus, using the findings of the current study to show people that there are different perspectives to be taken in any situation, and teaching them to be able to take that perspective, could ultimately lead to less relationship aggression. At the very least, the idea that people see conflictual incidents differently and may not agree on what or why it happened or the effects of 
the conflicts can act as a starting point in conversations in IPA prevention. Future research should investigate the extent to which partners tend to confuse the effects of different experiences of IPA and how that may relate to successful IPA treatments. Thus, information on both partners' perspectives of why the aggression took place, what emotional effects resulted from the aggression, as well as the aggressive behaviors that were actually enacted could be vital for helping partners understand each other and work on reducing or eradicating their relationship aggression.

\section{LIMITATIONS AND FUTURE DIRECTION}

Due to the exploratory nature of the present study, we did not adjust our alpha. Research should further investigate agreement in each of the areas reported (i.e., IPA behaviors, attributions, and emotions) with regard to specific instances of IPA. While research on the various factors involved in couples' IPA in the more general sense is informative, investigating

specific instances of aggression could further help understand exactly why people perpetrate, and what is taking place within a given instance of aggression, and how specific forms of perpetration impact both parties involved.

The current study utilized a small homogeneous sample size using a cross-sectional design. Future research should utilize larger, more diverse samples, in order to develop a broader understanding of the agreement between partners, as well as to determine if these findings are supported in diverse populations. In addition, future research should employ longitudinal designs to determine how agreement may change over time. In addition, selection bias may have impacted the current study (i.e., very violent couples may not sign up for our study). Future research should recruit participants with histories of severe violence (e.g., shelters, courts) in order to see if these results are supported in very violent couples. 
Future research should also investigate agreement on the actual enactment of aggression, and avoid conflating agreement on the presence of aggression with the absence of aggression. In order to implement successful IPA intervention and prevention efforts, it is imperative to understand the extent to which partners have similar perspectives of the IPA that occurs within their relationship, thus agreement specifically on the aggression that occurs should be used.

Future research should investigate the extent to which frequency of relationship aggression is related to inaccurate memories of the aggression that occurs. In addition, future research should investigate how memories of relationship aggression may transform over time. Understanding how people make sense of the relationship aggression that has occurred has implications for both research and practice. If the experience of multiple instances of aggression leads to partners disagreeing on what actually happens during IPA events, then asking participants and clients to report on the IPA that has occurred within the past year may be too long of a timeframe for an accurate reporting, not to report on a given incident (as time since the incident was not a predictor of agreement), but perhaps simply because of the extent of relevant events to sift through in their memories. In other words, there may simply be too many similar incidents occurring to understand what led up to, happened during, and resulted from, specific incidents of aggression. Thus, future research and clinicians should focus their efforts more on teaching individuals to distinguish between various instances of relationship aggression when trying to understand them.

The tendency of partners to report divergent perceptions of IPA events has clinical and research implications. For instance, how/why can one partner say a behavior (e.g., pushing, blaming) occurred, and the other deny that it happened? Moving forward, researchers and theorists should seriously consider this variation in partners' reports. The current study's findings 
imply that research involving one partner's perceptions of IPA may not give an accurate portrayal of the relationship aggression that they experience. Future research should further investigate the discrepancies between partners' accounts of IPA experiences. While such a study would have ethical issues to consider, future research could reveal these discrepancies to couples and ask them to walk through and explain the events with the researchers. Perhaps allowing couples to run through the IPA events together may aid research in understanding these large disconnects. In addition, this may help participants learn how their partners are experiencing the events, perhaps fostering a better understanding of their partners and relationships in general.

\section{CONCLUSION}

It is well documented that IPA is a considerable problem in our society (e.g., Edwards et al., 2009; Coker et al., 2002). Thus, understanding the various facets of IPA is imperative to expanding our knowledge of IPA as a whole, which can lead to more successful prevention and intervention programs. Previous research has examined both partners' perceptions of IPAspecific behaviors that occur, as well as their attributions for IPA, while research has yet to explore agreement on emotional effects of IPA. Using an empirical study investigating both partners' perceptions of IPA, the current study was able to examine these concepts. The current study found that romantic partners typically have little agreement on what occurs during instances of relationship aggression, why that aggression took place, and how that aggression emotionally impacted each partner, however agreement was heightened for behaviors and attributions for IPA that were directly related to relationship wellbeing.

It is clear that both couples are typically needed to make sense of instances of IPA, as each partner has a different interpretation of the events. Future research should further investigate the different perspectives that partners form for instances of IPA, and explore 
methods of bridging the gap on partners' interpretations. The current study shows evidence that partners do not typically have consistent accounts of their relationship conflicts. Thus, researching just one partner may not be enough to understand the aggression that occurs within relationships. Further, it is essential for clinicians, intervention programmers, as well as members of the justice system, to recognize that one partner's perspective of a prior IPA event does not necessary equate to the full story. Thus, it is important to educate couples that there are two sides to every conflict that they experience, and the partners involved may have very different perspectives of the incidents. 


\section{REFERENCES}

Adams, J. M., \& Jones, W. H. (1997). The conceptualization of marital commitment: An integrative analysis. Journal of Personality and Social Psychology, 72, 1177-1196.

Agnew, C. R, Loving, T J., \& Drigotas, S. M. (2001). Substituting the forest for the trees: Social networks and the prediction of romantic relationship state and fate. Journal of Personality and Social Psychology, 81, 1042-1057.

Archer, J. (2000). Sex differences in aggression between heterosexual partners: A meta-analytic review. Psychological Bulletin, 126, 651-680. doi:10.1037/0033-2909.126.5.651

Armstrong, T. G., Wernke, J. Y., Medina, K. L., \& Schafer, J. (2002). Do partners agree about the occurrence of intimate partner violence? A review of the current literature. Trauma, Violence, \& Abuse, 3(3), 181-193.

Arriaga, X. B., \& Rusbult, C. E. (1998). Standing in my partner's shoes: Partner perspective taking and reactions to accommodative dilemmas. Personality and Social Psychology Bulletin, 24(9), 927-948.

Babcock, J. C., Jacobson, N. S., Gottman, J. M., \& Yerington, T. P. (2000). Attachment, emotional regulation, and the function of marital violence: Differences between secure, preoccupied, and dismissing violent and nonviolent husbands. Journal of Family Violence, 15, 391-409.

Babcock, J. C., \& La Taillade, J. J. (2000). Evaluating interventions for men who batter. In J. P. Vincent \& E. N., Jouriles (Eds.), Domestic violence: Guidelines for research-informed practice, (pp. 37-77). London: Jessica Kingsley Publishers.

Bograd, M. (1988). How battered women and abusive men account for domestic violence: Excuses, justifications, or explanations? In G. T. Hotaling, D. Finkelhor, J. T. Kirkpatrick, M. A. Straus (Eds.), Coping with family violence: Research and policy perspectives (pp. 60-77). Thousand Oaks, CA US: Sage Publications, Inc.

Booth, A., \& Welch, S. (1978). Spousal consensus and its correlates: A reassessment. Journal of Marriage And The Family, 40(1), 23-32.

Burton, S., \& Blair, E. (1991). Task conditions, response formulation processes, and response accuracy for behavioral frequency questions in surveys. Public Opinion Quarterly, 55(1), 50-79. doi:10.1086/269241

Caetano, R., Field, C., Ramisetty-Mikler, S., \& Lipsky, S. (2009). Agreement on reporting of physical, psychological, and sexual violence among white, black, and Hispanic couples in the United States. Journal of interpersonal violence, 24(8), 1318-1337. 
Caetano, R., Schafer, J., Field, C., \& Nelson, S. M. (2002). Agreement on reports of intimate partner violence among white, black, and Hispanic couples in the United States. Journal of Interpersonal Violence, 17(12), 1308-1322.

Caldwell, J. E., Swan, S. C., Allen, C. T., Sullivan, T. P., \& Snow, D. L. (2009). Why I hit him: Women's reasons for intimate partner violence. Journal of Aggression, Maltreatment \& Trauma, 18(7), 672-697. doi:10.1080/10926770903231783

Carrado, M., George, M. J., Loxam, E., Jones, L. L., \& Templar, D. (1996). Aggression in British heterosexual relationships: A descriptive analysis. Aggressive Behavior, 22(6), 401-415.

Cascardi, M., \& Vivian, D. (1995). Context for specific episodes of marital violence: gender and severity of violence differences. Journal of Family Violence, 10(3), 265-293.

Christopher, F., Owens, L. A., \& Stecker, H. L. (1993). An examination of single men's and women's sexual aggressiveness in dating relationships. Journal of Social and Personal Relationships, 10(4), 511-527. doi:10.1177/0265407593104003

Coker, A. L., Davis, K. E., Arias, I., Desai, S., Sanderson, M., Brandt, H. M., \& Smith, P. H. (2002). Physical and mental health effects of intimate partner violence for men and women. American journal of preventive medicine, 23(4), 260-268.

Cunradi, C., Bersamin, M., \& Ames, G. (2009). Agreement on intimate partner violence among a sample of blue-collar couples. Journal of Interpersonal Violence, 24(4), 551-568. doi: $10.1177 / 0886260508317189$

DeKeseredy, W. S., Saunders, D. G., Schwartz, M. D., \& Alvi, S. (1997). The meanings and motives for women's use of violence in Canadian college dating relationships: Results from a national survey. Sociological Spectrum, 17(2), 199-222.

doi:10.1080\%2F02732173.1997.9982160

Dobash, R., \& Dobash, R. P. (1984). The nature and antecedents of violent events. British Journal of Criminology, 24(3), 269-288.

Downs, W. R., Rindels, B., \& Atkinson, C. (2007). Women's use of physical and nonphysical self-defense strategies during incidents of partner violence. Violence Against Women, 13(1), 28-45. doi:10.1177\%2F1077801206294807

Edwards, A. L. (1957). Social desirability and probability of endorsement of items in the interpersonal check list. Journal of Abnormal and Social Psychology, 55, 394-396. doi: $10.1037 / \mathrm{h} 0048497$

Edwards, K. M., Desai, A. D., Gidycz, C. A., \& VanWynsberghe, A. (2009). College women's aggression in relationships: The role of childhood and adolescent victimization. Psychology of Women Quarterly, 33(3), 255-265. 
Epstein-Ngo, Q. M., Cunningham, R. M., Whiteside, L. K., Chermack, S. T., Booth, B. M., Zimmerman, M. A., \& Walton, M. A. (2013). A daily calendar analysis of substance use and dating violence among high risk urban youth. Drug \& Alcohol Dependence, 130(13), 194-200. doi:10.1016/j.drugalcdep.2012.11.006

Fals-Stewart, W. (2003). The occurrence of partner physical aggression on days of alcohol consumption: A longitudinal diary study. Journal of Consulting and Clinical Psychology, 71(1), 41-52. doi:10.1037/0022-006X.71.1.41

Fernández-Fuertes, A. A., \& Fuertes, A. (2010). Physical and psychological aggression in dating relationships of Spanish adolescents: Motives and consequences. Child Abuse \& Neglect, 34(3), 183-191. doi:10.1016/j.chiabu.2010.01.002

Fiebert, M. S., \& Gonzalez, D. M. (1997). College women who initiate assaults on their male partners and the reasons offered for such behavior. Psychological Reports, 80(2), 583590. doi:10.2466/pr0.1997.80.2.583

Fincham, F. D., Beach, S. R., \& Baucom, D. H. (1987). Attribution processes in distressed and nondistressed couples: 4. Self-partner attribution differences. Journal of Personality and Social Psychology, 52, 739-748.

Fiske, S. T., \& Taylor, S. E. (1991). Social cognition (2nd ed.). NY: McGraw-Hill.

Flemke, K., \& Allen, K. R. (2008). Women's experience of rage: A critical feminist analysis. Journal of Marital \& Family Therapy, 34(1), 58-74. doi:10.1111/j.17520606.2008.00053.x

Fletcher, G. J. O., Fitness, J., \& Blampied, N. M. (1990). The link between attributions and happiness in close relationships: The roles of depression and explanatory style. Journal of Social and Clinical Psychology, 9, 243-255.

Fletcher, G. J., \& Kerr, P. S. (2010). Through the eyes of love: reality and illusion in intimate relationships. Psychological bulletin, 136(4), 627-658.

Follingstad, D. R., Wright, S., Lloyd, S., \& Sebastian, J. A. (1991). Sex differences in motivations and effects in dating violence. Family Relations, 40(1), 51-57.

Foshee, V. A., Bauman, K. E., Arriaga, X. B., Helms, R. W., Koch, G. G., \& Linder, G. F. (1998). An evaluation of Safe Dates, an adolescent dating violence prevention program. American journal of public health, 88(1), 45-50.

Foshee, V. A., Bauman, K. E., Linder, F., Rice, J., \& Wilcher, R. (2007). Typologies of adolescent dating violence. Journal of Interpersonal Violence, 22(5), 498-519. doi:10.1177\%2F0886260506298829 
Fraley, R. C., Waller, N. G., \& Brennan, K. A. (2000). An item response theory analysis of selfreport measures of adult attachment. Journal of personality and social psychology, 78(2), 350-365.

Freeman, A. J., Schumacher, J. A., \& Coffey, S. F. (2015). Social desirability and partner agreement of men's reporting of intimate partner violence in substance abuse treatment settings. Journal of interpersonal violence, 30(4), 565-579.

Gagné, F. M., \& Lydon, J. E. (2001). Mind-set and close relationships: when bias leads to (In) accurate predictions. Journal of personality and social psychology, 81(1), 85-96.

Golding, J. M. (1999). Intimate partner violence as a risk factor for mental disorders: A metaanalysis. Journal of Family Violence, 14, 99-132.

Graham-Kevan, N., \& Archer, J. (2003). Intimate terrorism and common couple violence: A test of Johnson's predictions in four British samples. Journal of Interpersonal Violence, 18(11), 1247-1270.

Gratz, K. L., \& Roemer, L. (2004). Multidimensional assessment of emotion regulation and dysregulation: Development, factor structure, and initial validation of the difficulties in emotion regulation scale. Journal of Psychopathology and Behavioral Assessment, 26(1), 41-54.

Greene, K., \& Bogo, M. (2002). The different faces of intimate violence: Implications for assessment and treatment. Journal of Marital and Family Therapy, 28(4), 455-466.

Hamburger, M. E., Hogben, M., McGowan, S., \& Dawson, L. J. (1996). Assessing hypergender ideologies: Development and initial validation of a gender-neutral measure of adherence to extreme gender-role beliefs. Journal of Research in Personality, 30(2), 157-178.

Hamberger, L., Lohr, J., \& Bonge, D. (1994). The intended function of domestic violence is different for arrested male and female perpetrators. Family Violence \& Sexual Assault Bulletin, 10(3-4), 40-44.

Harned, M. S. (2001). Abused women or abused men? An examination of the context and outcomes of dating violence. Violence and Victims, 16(3), 269-285.

Henning, K., Jones, A. R., \& Holdford, R. (2005). 'I didn't do it, but if I did I had a good reason': Minimization, denial, and attributions of blame among male and female domestic violence offenders. Journal of Family Violence, 20(3), 131-139. doi:10.1007/s10896005-3647-8

Hettrich, E. L., \& O'Leary, K. (2007). Females' reasons for their physical aggression in dating relationships. Journal of Interpersonal Violence, 22(9), 1131-1143.

doi:10.1177\%2F0886260507303729 
Jackson, S. M., Cram, F., \& Seymour, F. W. (2000). Violence and sexual coercion in high school students' dating relationships. Journal of Family Violence, 15(1), 23-36.

Jacobson, N. S., \& Gottman, J. M. (1998). When men batter women: New insights into ending abusive relationships. New York: Simon and Schuster.

Johnson, M. P. (1995). Intimate terrorism and common couple violence: Two forms of violence against women. Journal of Marriage and the Family, 57, 283-294.

Jones, R. K. (1993). Female victim perceptions of the causes of male spouse abuse. Sociological Inquiry, 63(3), 351-361.

Jones, E. E., \& Nisbett, R. E. (1972). The actor and the observer: Divergent perceptions of the causes of behavior. In E. E. Jones, D. E. Kanhouse, H. H. Kelley, R. E. Nisbett, S. Valins, \& B. Weiner (Eds.), Attribution: Perceiving the causes of behavior (pp. 79-94). NY: General Learning Press.

Kernsmith, P. (2005). Exerting power or striking back: A gendered comparison of motivations for domestic violence perpetration. Violence \& Victims, 20(2), 173-185. doi:10.1891\%2Fvivi.2005.20.2.173

Kernsmith, P. D., \& Tolman, R. M. (2011). Attitudinal correlates of girls' use of violence in teen dating relationships. Violence Against Women, 17(4), 500-516. doi: $10.1177 / 1077801211404312$

Jacobson, N. S., \& Moore, D. (1981). Spouses as observers of the events in their relationships. Journal of Consulting and Clinical Psychology, 49, 269-277.

Koss, M. P., Abbey, A., Campbell, R., Cook, S., Norris, J., Testa, M., Ullman, S., West, C., \& White, J. (2007). Revising the SES: A collaborative process to improve assessment of sexual aggression and victimization. Psychology of Women Quarterly, 31, 357-370.

La Taillade, J. J., Epstein, N. B., \& Werlinich, C. A. (2006). Conjoint treatment of intimate partner violence: A cognitive behavioral approach. Journal of Cognitive Psychotherapy, 20(4), 393-410.

Landis, J. R., \& Koch, G. G. (1977). The measurement of observer agreement for categorical data. Biometrics, 33, 159-174.

Leisring, P. A. (2012). Physical and emotional abuse in romantic relationships: Motivation for perpetration among college women. Journal of Interpersonal Violence, 28(7), 1437-1454. doi: $10.1177 / 0886260512468236$

Lemay, E. P., Jr., \& Neal, A. M. (2014). Accurate and biased perceptions of responsive support predict well-being. Motivation and Emotion, 38(2), 270-286. 
Lindsay, D. S., Allen, B. P., Chan, J. C., \& Dahl, L. C. (2004). Eyewitness suggestibility and source similarity: Intrusions of details from one event into memory reports of another event. Journal of Memory and Language, 50(1), 96-111.

Makepeace, J. M. (1986). Gender differences in courtship violence victimization. Family Relations: An Interdisciplinary Journal of Applied Family Studies, 35(3), 383-388. doi: $10.2307 / 584365$

Maner, J. K., Gailliot, M. T., Rouby, D. A., \& Miller, S. L. (2007). Can't take my eyes off you: Attentional adhesion to mates and rivals. Journal of personality and social psychology, 93(3), 389-401.

Margolin, G. (1987). The multiple forms of aggressiveness between marital partners: How do we identify them?. Journal of Marital and Family Therapy,13(1), 77-84.

McArthur, L. Z., \& Baron, R. M. (1983). Toward an ecological theory of social perception. Psychological Review, 90, 215-238.

McNulty, J. K., \& Hellmuth, J. C. (2008). Emotion regulation and intimate partner violence in newlyweds. Journal of family psychology, 22(5), 794-797.

Moffitt, T. E., Caspi, A., Krueger, R. F., Magdol, L., Margolin, G., Silva, P. A., \& Sydney, R. (1997). Do partners agree about abuse in their relationship?: A psychometric evaluation of interpartner agreement. Psychological Assessment, 9(1), 47-56. doi:10.1037/10403590.9.1.47

Murray, S. L., Holmes, J. G., \& Griffin, D. W. (1996). The benefits of positive illusions: Idealization and the construction of satisfaction in close relationships. Journal of Personality and Social Psychology, 70(1), 79-98.

Neal, A. M., \& Edwards, K. M. (2015). Perpetrators' and victims' attributions for IPA: A critical review of the literature.

Olson, L. N., \& Lloyd, S. A. (2005). 'It depends on what you mean by starting': An exploration of how women define initiation of aggression and their motives for behaving aggressively. Sex Roles, 53(7-8), 603-617. doi:10.1007/s11199-005-7145-5

Pahl, J. M. (1985). Marital violence and marital problems. In J. M. Pahl (Ed.), Private violence and public policy: The needs of battered women and the response of public services (pp. 29-43. London/Boston: Routledge \& K. Paul.

Perry, A. R., \& Fromuth, M. (2005). Courtship violence using couple data: Characteristics and perceptions. Journal of Interpersonal Violence, 20(9), 1078-1095. doi:10.1177\%2F0886260505278106

Presley, C. A., Meilman, P. W., Cashin, J. R., \& Lyerla, R. (1993). Alcohol and drugs on 
American college campuses. Use, consequences, and perceptions of the campus environment. Volume III. Carbondale, IL: Southern Illinois University.

Preston, C. C., \& Colman, A. M. (2000). Optimal number of response categories in rating scales: Reliability, validity, discriminating power, and respondent preferences. Acta Psychologica, 104(1), 1-15. doi:10.1016/S0001-6918(99)00050-5

Rhoades, G. K., Stanley, S. M., Kelmer, G., \& Markman, H. J. (2010). Physical aggression in unmarried relationships: the roles of commitment and constraints. Journal of Family Psychology, 24(6), 678-687.

Rosenberg, M. (1965). Society and the adolescent self-image. Princeton, NJ: Princeton Univ. Press.

Rusbult, C. E., Martz, J. M., \& Agnew, C. R. (1998). The investment model scale: Measuring commitment level, satisfaction level, quality of alternatives, and investment size. Personal relationships, 5(4), 357-387.

Sarason, I. G., Sarason, B. R., \& Pierce, G. R. (1995). Stress and social support. In S. E. Hobfoll \& M. W. deVries (Eds.), Extreme stress and communities: Impact and intervention (pp. 179-197). New York: Kluwer Academic/Plenum Publishers.

Saunders, J. B., Aasland, O. G., Babor, T. F., de la Fuente, J. R., \& Grant, M. (1993). Development of the alcohol use disorders identification test (AUDIT): WHO collaborative project on early detection of persons with harmful alcohol consumptionII. Addiction, 88(6), 791-804.

Schafer, J., Caetano, R., \& Clark, C. L. (1998). Rates of intimate partner violence in the United States. American journal of public health, 88(11), 1702-1704.

Shorey, R. C., Meltzer, C., \& Cornelius, T. L. (2010). Motivations for self-defensive aggression in dating relationships. Violence and Victims, 25(5), 662-676. doi:10.1891/08866708.25.5.662

Smeets, T., Candel, I., \& Merckelbach, H. (2004). Accuracy, completeness, and consistency of emotional memories. The American journal of psychology, 117(4), 595-609.

Stets, J. E., \& Straus, M. A. (1990). Gender differences in reporting marital violence and its medical and psychological consequences. In M. A. Straus \& R. J. Gelles (Eds.). Physical violence in American families: Risk factors and adaptations to violence in 8,145 families (pp. 151-166). New Brunswick, NJ: Transaction.

Stith, S. M., Rosen, H., McCollum, E. E., \& Thomsen, C. J. (2004). Treating intimate partner violence within intact couple relationships: Outcomes of multi-couple versus individual couple therapy. Journal of Marital and Family Therapy, 30(3), 305-318. 
Storms, M. D. (1973). Videotape and the attribution process: reversing actors' and observers' points of view. Journal of Personality and Social Psychology, 27(2), 165-175.

Stuart, G. L., Moore, T. M., Elkins, S. R., O’Farrell, T. J., Temple, J. R., Ramsey, S. E., \& Shorey, R. C. (2013). The temporal association between substance use and intimate partner violence among women arrested for domestic violence. Journal of Consulting and Clinical Psychology, 81(4), 681-690.

Stuart, G. L., Moore, T. M., Gordon, K., Hellmuth, J. C., Ramsey, S. E., \& Kahler, C. W. (2006). Reasons for intimate partner violence perpetration among arrested women. Violence Against Women, 12(7), 609-621. doi:10.1177\%2F1077801206290173

Stuart, G. L., Moore, T. M., Ramsey, S. E., \& Kahler, C. W. (2004). Hazardous drinking and relationship violence perpetration and victimization in women arrested for domestic violence. Journal of Studies on Alcohol, 65(1), 46-53.

Szinovacz, M. E., \& Egley, L. C. (1995). Comparing one-partner and couple data on sensitive marital behaviors: The case of marital violence. Journal of Marriage and the Family, 57(4), 995-1010.

Vazquez, S. P., Stohr, M. K., \& Purkiss, M. (2005). Intimate partner violence incidence and characteristics: Idaho NIBRS 1995 to 2001 data. Criminal Justice Policy Review, 16(1), 99-114.

Weng, L. J. (2004). Impact of the number of response categories and anchor labels on coefficient alpha and test-retest reliability. Educational and Psychological Measurement, 64(6), 956972.

Walley-Jean, J., \& Swan, S. (2009). Motivations and justifications for partner aggression in a sample of African American college women. Journal of Aggression, Maltreatment \& Trauma, 18(7), 698-717. doi:10.1080/10926770903231759

Whitaker, M. (2014). Motivational attributions about intimate partner violence among male and female perpetrators. Journal of Interpersonal Violence, 29(3), 517-535. doi:10.1177\%2F0886260513505211 
Table 1: General Agreement of Incident-Specific IPA.

\begin{tabular}{lccccc}
\hline Type of IPA & $\begin{array}{c}\text { Agreed IPA } \\
\text { Didn't Occur: } \\
\boldsymbol{N}(\boldsymbol{\%})\end{array}$ & $\begin{array}{c}\text { Only Victim } \\
\text { Reported IPA: } \\
\boldsymbol{N}(\boldsymbol{\%})\end{array}$ & $\begin{array}{c}\text { Only Perpetrator } \\
\text { Reported IPA: } \\
\boldsymbol{N}(\boldsymbol{\%})\end{array}$ & $\begin{array}{c}\text { Agreed IPA } \\
\text { Occurred: } \\
\boldsymbol{N}(\boldsymbol{\%})\end{array}$ & Kappa \\
\hline Psychological & $75(45.45)$ & $30(18.18)$ & $28(16.97)$ & $32(19.39)$ & $\mathbf{0 . 2 5}$ \\
Physical & $149(90.30)$ & $8(4.85)$ & $6(3.64)$ & $2(1.21)$ & $\mathbf{0 . 1 8}$ \\
Sexual & $163(98.79)$ & $2(1.21)$ & $0(0)$ & $0(0)$ & NC \\
Any IPA & $74(44.85)$ & $30(18.18)$ & $25(15.15)$ & $36(21.82)$ & $\mathbf{0 . 3 0}$ \\
\hline
\end{tabular}

Note: $\mathrm{NC}=$ Not calculated , cell $N$ too low. Bold $=$ statistically significant 
Table 2: Couples with One or Two Partners Indicating Any Aggression.

\begin{tabular}{|c|c|c|}
\hline Variable & $\begin{array}{c}\text { One Partner: } \\
M(S D)\end{array}$ & $\begin{array}{c}\text { Both } \\
\text { Partners: } \\
M(S D)\end{array}$ \\
\hline Alcohol Use & $6.26(3.15)$ & $8.65(4.73)$ \\
\hline Emotion Dysregulation & $3.12(0.97)$ & $3.67(1.02)$ \\
\hline Controlling Behavior & $1.34(0.29)$ & $1.57(0.41)$ \\
\hline Attachment Anxiety & $4.24(1.72)$ & $4.74(1.40)$ \\
\hline Relationship Investment & $6.85(1.32)$ & $7.31(1.22)$ \\
\hline Perceptions of Own Future Perpetration & $1.24(0.58)$ & $1.84(1.18)$ \\
\hline Perceptions One's Partner's Future Perpetration & $1.26(0.70)$ & $1.92(1.18)$ \\
\hline Past Year Sexual IPA Perpetration & $0.02(0.22)$ & $0.18(0.66)$ \\
\hline Past Year Physical IPA Victimization & $0.38(1.71)$ & $3.17(7.67)$ \\
\hline Past Year Physical IPA Perpetration & $0.44(1.61)$ & $2.30(5.27)$ \\
\hline Past Year Psychological IPA Victimization & $2.23(5.82)$ & $8.35(11.08)$ \\
\hline Past Year Psychological IPA Perpetration & $2.02(3.54)$ & $7.55(9.95)$ \\
\hline Any Past Year IPA Victimization & $2.64(6.96)$ & $11.61(16.11)$ \\
\hline Any Past Year IPA Perpetration & $2.49(4.35)$ & $10.04(12.55)$ \\
\hline Self-Esteem & $7.18(1.22)$ & $6.63(1.47)$ \\
\hline Age & $19.62(1.98)$ & $19.75(1.62)$ \\
\hline Relationship Length & $14.96(19.15)$ & $16.55(19.36)$ \\
\hline Socioeconomic Status & $7.24(2.22)$ & $7.33(2.19)$ \\
\hline Attachment Avoidance & $4.16(1.58)$ & $4.22(1.49)$ \\
\hline Hypergender ideology & $2.47(0.95)$ & $2.71(1.21)$ \\
\hline Relationship Commitment & $7.50(1.49)$ & $7.45(1.35)$ \\
\hline Relationship Satisfaction & $7.98(1.09)$ & $7.82(0.99)$ \\
\hline Qualities of Alternatives & $3.55(1.92)$ & $4.03(1.88)$ \\
\hline Social Desirability & $4.12(0.20)$ & $4.14(0.16)$ \\
\hline Time Since IPA Incident & $2.27(4.47)$ & $2.25(4.25)$ \\
\hline Past Year Sexual IPA Victimization & $0.07(.34)$ & $0.17(0.58)$ \\
\hline
\end{tabular}

Note: Bold = statistically significant. 
Table 3: Agreement of Incident-Specific Behaviors of IPA ( $N=84$ Couples).

\begin{tabular}{|c|c|c|c|c|c|}
\hline Behavior & $\begin{array}{c}\text { Agreed Didn't } \\
\text { Occur: } \\
N(\%)\end{array}$ & $\begin{array}{c}\text { Only Partner- } \\
\text { Reported: } \\
N(\%)\end{array}$ & $\begin{array}{c}\text { Only Self- } \\
\text { Reported: } \\
N(\%)\end{array}$ & $\begin{array}{c}\text { Agreed } \\
\text { Occurred: } \\
N(\%)\end{array}$ & Kappa \\
\hline Blamed for bad things they did. & $150(90.91)$ & $7(4.24)$ & $4(2.42)$ & $4(2.42)$ & 0.39 \\
\hline $\begin{array}{l}\text { Told could not talk to someone } \\
\text { of the opposite sex. }\end{array}$ & $139(84.24)$ & $11(6.67)$ & $8(4.85)$ & $7(4.24)$ & 0.36 \\
\hline $\begin{array}{l}\text { Did something just to make } \\
\text { jealous. }\end{array}$ & $139(84.24)$ & $14(8.48)$ & $7(4.24)$ & $5(3.03)$ & 0.26 \\
\hline $\begin{array}{l}\text { Said things to hurt feelings on } \\
\text { purpose. }\end{array}$ & $104(63.03)$ & $26(15.76)$ & $22(13.33)$ & $13(7.88)$ & 0.17 \\
\hline $\begin{array}{l}\text { Brought up something from the } \\
\text { past to hurt. }\end{array}$ & $129(78.18)$ & $22(13.33)$ & $10(6.01)$ & $4(2.42)$ & 0.10 \\
\hline Pushed, grabbed, or shoved. & $151(91.52)$ & $6(3.64)$ & $7(4.24)$ & $1(0.61)$ & 0.09 \\
\hline Insulted in front of others. & $146(88.48)$ & $11(6.67)$ & $7(4.24)$ & $1(0.61)$ & 0.04 \\
\hline Slapped. & $162(98.18)$ & $2(1.21)$ & $1(0.61)$ & $0(0)$ & -0.01 \\
\hline $\begin{array}{l}\text { Threw something at them that } \\
\text { hit them. }\end{array}$ & $162(98.18)$ & $2(1.21)$ & $1(0.61)$ & $0(0)$ & -0.01 \\
\hline $\begin{array}{l}\text { Slammed me or held against a } \\
\text { wall. }\end{array}$ & $163(98.79)$ & $1(0.61)$ & $1(0.61)$ & $0(0)$ & -0.01 \\
\hline Hit with a fist. & $163(98.79)$ & $1(0.61)$ & $1(0.61)$ & $0(0)$ & -0.01 \\
\hline Started to hit but stopped. & $163(98.79)$ & $1(0.61)$ & $1(0.61)$ & $0(0)$ & -0.01 \\
\hline $\begin{array}{l}\text { Threw something at them but } \\
\text { missed. }\end{array}$ & $163(98.79)$ & $1(0.61)$ & $1(0.61)$ & $0(0)$ & -0.01 \\
\hline $\begin{array}{l}\text { Made describe where they were } \\
\text { every minute of day. }\end{array}$ & $158(95.76)$ & $4(2.42)$ & $3(1.81)$ & $0(0)$ & -0.02 \\
\hline $\begin{array}{l}\text { Told could not talk to someone } \\
\text { of the same sex. }\end{array}$ & $160(96.97)$ & $3(1.81)$ & $2(1.21)$ & $0(0)$ & -0.02 \\
\hline $\begin{array}{l}\text { Threatened to start dating } \\
\text { someone else. }\end{array}$ & $153(92.73)$ & $4(2.42)$ & $8(4.85)$ & $0(0)$ & -0.03 \\
\hline
\end{tabular}


Would not let do things with other people.

Hit with something hard

besides a fist.

Fondled, kissed, or rubbed up against private areas of body (lips, breast/chest, crotch or butt) or removed some clothes

without consent (but did not attempt sexual penetration).

Had oral sex with partner or made partner have oral sex

without consent.

Put penis, fingers, or objects into butt without consent.

Tried to choke.

Put down looks.

Damaged personal belongings.

Even though it didn't happen,

TRIED to put penis, fingers, or objects into butt without my consent.

Put penis, fingers, or objects into vagina without consent. ${ }^{a}$

Even though it didn't happen,

TRIED to put penis, fingers, or objects into vagina without

consent. $^{\mathrm{a}}$

Even though it didn't happen,

TRIED to have oral sex, or make partner have oral sex

without consent.

Scratched.

$165(100)$
$0(0)$

$0(0)$
NC

$\mathrm{NC}$

$\mathrm{NC}$

$\begin{array}{lll}0(0) & 0(0) & \mathrm{NC} \\ (0.61) & 0(0) & \mathrm{NC}\end{array}$

$0(0)$

0 (0)

$\mathrm{NC}$

NC

NC

NC

$0(0)$ 
Physically twisted arm.

Kicked.

Bent fingers.

Bit.

Dumped out of a car.

Burned.

Beat up.

Assaulted with a knife or gun.

Threatened to hurt.

\begin{tabular}{lllll}
$165(100)$ & $0(0)$ & $0(0)$ & $0(0)$ & $\mathrm{NC}$ \\
$165(100)$ & $0(0)$ & $0(0)$ & $0(0)$ & $\mathrm{NC}$ \\
$165(100)$ & $0(0)$ & $0(0)$ & $0(0)$ & $\mathrm{NC}$ \\
$165(100)$ & $0(0)$ & $0(0)$ & $0(0)$ & $\mathrm{NC}$ \\
$165(100)$ & $0(0)$ & $0(0)$ & $0(0)$ & $\mathrm{NC}$ \\
$165(100)$ & $0(0)$ & $0(0)$ & $0(0)$ & $\mathrm{NC}$ \\
$165(100)$ & $0(0)$ & $0(0)$ & $0(0)$ & $\mathrm{NC}$ \\
$165(100)$ & $0(0)$ & $0(0)$ & $0(0)$ & $\mathrm{NC}$ \\
$165(100)$ & $0(0)$ & $0(0)$ & $0(0)$ & $\mathrm{NC}$ \\
\hline
\end{tabular}

Note: Behaviors are listed in order from most to least agreement. $\mathrm{NC}=$ Not calculated, cell $N$ too low. Bold $=$ statistically significant.

${ }^{\text {a }}$ Female-victim only event, total possible $N=84$ individuals. 
Table 4: Correlates of Agreement on Specific IPA-Related Behaviors.

\begin{tabular}{|c|c|}
\hline Variable & Correlation $(r)$ \\
\hline Alcohol Use & 0.18 \\
\hline Emotion Dysregulation & 0.18 \\
\hline Controlling Behavior & 0.36 \\
\hline Attachment Anxiety & 0.12 \\
\hline Relationship Investment & 0.05 \\
\hline Perceptions of Own Future Perpetration & 0.26 \\
\hline Perceptions One's Partner's Future Perpetration & 0.17 \\
\hline Past Year Sexual IPA Perpetration & 0.09 \\
\hline Past Year Physical IPA Victimization & 0.22 \\
\hline Past Year Physical IPA Perpetration & 0.26 \\
\hline Past Year Psychological IPA Victimization & 0.31 \\
\hline Past Year Psychological IPA Perpetration & 0.42 \\
\hline Any Past Year IPA Victimization & 0.32 \\
\hline Any Past Year IPA Perpetration & 0.44 \\
\hline Self-Esteem & -0.06 \\
\hline Age & -0.04 \\
\hline Relationship Length & -0.04 \\
\hline Socioeconomic Status & 0.05 \\
\hline Attachment Avoidance & 0.04 \\
\hline Hypergender Ideology & 0.17 \\
\hline Relationship Commitment & -0.12 \\
\hline Relationship Satisfaction & -0.03 \\
\hline Qualities of Alternatives & 0.06 \\
\hline Social Desirability & -0.10 \\
\hline Time Since IPA Incident & 0.00 \\
\hline Past Year Sexual IPA Victimization & 0.06 \\
\hline
\end{tabular}

Note: Bold = statistically significant. 
Table 5: Agreement of Incident-Specific Attributions for IPA ( $N=42$ Couples).

\begin{tabular}{|c|c|c|c|c|c|}
\hline Attribution & $\begin{array}{c}\text { Neither } \\
\text { Reported } \\
\text { Attribution: } \\
N(\%)\end{array}$ & $\begin{array}{c}\text { Only } \\
\text { Partner- } \\
\text { Reported } \\
\text { Attribution: } \\
N(\%) \\
\end{array}$ & $\begin{array}{l}\text { Only Self-Reported } \\
\text { Attribution: } N(\%)\end{array}$ & $\begin{array}{c}\text { Both } \\
\text { Reported } \\
\text { Attribution: } \\
N(\%)\end{array}$ & Kappa \\
\hline $\begin{array}{l}\text { Under influence of drugs or } \\
\text { alcohol }\end{array}$ & $38(67.9)$ & $3(5.4)$ & $4(7.1)$ & $11(19.6)$ & 0.67 \\
\hline Jealousy & $27(48.2)$ & $7(12.5)$ & $11(19.6)$ & $11(19.6)$ & 0.30 \\
\hline Didn't believe partner cared & $36(64.3)$ & $8(14.3)$ & $6(10.7)$ & $6(10.7)$ & 0.30 \\
\hline Punish partner for wrongdoing & $27(49.1)$ & $8(14.5)$ & $10(18.2)$ & $10(18.2)$ & 0.28 \\
\hline $\begin{array}{l}\text { Afraid partner was going to leave } \\
\text { them }\end{array}$ & $39(69.6)$ & $9(16.1)$ & $4(7.1)$ & $4(7.1)$ & 0.25 \\
\hline Get control over partner & $33(58.9)$ & $10(17.9)$ & $7(12.5)$ & $6(10.7)$ & 0.21 \\
\hline Make partner agree with them & $24(43.6)$ & $12(21.8)$ & $9(16.4)$ & $10(18.2)$ & 0.19 \\
\hline Hurt partner's feelings & $34(60.7)$ & $8(14.3)$ & $9(16.1)$ & $5(8.9)$ & 0.17 \\
\hline Prove love & $42(76.4)$ & $4(7.3)$ & $7(12.7)$ & $2(3.6)$ & 0.16 \\
\hline Cheated on & $47(83.9)$ & $1(1.8)$ & $7(12.5)$ & $1(1.8)$ & 0.15 \\
\hline $\begin{array}{l}\text { Partner was going to walk away } \\
\text { or leave a conflict before it was } \\
\text { solved }\end{array}$ & $39(69.6)$ & $7(12.5)$ & $7(12.5)$ & $3(5.4)$ & 0.15 \\
\hline Show anger & $10(17.9)$ & $9(16.1)$ & $15(26.8)$ & $22(39.3)$ & 0.11 \\
\hline Feel more powerful & $35(62.5)$ & $13(23.2)$ & $5(8.9)$ & $3(5.4)$ & 0.07 \\
\hline Inability to express self verbally & $22(40.0)$ & $14(25.5)$ & $10(18.2)$ & $9(16.4)$ & 0.08 \\
\hline Retaliation for emotional hurt & $14(25.0)$ & $10(17.9)$ & $17(30.4)$ & $15(26.8)$ & 0.05 \\
\hline Provoked or pushed over the edge & $26(46.4)$ & $9(16.1)$ & $15(26.8)$ & $6(10.7)$ & 0.03 \\
\hline $\begin{array}{l}\text { Didn't know what to do with } \\
\text { feelings }\end{array}$ & $23(41.8)$ & $16(29.1)$ & $9(16.4)$ & $7(12.7)$ & 0.02 \\
\hline Displaced anger & $30(53.6)$ & $11(19.6)$ & $11(19.6)$ & $4(7.1)$ & 0.00 \\
\hline Wanted to have sex and partner & $55(98.2)$ & $1(1.8)$ & $0(0)$ & $0(0)$ & 0.00 \\
\hline
\end{tabular}


didn't

Sexually arousing

\begin{tabular}{lcccc}
$52(94.5)$ & $1(1.8)$ & $2(3.6)$ & $0(0)$ & -0.03 \\
$50(89.3)$ & $2(3.6)$ & $4(7.1)$ & $0(0)$ & -0.05 \\
$48(87.3)$ & $2(3.6)$ & $5(9.1)$ & $0(0)$ & -0.06 \\
$16(28.6)$ & $13(23.2)$ & $17(30.4)$ & $10(17.9)$ & -0.08 \\
$13(22.2)$ & $15(26.8)$ & $16(28.6)$ & $12(21.4)$ & -0.11 \\
$40(71.4)$ & $9(16.1)$ & $7(12.5)$ & $0(0)$ & -0.16 \\
$37(66.1)$ & $10(17.9)$ & $9(16.1)$ & $0(0)$ & -0.20 \\
$53(94.6)$ & $0(0)$ & $3(5.4)$ & $0(0)$ & $\mathrm{NC}$ \\
$55(98.2)$ & $1(1.8)$ & $0(0)$ & $0(0)$ & $\mathrm{NC}$ \\
\hline
\end{tabular}

To protect self (i.e., self-defense)

Get away from partner

Get partner to do something or

stop doing something

Because of stress

Shut partner up or to get partner

to leave them alone

Get attention

Retaliation for being hit first

Make partner scared or afraid

Note: Attributions are listed in order from most to least agreement. Total $N$ of all rows not equal due to missing data.

$\mathrm{NC}=$ Not calculated, cell $N$ too low. Bold $=$ statistically significant. 
Table 6: Agreement of Emotions After Incident-Specific IPA.

\begin{tabular}{|c|c|c|c|c|c|}
\hline Emotion & $\begin{array}{c}\text { Agreed Emotion } \\
\text { Didn't Occur: } \\
\qquad N(\%)\end{array}$ & $\begin{array}{c}\text { Only Self-Reported } \\
\text { Emotion: } \\
N(\%)\end{array}$ & $\begin{array}{c}\text { Only Partner- } \\
\text { Reported Emotion: } \\
\text { N (\%) }\end{array}$ & $\begin{array}{c}\text { Agreed } \\
\text { Emotion } \\
\text { Occurred: } \\
N(\%)\end{array}$ & Kappa \\
\hline Uncertain About Things & $41(26.80)$ & $35(22.88)$ & $26(16.99)$ & $51(33.33)$ & 0.20 \\
\hline On Edge & $59(37.11)$ & $33(20.75)$ & $32(20.13)$ & $35(22.01)$ & 0.16 \\
\hline Tense & $47(30.32)$ & $31(20.00)$ & $35(22.58)$ & $42(27.10)$ & 0.15 \\
\hline Unhappy & $18(12.77)$ & $24(17.02)$ & $27(19.15)$ & $72(51.06)$ & 0.15 \\
\hline Afraid & $108(69.23)$ & $19(12.18)$ & $21(13.46)$ & $8(5.13)$ & 0.13 \\
\hline Worthless & $102(64.97)$ & $25(15.92)$ & $20(12.74)$ & $10(6.37)$ & 0.13 \\
\hline Confused & $39(25.32)$ & $38(24.68)$ & $30(19.48)$ & $47(30.52)$ & 0.12 \\
\hline Depressed & $68(43.31)$ & 34 (21.66) & $31(19.75)$ & $24(15.29)$ & 0.10 \\
\hline Helpless & $90(57.32)$ & $23(14.65)$ & $31(19.75)$ & $13(8.28)$ & 0.10 \\
\hline Angry & 53 (34.19) & $31(20.00)$ & $38(24.52)$ & $33(21.29)$ & 0.10 \\
\hline Cheerful & $59(37.58)$ & $36(22.93)$ & 35 (22.29) & $27(17.20)$ & 0.06 \\
\hline Aroused & $134(82.21)$ & $13(7.98)$ & $16(9.82)$ & $0(0)$ & -0.10 \\
\hline
\end{tabular}

Note: Emotions are listed in order from most to least agreement. Total $N$ of all rows not equal due to missing data.

$\mathrm{NC}=$ Not calculated, cell $N$ too low. Bold = statistically significant. 
Table 7: Correlates of Agreement on IPA Emotional Effects.

\begin{tabular}{|c|c|}
\hline Variable & $\begin{array}{c}\text { Correlation } \\
(r)\end{array}$ \\
\hline Alcohol Use & -0.04 \\
\hline Emotion Dysregulation & 0.05 \\
\hline Controlling Behavior & 0.11 \\
\hline Attachment Anxiety & 0.10 \\
\hline Relationship Investment & 0.15 \\
\hline $\begin{array}{l}\text { Perceptions of Own Future Perpetration } \\
\text { Perceptions One's Partner's Future }\end{array}$ & 0.08 \\
\hline Perpetration & 0.09 \\
\hline Past Year Sexual IPA Perpetration & -0.03 \\
\hline Past Year Physical IPA Victimization & 0.02 \\
\hline Past Year Physical IPA Perpetration & -0.01 \\
\hline Past Year Psychological IPA Victimization & 0.11 \\
\hline Past Year Psychological IPA Perpetration & 0.19 \\
\hline Any Past Year IPA Victimization & 0.09 \\
\hline Any Past Year IPA Perpetration & 0.14 \\
\hline Self-Esteem & 0.06 \\
\hline Age & 0.03 \\
\hline Relationship Length & 0.01 \\
\hline Socioeconomic Status & 0.05 \\
\hline Attachment Avoidance & -0.10 \\
\hline Hypergender ideology & 0.03 \\
\hline Relationship Commitment & 0.00 \\
\hline Relationship Satisfaction & -0.04 \\
\hline Qualities of Alternatives & 0.03 \\
\hline Social Desirability & 0.13 \\
\hline Time Since IPA Incident & -0.04 \\
\hline Past Year Sexual IPA Victimization & -0.05 \\
\hline
\end{tabular}

Note: Bold = statistically significant. 
Figure 1. Breakdown of Participants in Current Study.

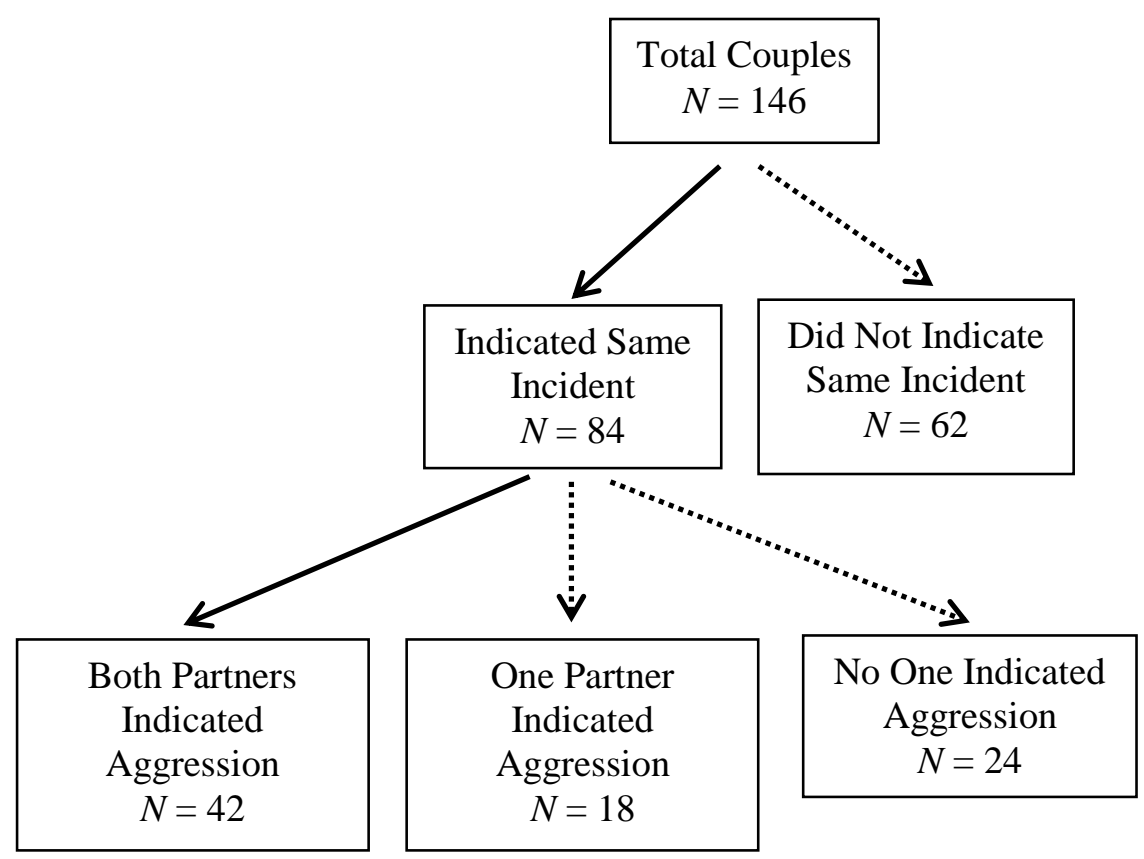


APPENDICES 


\section{Appendix A:}

IRB Approval Letter

\section{6-Jul-2014}

Neal, Angela

Psychology, Conant Hall

30 High Ridge Drive

Dover, NH 03820

IRB \#: 6010

Study: Motives for IPV Perpetration and the Meanings Victims Ascribe to Their Partners' Perpetration: An Empirical Investigation of Both Perspectives

Approval Date: 16-Jul-2014

The Institutional Review Board for the Protection of Human Subjects in Research (IRB) has reviewed and approved the protocol for your study.

Approval is granted to conduct your study as described in your protocol for one year from the approval date above. At the end of the approval period you will be asked to submit a report with regard to the involvement of human subjects in this study. If your study is still active, you may request an extension of IRB approval.

Researchers who conduct studies involving human subjects have responsibilities as outlined in the attached document, Responsibilities of Directors of Research Studies Invo/ving Human Subjects. (This document is also available at http://unh.edu/research/irbapplication-resources.) Please read this document carefully before commencing your work involving human subjects.

If you have questions or concerns about your study or this approval, please feel free to contact me at 603-862-2003 or lulie.simpson@unh.edu. Please refer to the IRB \# above in all correspondence related to this study. The IRB wishes you success with your research.

For the IRB

Director

cc: File

Edwards, Katie 


\section{Appendix B:}

\section{SONA Recruitment Message}

In this study you and your relationship partner will complete a survey in our lab, which will include questions about relationship conflict and experiences. You must be in a relationship and bring your partner to the study session to participate (you must BOTH be at least 18). In exchange for your participation, you will receive 2 course credits. Your partner will also receive 2 course credits if he or she needs it or will receive \$20. If none of the times listed work for you and you would like to participate, please email Angela Neal at amf632@wildcats.unh.edu with all possible times you and your partner could participate. Alternative activity: If you are younger than 18 or elect to not do the study above, instead of completing the study, you have the option of having the researcher demonstrate the above study, which you will observe for 45 minutes. You will then discuss the hypotheses and possible outcomes of the experiment, and you will complete a written assignment. This activity is designed to be comparable in duration with the first part of the research study. To choose this option you MUST contact the researcher to schedule an appointment, and you will not be paid for this option, only credited. 


\section{APPENDIX C:}

Participant Recruitment Flier

\section{Research Opportunity: Earn \$20 Each!}

\section{Are you 18-30 years old and in a romantic relationship with someone 18-30?}

If YES, and either of you are a college student, please email or call us about both you and your partner taking part in a confidential survey at the UNH: Durham

$$
\text { campus! }
$$

\section{Please Call or Email: 603-862-4901 UNH.Couples@gmail.com}

This research is being conducted by researchers (Angela Neal and Dr. Katie Edwards) at the University of New Hampshire.

Take a Slip Below to Remember!

\begin{tabular}{|c|c|c|c|c|c|c|}
\hline 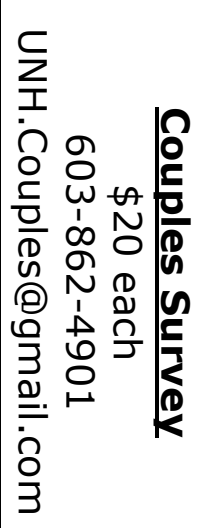 & 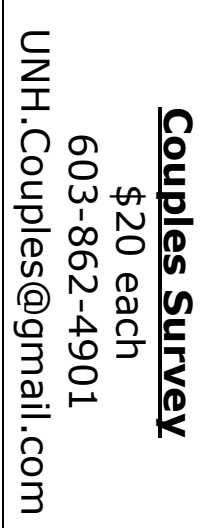 & 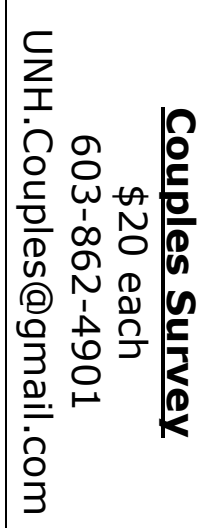 & 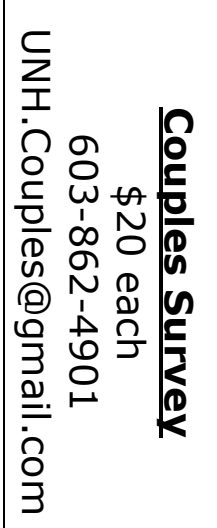 & 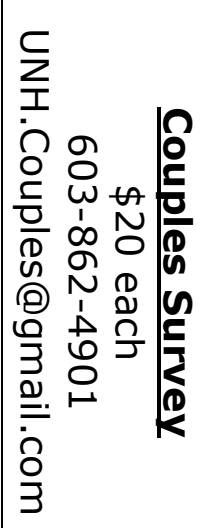 & 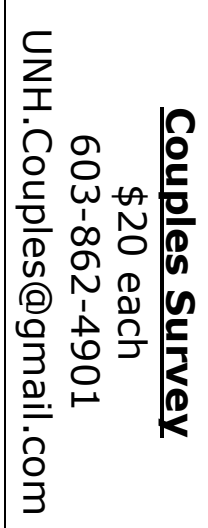 & 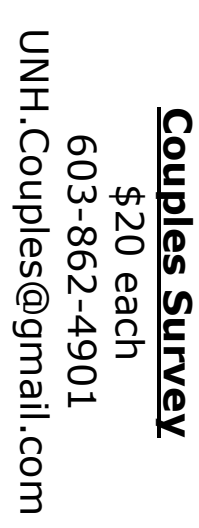 \\
\hline
\end{tabular}




\section{Appendix D:}

\section{Safety Screener}

(This was verbally asked over the phone before community participants came to the lab, and verbally asked after both student and community participants came to the lab)

How old are you?

How old is your partner?

Are you afraid of your partner?

How long have you been in your relationship?

If either member of the couple indicated they fear their partner, they were not eligible for participation. 


\section{Appendix E:}

Informed Consents

Informed Consent (Student Participants)

CONSENT FORM FOR PARTICIPATION IN A RESEARCH STUDY

\section{TITLE OF RESEARCH STUDY:}

This study, Understanding Dynamics of Romantic Relationships, is being conducted by Angela M. Neal, M.A., a graduate student in the Department of Psychology at UNH, under the supervision of Katie Edwards, Ph.D., Assistant Professor of Psychology and Women's Studies at UNH.

\section{WHAT IS THE PURPOSE OF THIS STUDY?}

The purpose of this study is to understand better how partners in a dating relationship experience conflict. In order to participate in this study, you must be at least 18 years old, currently involved in a romantic relationship (of any length and any degree of seriousness and exclusivity). It is anticipated that approximately 250 couples will participate in this study.

\section{WHAT DOES YOUR PARTICIPATION IN THIS STUDY INVOLVE?}

If you agree to participate in this study, you will be asked to complete several questionnaires, some of which will ask about personal and sexual information. You will also be asked about conflict in your current relationship. It is extremely important to collect reliable information. Therefore, we ask that you answer all questions honestly.

You are free to refuse to answer any of the questions. You will both be asked to complete a series of questionnaires in multiple stages. The initial questionnaire, which should take approximately 30 minutes to complete, during which, you will be asked to provide a list of conflicts and arguments that you have experienced in your current relationship. You will give these sheets to the researcher and continue to complete your questionnaire. The researcher may return with selected conflicts for you to describe in further detail and/or questionnaires about your relationship more in-depth. This should take approximately 60 minutes. Upon completion of this, you will be provided with debriefing information about the study and reunited with your partner.

\section{WHAT ARE THE POSSIBLE RISKS OF PARTICIPATING IN THIS STUDY?}

Some individuals might experience emotional discomfort while answering some of the questions. However, we know from previous research that for the vast majority of participants, answering these types of questions is not upsetting, and for those individuals who report being upset, it is usually minimal and temporary. Participation is voluntary, and you may stop responding and withdraw from the study at any point. An additional risk is the potential breach of confidentiality. Although this is extremely unlikely, there are instances that we are required to report to government and/or law enforcement officials (e.g., current or recent child abuse in which there is an identifiable victim and 
perpetrator, threats of killing or seriously harming yourself or another identifiable person). However, we do not have to report past abuse and none of the questions will be specifically asking you about things we are required to report.

\section{WHAT HAPPENS IF I GET SICK OR HURT FROM TAKING PART IN THIS STUDY?}

There are no direct physical risks involved with participating in this study.

\section{WHAT ARE THE POSSIBLE BENEFITS OF PARTICIPATING IN THIS STUDY?}

Previous research suggests that individuals who participate in this type of research often report personal benefits to their participation such as gaining a deeper understanding of their experiences, feeling as if others were interested in hearing their stories. In addition, many individuals report that they are proud to contribute to science and psychological interventions.

\section{IF YOU CHOOSE TO PARTICIPATE IN THIS STUDY, WILL IT COST YOU ANYTHING?}

There are no costs to participants for participating in this study.

\section{WILL YOU RECEIVE ANY COMPENSATION FOR PARTICIPATING IN THIS STUDY?}

If both members of the couple require course credit, each participant will receive two (2) course credits for completing the study. If only one member of the couple requires course credit, he or she will receive two (2) course credits and the other will receive $\$ 20$ for completing the study.

\section{WHAT OTHER OPTIONS ARE AVAILABLE IF YOU DO NOT WANT TO TAKE PART IN THIS STUDY?}

You understand that your consent to participate in this research is entirely voluntary, and you and/or your partner can withdraw after starting and still receive payment. You must at least start the study, however, to receive compensation.

\section{CAN YOU WITHDRAW FROM THIS STUDY?}

If you consent to participate in this study, you are free to stop your participation in the study at any time.

\section{HOW WILL THE CONFIDENTIALITY OF YOUR RECORDS BE PROTECTED?}

The researcher seeks to maintain the confidentiality of all data and records associated with your participation in this research and your identity will be protected.

Confidentiality will be protected by assigning each participant a number to which all data are referred. Only the investigators will have access to the information linking names and participant numbers and this list will be destroyed upon completion of the study. 
None of the information you might share regarding sensitive aspects of your relationship will be shared with anyone, including university officials, parents, police, or your relationship partner. However, you also should understand that the researcher is required by law to report certain information to government and/or law enforcement officials (e.g., communicable diseases, current or recent child abuse in which there is an identifiable victim and perpetrator, threats of killing or seriously harming yourself or another identifiable person).

The survey paper worksheets will be kept in a locked cabinet, and the computer survey data will be stored on a computer, both in the researcher's locked laboratory. Only key study personnel will have access to the study data. The quantitative data will be aggregated for the analyses and no names or identifying information will be attached to the presentation of these results. The qualitative data will also be aggregated. However, in presentations and publications, participants' written responses may be used in the form of quotations, but no names or other identifying information will be included.

The online survey does not present any greater risk of loss of personal privacy than would be encountered in everyday life when sending and/or receiving information over the Internet. Reasonable efforts have been undertaken to minimize any such potential risks but any form of communication over the Internet carries a minimal risk of loss of confidentiality.

\section{WHOM TO CONTACT IF YOU HAVE QUESTIONS ABOUT THIS STUDY}

If you have any questions pertaining to the research you can contact Angela M. Neal, M.A. at [603-862-4901] or amf632@wildcats.unh.edu, or Katie Edwards, Ph.D. at 603862-3720 or Katie.Edwards@unh.edu.

If you have questions about your rights as a research subject you can contact Dr. Julie Simpson in UNH Research Integrity Services, 603-862-2003 or Julie.simpson@ unh.edu to discuss them.

\section{Check/click here if you consent to participate}

\section{Click the " $X$ " in the top corner of your browser and inform the researcher if you do NOT consent to participate}


Informed Consent (Community Participants)

CONSENT FORM FOR PARTICIPATION IN A RESEARCH STUDY

\section{TITLE OF RESEARCH STUDY:}

This study, Understanding Dynamics of Romantic Relationships, is being conducted by Angela M. Neal, M.A., a graduate student in the Department of Psychology at UNH, under the supervision of Katie Edwards, Ph.D., Assistant Professor of Psychology and Women's Studies at UNH.

\section{WHAT IS THE PURPOSE OF THIS STUDY?}

The purpose of this study is to understand better how partners in a dating relationship experience conflict. In order to participate in this study, you must be at least 18 years old, currently involved in a romantic relationship (of any length and any degree of seriousness and exclusivity). It is anticipated that approximately 250 couples will participate in this study.

\section{WHAT DOES YOUR PARTICIPATION IN THIS STUDY INVOLVE?}

If you agree to participate in this study, you will be asked to complete several questionnaires, some of which will ask about personal and sexual information. You will also be asked about conflict in your current relationship. It is extremely important to collect reliable information. Therefore, we ask that you answer all questions honestly.

You are free to refuse to answer any of the questions. You will both be asked to complete a series of questionnaires in multiple stages. The initial questionnaire, which should take approximately 30 minutes to complete, during which, you will be asked to provide a list of conflicts and arguments that you have experienced in your current relationship. You will give these sheets to the researcher and continue to complete your questionnaire. The researcher may return with selected conflicts for you to describe in further detail and/or questionnaires about your relationship more in-depth. This should take approximately 60 minutes. Upon completion of this, you will be provided with debriefing information about the study and reunited with your partner.

\section{WHAT ARE THE POSSIBLE RISKS OF PARTICIPATING IN THIS STUDY?}

Some individuals might experience emotional discomfort while answering some of the questions. However, we know from previous research that for the vast majority of participants, answering these types of questions is not upsetting, and for those individuals who report being upset, it is usually minimal and temporary. Participation is voluntary, and you may stop responding and withdraw from the study at any point. An additional risk is the potential breach of confidentiality. Although this is extremely unlikely, there are instances that we are required to report to government and/or law enforcement officials (e.g., current or recent child abuse in which there is an identifiable victim and perpetrator, threats of killing or seriously harming yourself or another identifiable person). However, we do not have to report past abuse and none of the questions will be specifically asking you about things we are required to report. 


\section{WHAT HAPPENS IF I GET SICK OR HURT FROM TAKING PART IN THIS STUDY?}

There are no direct physical risks involved with participating in this study.

\section{WHAT ARE THE POSSIBLE BENEFITS OF PARTICIPATING IN THIS STUDY?}

Previous research suggests that individuals who participate in this type of research often report personal benefits to their participation such as gaining a deeper understanding of their experiences, feeling as if others were interested in hearing their stories. In addition, many individuals report that they are proud to contribute to science and psychological interventions.

\section{IF YOU CHOOSE TO PARTICIPATE IN THIS STUDY, WILL IT COST YOU ANYTHING? \\ There are no costs to participants for participating in this study.}

\section{WILL YOU RECEIVE ANY COMPENSATION FOR PARTICIPATING IN THIS STUDY?}

Each member will receive $\$ 20$ for participating.

\section{WHAT OTHER OPTIONS ARE AVAILABLE IF YOU DO NOT WANT TO TAKE PART IN THIS STUDY?}

You understand that your consent to participate in this research is entirely voluntary, and you and/or your partner can withdraw after starting and still receive payment. You must at least start the study, however, to receive compensation.

\section{CAN YOU WITHDRAW FROM THIS STUDY?}

If you consent to participate in this study, you are free to stop your participation in the study at any time.

\section{HOW WILL THE CONFIDENTIALITY OF YOUR RECORDS BE PROTECTED?}

The researcher seeks to maintain the confidentiality of all data and records associated with your participation in this research and your identity will be protected.

Confidentiality will be protected by assigning each participant a number to which all data are referred. Only the investigators will have access to the information linking names and participant numbers and this list will be destroyed upon completion of the study.

None of the information you might share regarding sensitive aspects of your relationship will be shared with anyone, including university officials, parents, police, or your relationship partner. However, you also should understand that the researcher is required by law to report certain information to government and/or law enforcement officials (e.g., communicable diseases, current or recent child abuse in which there is an identifiable victim and perpetrator, threats of killing or seriously harming yourself or another identifiable person). 
The survey paper worksheets will be kept in a locked cabinet, and the computer survey data will be stored on a computer, both in the researcher's locked laboratory. Only key study personnel will have access to the study data. The quantitative data will be aggregated for the analyses and no names or identifying information will be attached to the presentation of these results. The qualitative data will also be aggregated. However, in presentations and publications, participants' written responses may be used in the form of quotations, but no names or other identifying information will be included.

The online survey does not present any greater risk of loss of personal privacy than would be encountered in everyday life when sending and/or receiving information over the Internet. Reasonable efforts have been undertaken to minimize any such potential risks but any form of communication over the Internet carries a minimal risk of loss of anonymity.

\section{WHOM TO CONTACT IF YOU HAVE QUESTIONS ABOUT THIS STUDY}

If you have any questions pertaining to the research you can contact Angela M. Neal, M.A. at [603-862-4901] or amf632@wildcats.unh.edu, or Katie Edwards, Ph.D. at 603862-3720 or Katie.Edwards@unh.edu.

If you have questions about your rights as a research subject you can contact Dr. Julie Simpson in UNH Research Integrity Services, 603-862-2003 or Julie.simpson@unh.edu to discuss them.

\section{Check/click here if you consent to participate}

\section{Click the " $X$ " in the top corner of your browser and inform the researcher if you do NOT consent to participate}




\section{Appendix F:}

Demographics

1. What is your gender?
a. Male/man
b. Female/woman
c. Other:

2. What is your age in years?

3. How many romantic partners do you have?

4. What is your partner's age in years?

5. What is the gender of your partner?

6. What is your race?
a. Caucasian
b. African American
c. Latino/Hispanic
d. Asian or Pacific Islander
e. Native American
f. Two or more races
g. Other (please write in):

7. What is your highest level of education?
a. Some high school
b. High school diploma
c. High school GED
d. Some college
e. 2 year associates degree
f. 4 year bachelor's degree
g. Graduate degree (e.g., masters, doctorate)
h. Other (please write in):

8. How long have you and your partner been in a relationship (in months)?

9. How would you classify your relationship with your partner?
a. Friends with benefits
b. Casual dating relationship
c. Serious dating relationship
d. Engaged
e. Married
f. Other (please write in): 
10. Approximately what is your family's yearly income? Please provide your best estimate.

a. Unemployed or disabled

b. $\$ 10,000-\$ 20,000$

c. $\$ 21,000-\$ 30,000$

d. $\$ 31,000-\$ 40,000$

e. $\$ 41,000-\$ 50,000$

f. $\$ 51,000-\$ 75,000$

g. $\$ 76,000-\$ 100,000$

h. $\$ 100,000-\$ 150,000$

i. $\$ 151,000$ or more

11. Are you living with your partner?

12. How did you hear about this study? 


\section{Appendix G:}

Debriefing Forms

$\underline{\text { Student Participants Debriefing }}$

\section{DEBRIEFING FORM FOR PARTICIPATION IN A RESEARCH STUDY}

Thank you for your participation in this research study. The purpose of this study is to investigate experiences of conflict in romantic relationships, the various factors related to these experiences. Research suggests that experiences of aggression are common in college students dating relationships. Thus, it is important to understand the factors that are related to students' use and receipt of aggression in relationships. It is especially important to understand how both partners in a romantic relationship perceive the conflict within that relationship. This type of research could inform future psychological research and interventions aimed to promote healthy relationships.

It is critical for us to collect accurate and reliable data. Therefore, we ask that you not talk with other students who may potentially participate in this study about the details of participation. Sharing information about the study with other potential participants could lead to the collection of inaccurate and unreliable data. We greatly appreciate your cooperation with this request.

If you are concerned about any of the topics covered in this study, or if you would like more information or reading material on this topic, please contact one of the resources below. If you are experiencing conflict in your relationship or any form of aggression, you are encouraged to contact one of these resources.

1. The Counseling Center 862-2090 http://www.unhcc.unh.edu/

2. Sexual Harassment and Rape Prevention Program (SHARPP) 862-3494 http://www.unh.edu/sharpp/

3. Sexual Assault Services 1-888-747-7070

4. New Hampshire Domestic Violence Hotline: 1-866-644-3574

5. New Hampshire Sexual Assault Hotline: 1-800-277-5570

The principal investigator of this study is Angela M. Neal, M.A. and she can be reached at amf632@wildcats.unh.edu or 603-862-4901. Angela is under the supervision of Dr. Katie Edwards (Assistant Professor of Psychology) and she can be reached at Katie.Edwards@unh.edu or 603-862-3720. 
If you would like to receive more specific information about the study, please contact the researchers at the emails/phone numbers listed above. The researchers will gladly schedule a time to meet with you to provide you with more information. 


\section{Community Participants Debriefing}

\section{DEBRIEFING FORM FOR PARTICIPATION IN A RESEARCH STUDY}

Thank you for your participation in this research study. The purpose of this study is to investigate experiences of conflict in romantic relationships, the various factors related to these experiences. Research suggests that experiences of aggression are common in college students dating relationships. Thus, it is important to understand the factors that are related to students' use and receipt of aggression in relationships. It is especially important to understand how both partners in a romantic relationship perceive the conflict within that relationship. This type of research could inform future psychological research and interventions aimed to promote healthy relationships.

It is critical for us to collect accurate and reliable data. Therefore, we ask that you not talk with other students who may potentially participate in this study about the details of participation. Sharing information about the study with other potential participants could lead to the collection of inaccurate and unreliable data. We greatly appreciate your cooperation with this request.

If you are concerned about any of the topics covered in this study, or if you would like more information or reading material on this topic, please contact one of the resources below. If you are experiencing conflict in your relationship or any form of aggression, you are encouraged to contact one of these resources.

1. Sexual Assault Services 1-888-747-7070

2. New Hampshire Domestic Violence Hotline: 1-866-644-3574

3. New Hampshire Sexual Assault Hotline: 1-800-277-5570

The principal investigator of this study is Angela M. Neal, M.A. and she can be reached at amf632@wildcats.unh.edu or 603-862-4901. Angela is under the supervision of Dr. Katie Edwards (Assistant Professor of Psychology) and she can be reached at Katie.Edwards@unh.edu or 603-862-3720.

If you would like to receive more specific information about the study, please contact the researchers at the emails/phone numbers listed above. The researchers will gladly schedule a time to meet with you to provide you with more information. 


\section{Appendix H:}

Sexual Experiences Survey (SES-SFV; Koss et al., 2007)

DIRECTIONS: Place a check mark in the box showing the number of times each experience has happened to you BY YOUR PARTNER within the last year. If several experiences occurred on the same occasion--for example, if one night someone told you some lies and had sex with you when you were drunk, you would check both boxes a and c. The past 12 months refers to the past year going back from today. Please do not skip any items and answer all items honestly.

\section{How often did this happen in the last year?}

0 $=$ Never.

$1=1-3$ times.

$2=4-9$ times.

$3=10$ or more times.

1. In the past year, my partner fondled, kissed, or rubbed up against the private areas of my body (lips, breast/chest, crotch or butt) or removed some of my clothes without my consent (but did not attempt sexual penetration) by:

a. Telling lies, threatening to end the relationship, threatening to spread rumors about me, making promises I knew were untrue, or continually verbally pressuring me after I said I didn't want to.

b. Showing displeasure, criticizing my sexuality or attractiveness, getting angry but not using physical force, after I said I didn't want to.

c. Taking advantage of me when I was too drunk or out of it to stop what was happening.

d. Threatening to physically harm me or someone close to me.

e. Using force, for example holding me down with their body weight, pinning my arms, or having a weapon.

2. In the past year, my partner had oral sex with me or made me have oral sex with them without my consent by:

a. Telling lies, threatening to end the relationship, threatening to spread rumors about me, making promises I knew were untrue, or continually verbally pressuring me after I said I didn't want to.

b. Showing displeasure, criticizing my sexuality or attractiveness, getting angry but not using physical force, after I said I didn't want to.

c. Taking advantage of me when I was too drunk or out of it to stop what was happening.

d. Threatening to physically harm me or someone close to me.

e. Using force, for example holding me down with their body weight, pinning my arms, or having a weapon.

3. If you are a male, check box and skip to item 4 
In the past year, my partner put his penis into my vagina, or someone inserted fingers or objects without my consent by:

a. Telling lies, threatening to end the relationship, threatening to spread rumors about me, making promises I knew were untrue, or continually verbally pressuring me after I said I didn't want to.

b. Showing displeasure, criticizing my sexuality or attractiveness, getting angry but not using physical force, after I said I didn't want to.

c. Taking advantage of me when I was too drunk or out of it to stop what was happening.

d. Threatening to physically harm me or someone close to me.

e. Using force, for example holding me down with their body weight, pinning my arms, or having a weapon.

4. In the past year, my partner put his penis into my butt, or someone inserted fingers or objects without my consent by:

a. Telling lies, threatening to end the relationship, threatening to spread rumors about me, making promises I knew were untrue, or continually verbally pressuring me after I said I didn't want to.

b. Showing displeasure, criticizing my sexuality or attractiveness, getting angry but not using physical force, after I said I didn't want to.

c. Taking advantage of me when I was too drunk or out of it to stop what was happening.

d. Threatening to physically harm me or someone close to me.

e. Using force, for example holding me down with their body weight, pinning my arms, or having a weapon.

5. In the past year, even though it didn't happen, my partner TRIED to have oral sex with me, or make me have oral sex with them without my consent by:

a. Telling lies, threatening to end the relationship, threatening to spread rumors about me, making promises I knew were untrue, or continually verbally pressuring me after I said I didn't want to.

b. Showing displeasure, criticizing my sexuality or attractiveness, getting angry but not using physical force, after I said I didn't want to.

c. Taking advantage of me when I was too drunk or out of it to stop what was happening.

d. Threatening to physically harm me or someone close to me.

e. Using force, for example holding me down with their body weight, pinning my arms, or having a weapon.

6. If you are male, check this box and skip to item 7.

In the past year, even though it didn't happen, my partner TRIED to put his penis into my vagina, or someone tried to stick in fingers or objects without my consent by: 
a. Telling lies, threatening to end the relationship, threatening to spread rumors about me, making promises I knew were untrue, or continually verbally pressuring me after I said I didn't want to.

b. Showing displeasure, criticizing my sexuality or attractiveness, getting angry but not using physical force, after I said I didn't want to.

c. Taking advantage of me when I was too drunk or out of it to stop what was happening.

d. Threatening to physically harm me or someone close to me.

e. Using force, for example holding me down with their body weight, pinning my arms, or having a weapon.

\section{In the past year, even though it didn't happen, my partner TRIED to put his penis} into my butt, or someone tried to stick in objects or fingers without my consent by:

a. Telling lies, threatening to end the relationship, threatening to spread rumors about me, making promises I knew were untrue, or continually verbally pressuring me after I said I didn't want to.

b. Showing displeasure, criticizing my sexuality or attractiveness, getting angry but not using physical force, after I said I didn't want to.

c. Taking advantage of me when I was too drunk or out of it to stop what was happening.

d. Threatening to physically harm me or someone close to me.

e. Using force, for example holding me down with their body weight, pinning my arms, or having a weapon. 
Sexual Experiences Survey (SES-SFP; Koss et al., 2007)

DIRECTIONS: Place a check mark in the box showing the number of times you did the things below TO YOUR PARTNER during the past year. If several experiences occurred on the same occasion--for example, if one night you told some lies and had sex with someone who was drunk, you would check both boxes a and c. The past 12 months refers to the past year going back from today. Please do not skip any items and answer all items honestly.

How often did this happen in the last year?

0 $=$ Never.

$1=1-3$ times.

$2=4-9$ times.

$3=10$ or more times.

1. In the past year, I fondled, kissed, or rubbed up against the private areas of my partner's body (lips, breast/chest, crotch or butt) or removed some of their clothes without their consent (but did not attempt sexual penetration) by:

a. Telling lies, threatening to end the relationship, threatening to spread rumors about them, making promises about the future I knew were untrue, or continually verbally pressuring them after they said they didn't want to.

b. Showing displeasure, criticizing their sexuality or attractiveness, getting angry but not using physical force after they said they didn't want to.

c. Taking advantage when they were too drunk or out of it to stop what was happening.

d. Threatening to physically harm them or someone close to them.

e. Using force, for example holding them down with my body weight, pinning their arms, or having a weapon.

2. In the past year, I had oral sex with my partner or had my partner perform oral sex on me without their consent by:

a. Telling lies, threatening to end the relationship, threatening to spread rumors about them, making promises about the future I knew were untrue, or continually verbally pressuring them after they said they didn't want to.

b. Showing displeasure, criticizing their sexuality or attractiveness, getting angry but not using physical force after they said they didn't want to.

c. Taking advantage when they were too drunk or out of it to stop what was happening.

d. Threatening to physically harm them or someone close to them.

e. Using force, for example holding them down with my body weight, pinning their arms, or having a weapon.

3. In the past year, I put my penis (men only) or I put my fingers or objects (all respondents) into a my partner's vagina without her consent by: 
a. Telling lies, threatening to end the relationship, threatening to spread rumors about them, making promises about the future I knew were untrue, or continually verbally pressuring them after they said they didn't want to.

b. Showing displeasure, criticizing their sexuality or attractiveness, getting angry but not using physical force after they said they didn't want to.

c. Taking advantage when they were too drunk or out of it to stop what was happening.

d. Threatening to physically harm them or someone close to them.

e. Using force, for example holding them down with my body weight, pinning their arms, or having a weapon.

4. In the past year, I put in my penis (men only) or I put my fingers or objects (all respondents) into my partner's butt without their consent by:

a. Telling lies, threatening to end the relationship, threatening to spread rumors about them, making promises about the future I knew were untrue, or continually verbally pressuring them after they said they didn't want to.

b. Showing displeasure, criticizing their sexuality or attractiveness, getting angry but not using physical force after they said they didn't want to.

c. Taking advantage when they were too drunk or out of it to stop what was happening.

d. Threatening to physically harm them or someone close to them.

e. Using force, for example holding them down with my body weight, pinning their arms, or having a weapon.

5. In the past year, even though it did not happen, I TRIED to have oral sex with my partner or make them have oral sex with me without their consent by:

a. Telling lies, threatening to end the relationship, threatening to spread rumors about them, making promises about the future I knew were untrue, or continually verbally pressuring them after they said they didn't want to.

b. Showing displeasure, criticizing their sexuality or attractiveness, getting angry but not using physical force after they said they didn't want to.

c. Taking advantage when they were too drunk or out of it to stop what was happening.

d. Threatening to physically harm them or someone close to them.

e. Using force, for example holding them down with my body weight, pinning their arms, or having a weapon.

6. In the past year, even though it did not happen, I TRIED to put my penis (men only) or I tried to put my fingers or objects (all respondents) into my partner's vagina without their consent by:

a. Telling lies, threatening to end the relationship, threatening to spread rumors about them, making promises about the future I knew were untrue, or continually verbally pressuring them after they said they didn't want to.

b. Showing displeasure, criticizing their sexuality or attractiveness, getting angry but not using physical force after they said they didn't want to. 
c. Taking advantage when they were too drunk or out of it to stop what was happening.

d. Threatening to physically harm them or someone close to them.

e. Using force, for example holding them down with my body weight, pinning their arms, or having a weapon.

\section{In the past year, even though it did not happen, I TRIED to put my penis (men only)} or I tried to put my fingers or objects (all respondents) into my partner's butt without their consent by:

a. Telling lies, threatening to end the relationship, threatening to spread rumors about them, making promises about the future I knew were untrue, or continually verbally pressuring them after they said they didn't want to.

b. Showing displeasure, criticizing their sexuality or attractiveness, getting angry but not using physical force after they said they didn't want to.

c. Taking advantage when they were too drunk or out of it to stop what was happening.

d. Threatening to physically harm them or someone close to them.

e. Using force, for example holding them down with my body weight, pinning their arms, or having a weapon. 


\section{Appendix I:}

Safe Dates

Physical Violence Victimization (Foshee et al., 1998)

How many times has any person that you have been on a date with done the following things to you in the past year? Only include it when the dating partner did it to you first. In other words, don't count it if they did it to you in self-defense.
0 $=$ Never .
$1=1-3$ times.
$2=4-9$ times.
$3=10$ or more times.

1. Scratched me.

2. Slapped me.

3. Physically twisted my arm.

4. Slammed me or held me against a wall.

5. Kicked me.

6. Bent my fingers.

7. Bit me.

8. Tried to choke me.

9. Pushed, grabbed, or shoved me.

10. Dumped me out of a car.

11. Threw something at me that hit me.

12. Burned me.

13. Hit me with a fist.

14. Hit me with something hard besides a fist.

15. Beat me up.

16. Assaulted me with a knife or gun. 


\section{Safe Dates}

\section{Physical Violence Perpetration (Foshee et al., 1998)}

How many times have you done the following things to a person that you have been on a date with in the past year? Only include when you did it to him/her first. In other words, don't count it if you did it in self-defense.

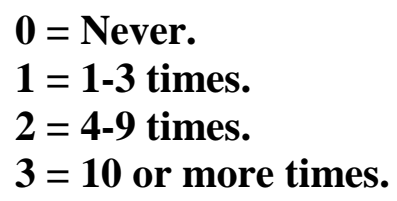

0 $=$ Never.

$1=1-3$ times.

$2=4-9$ times.

$3=10$ or more times.

1. Scratched them.

2. Slapped them.

3. Physically twisted their arm.

4. Slammed or held them against a wall.

5. Kicked them.

6. Bent their fingers.

7. Bit them.

8. Tried to choke them.

9. Pushed, grabbed, or shoved them.

10. Dumped them out of a car.

11. Threw something at them that hit them.

12. Burned them.

13. Hit them with my fist.

14. Hit them with something hard besides my fist.

15. Beat them up.

16. Assaulted them with a knife or gun. 


\section{Safe Dates}

\section{Psychological Violence Perpetration (Foshee et al., 1998)}

How often have you done the following things to someone you have had a date with in the past year?

0 $=$ Never.

$1=1-3$ times.

$2=4-9$ times.

$3=10$ or more times.

1. Damaged something that belonged to them.

2. Said things to hurt their feelings on purpose.

3. Insulted them in front of others.

4. Would not let them do things with other people.

5. Threatened to start dating someone else.

6. Told them they could not talk to someone of the opposite sex.

7. Did something just to make them jealous.

8. Blamed them for bad things I did.

9. Threatened to hurt them.

10. Made them describe where they were every minute of the day.

11. Brought up something from the past to hurt them.

12. Put down their looks. 


\section{Safe Dates}

\section{Psychological Violence Victimization (Foshee et al., 1998)}

How often has anyone that you have been on a date with done the following things to you in the past year?

$$
\begin{aligned}
& 0=\text { Never. } \\
& 1=1-3 \text { times. } \\
& 2=4-9 \text { times. } \\
& 3=10 \text { or more times. }
\end{aligned}
$$

1. Damaged something that belonged to me.

2. Said things to hurt my feelings on purpose.

3. Insulted me in front of others.

4. Would not let me do things with other people.

5. Threatened to start dating someone else.

6. Told me I could not talk to someone of the opposite sex.

7. Did something just to make me jealous.

8. Blamed me for bad things they did.

9. Threatened to hurt me.

10. Made me describe where I was every minute of the day.

11. Brought up something from the past to hurt me.

12. Put down my looks. 


\begin{abstract}
Appendix J:
Event-Specific IPA

Safe Dates and SES (Foshee et al., 1998; Koss et al., 2007)
\end{abstract}

\title{
Asked regarding each incident
}

DIRECTIONS: No matter how well a couple gets along, there are times when they disagree, get annoyed with the other person, want different things from each other, or just have spats or fights because they are in a bad mood, are tired, or for some other reason. Couples also have many different ways of trying to settle their differences. This is a list of things that might happen when you have had differences. Please indicate which behaviors you and your partner performed during the incident.

Please indicate what you did during the incident.

1. I fondled, kissed, or rubbed up against the private areas of my partner's body (lips, breast/chest, crotch or butt) or removed some of their clothes without their consent (but did not attempt sexual penetration).

2. I had oral sex with my partner or had my partner perform oral sex on me without their consent.

3. I put my penis (men only) or I put my fingers or objects (all respondents) into my partner's vagina without her consent.

4. I put in my penis (men only) or I put my fingers or objects (all respondents) into my partner's butt without their consent.

5. Even though it did not happen, I TRIED to have oral sex with my partner or make them have oral sex with me without their consent.

6. Even though it did not happen, I TRIED to put my penis (men only) or I tried to put my fingers or objects (all respondents) into my partner's vagina without their consent.

7. Even though it did not happen, I TRIED to put my penis (men only) or I tried to put my fingers or objects (all respondents) into my partner's butt without their consent.

8. Scratched them.

9. Slapped them.

10. Physically twisted their arm.

11. Slammed or held them against a wall.

12. Kicked them.

13. Bent their fingers.

14. Bit them.

15. Tried to choke them.

16. Pushed, grabbed, or shoved them.

17. Dumped them out of a car.

18. Threw something at them that hit them.

19. Burned them.

20. Hit them with my fist. 
21. Hit them with something hard besides my fist.

22. Beat them up.

23. Assaulted them with a knife or gun.

13. Damaged something that belonged to them.

14. Said things to hurt their feelings on purpose.

15. Insulted them in front of others.

16. Would not let them do things with other people.

17. Threatened to start dating someone else.

18. Told them they could not talk to someone of the opposite sex.

19. Did something just to make them jealous.

20. Blamed them for bad things I did.

21. Threatened to hurt them.

22. Made them describe where they were every minute of the day.

23. Brought up something from the past to hurt them.

24. Put down their looks.

25. Other (write-in):

Please indicate what your partner did during the incident.

1. My partner fondled, kissed, or rubbed up against the private areas of my body (lips, breast/chest, crotch or butt) or removed some of my clothes without my consent (but did not attempt sexual penetration).

2. My partner had oral sex with me or made me have oral sex with them without my consent.

3. My partner put his penis into my vagina, or someone inserted fingers or objects without my consent.

4. In the past year, my partner put his penis into my butt, or someone inserted fingers or objects without my consent by:

5. Even though it didn't happen, my partner TRIED to have oral sex with me, or make me have oral sex with them without my consent.

6. Even though it didn't happen, my partner TRIED to put his penis into my vagina, or someone tried to stick in fingers or objects without my consent.

7. Even though it didn't happen, my partner TRIED to put his penis into my butt, or someone tried to stick in objects or fingers without my consent.

8. Scratched me.

9. Slapped me.

10. Physically twisted my arm.

11. Slammed me or held me against a wall.

12. Kicked me.

13. Bent my fingers.

14. Bit me.

15. Tried to choke me.

16. Pushed, grabbed, or shoved me.

17. Dumped me out of a car.

18. Threw something at me that hit me. 
19. Burned me.

20. Hit me with a fist.

21. Hit me with something hard besides a fist.

22. Beat me up.

23. Assaulted me with a knife or gun.

24. Damaged something that belonged to me.

25. Said things to hurt my feelings on purpose.

26. Insulted me in front of others.

27. Would not let me do things with other people.

28. Threatened to start dating someone else.

29. Told me I could not talk to someone of the opposite sex.

30. Did something just to make me jealous.

31. Blamed me for bad things they did.

32. Threatened to hurt me.

33. Made me describe where I was every minute of the day.

34. Brought up something from the past to hurt me.

35. Put down my looks

36. Other (write-in): 


\section{Appendix K:}

\section{Attributions for IPA}

Modified version of the Motivation and Effects Questionnaire (Follingstad et al., 1991)

For each incident in which they OR their partner were aggressive:

$1=$ extremely disagree, 2 = strongly disagree, 3 = disagree, $4=$ slightly disagree, $5=$ neither disagree or agree, $6=$ slightly agree, $7=$ agree, $8=$ strongly agree, $9=$ extremely agree

Participant's Aggression:

To what extent did you engage in this aggression...:

1. To show anger?

2. Due to an inability to express self verbally?

3. To feel more powerful?

4. To get control over other person?

5. In retaliation for being hit first?

6. To protect self (i.e., self-defense)?

7. In retaliation for emotional hurt?

8. Anger displaced onto partner?

9. To punish person for wrongdoing?

10. To prove love?

11. Because it was sexually arousing?

12. To get attention?

13 . Because of jealousy?

Additional Attributions added based on the Reasons for Violence Scale (Stuart et al., 2006):

14. To get away from your partner?

15. Because of stress?

16. Because you didn't know what to do with feelings?

17. Because you were provoked or pushed over the edge?

18. Because you were cheated on?

19. Because they were going to walk away or leave a conflict before it was solved?

20. To shut them up or to get them to leave you alone?

21. To get them to do something or stop doing something?

22. To hurt their feelings?

23. To make them agree with them/you?

24. To make your partner scared or afraid?

25 . Because you were afraid your partner was going to leave you?

26. Because you didn't believe that your partner cared about you?

27 . Because you were under the influence of drugs or alcohol?

28. Because you wanted to have sex and they didn't? 
Partner's Aggression:

To what extent did your partner engage in this aggression...:

1. To show anger?

2. Due to an inability to express self verbally?

3. To feel more powerful?

4. To get control over other person?

5. In retaliation for being hit first?

6. To protect self (i.e., self-defense)?

7. In retaliation for emotional hurt?

8. Anger displaced onto partner?

9. To punish person for wrongdoing?

10. To prove love?

11. Because it was sexually arousing?

12. To get attention?

13. Because of jealousy?

Additional Attributions added based on the Reasons for Violence Scale (Stuart et al., 2006):

14. To get away from you?

15. Because of stress?

16. Because they didn't know what to do with feelings?

17. Because they were provoked or pushed over the edge?

18. Because they were cheated on?

19. Because you were going to walk away or leave a conflict before it was solved?

20. To shut you up or to get you to leave them alone?

21. To get you to do something or stop doing something?

22. To hurt your feelings?

23. To make you agree with them?

24. To make you scared or afraid?

25 . Because they were afraid you were going to leave them?

26 . Because they didn't believe that you cared about them?

27. Because they were under the influence of drugs or alcohol?

28. Because they wanted to have sex and you didn't? 


\section{Appendix L:}

Emotional Impact of IPA (Created by Authors)

Participants are asked the following (randomized if regarding themselves or their partner first) for each incident.

DIRECTIONS: Below is a list of words that describe feelings people have. Please read each one carefully. Then select the number that corresponds with the best description of how you/your partner felt after this incident.

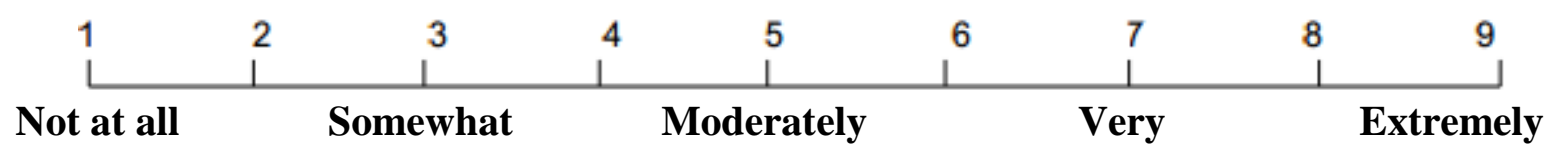

1. Unhappy

2. Depressed

3. Helpless

4. Worthless

5. Ashamed

6. Cheerful

7. Confused

8. Emotionally hurt

9. Uncertain about things

10. Tense

11. On edge

12. Afraid

13. Angry/Anxious

14. Aroused 


\section{Appendix M:}

Alcohol Use

Alcohol Use Disorders Identification Test (AUDIT; Saunders et al., 1993)

For 1-8: $0=$ never to $4=$ daily

For 9-10: $0=$ Never and $4=$ Yes, during the last year

1. How often do you have a drink containing alcohol?

2. How many drinks containing alcohol do you have on a typical day when you are drinking?

3. How often do you have 6 or more drinks on one occasion?

4. How often during the last year have you found that you were not able to stop drinking once you had started?

5. How often during the last year have you failed to do what was normally expected of you because of drinking?

6. How often during the last year have you needed a first drink in the morning to get yourself going after a heavy drinking session?

7. How often during the last year have you had a feeling of guilt or remorse after drinking?

8. How often during the last year have you been unable to remember what happened the night before because you were drinking?

9. Have you or someone else been injured as a result of your drinking?

10. Has a relative or friend, or a doctor or other health care worker been concerned about your drinking or suggested you cut down? 


\section{Appendix N:}

Attachment Anxiety

Experiences in Close Relationships Questionnaire - Revised Attachment Subscale of Anxiety (ECR-RFraley et al., 2000)

$1=$ extremely disagree, $2=$ strongly disagree, $3=$ disagree, $4=$ slightly disagree, $5=$ neither disagree or agree, $6=$ slightly agree, $7=$ agree, $8=$ strongly agree, $9=$ extremely agree

1. I'm afraid that I will lose my partner's love.

2. I often worry that my partner will not want to stay with me.

3. I often worry that my partner doesn't really love me.

4. I worry that romantic partners won't care about me as much as I care about them.

5. I often wish that my partner's feelings for me were as strong as my feelings for him or her.

6. I worry a lot about my relationships.

7. When my partner is out of sight, I worry that he or she might become interested in someone else.

8. When I show my feelings for romantic partners, I'm afraid they will not feel the same about me.

9. I rarely worry about my partner leaving me.

10. My romantic partner makes me doubt myself.

11. I do not often worry about being abandoned.

12. I find that my partner(s) don't want to get as close as I would like.

13. Sometimes romantic partners change their feelings about me for no apparent reason.

14. My desire to be very close sometimes scares people away.

15. I'm afraid that once a romantic partner gets to know me, he or she won't like who I really am.

16. It makes me mad that I don't get the affection and support I need from my partner.

17. I worry that I won't measure up to other people.

18. My partner only seems to notice me when I'm angry. 


\section{Appendix O:}

\section{Attachment Avoidance}

Experiences in Close Relationships Questionnaire - Revised Attachment Subscale of Avoidance (ECR-R; Fraley et al., 2000)

$1=$ extremely disagree, $2=$ strongly disagree, $3=$ disagree, $4=$ slightly disagree, $5=$ neither disagree or agree, $6=$ slightly agree, $7=$ agree, $8=$ strongly agree, $9=$ extremely agree

1. I prefer not to show a partner how I feel deep down.

2. I feel comfortable sharing my private thoughts and feelings with my partner.

3. I find it difficult to allow myself to depend on romantic partners.

4. I am very comfortable being close to romantic partners.

5. I don't feel comfortable opening up to romantic partners.

6. I prefer not to be too close to romantic partners.

7. I get uncomfortable when a romantic partner wants to be very close.

8. I find it relatively easy to get close to my partner.

9. It's not difficult for me to get close to my partner.

10. I usually discuss my problems and concerns with my partner.

11. It helps to turn to my romantic partner in times of need.

12. I tell my partner just about everything.

13. I talk things over with my partner.

14. I am nervous when partners get too close to me.

15. I feel comfortable depending on romantic partners.

16. I find it easy to depend on romantic partners.

17. It's easy for me to be affectionate with my partner.

18. My partner really understands me and my needs. 


\section{Appendix P:}

\section{Controlling Behavior}

The Controlling Behaviors Scale (Graham-Kevan \& Archer, 2003)

Economic. Each measure of economic control is the mean of five items with a 5-point response format ranging from 1 (never) to 9 (always). The items were as follows:

1. Did you/your partner disapprove of the other working or studying?

2. If yes, did you/your partner try and prevent or make difficult the other working or studying?

3. Did you/your partner feel it was necessary to have control of the other's money (e.g., wage, benefit)?

4. If yes, did you/your partner give the other an allowance or require other to ask for money?

5. Did you/your partner have knowledge of the family income?

Threats. Each measure of the use of threats is the mean of four items with a 5-point response format ranging from 1 (never) to 9 (always). The items were as follows:

1. Did you/your partner make or carry out threats do something to harm the other?

2. Did you/your partner threaten to leave the other and/or commit suicide?

3. Did you/your partner threaten to report the other to welfare?

4. Did you/your partner encourage the other to do illegal things he/she would not otherwise have done?

Intimidation. Each measure of the use of intimidation is the mean of five items with a 5-point response format ranging from 1 (never) to 9 (always). The items were as follows:

1. Did you/your partner use looks, actions, and/or gestures to change the other's behavior?

2. If yes, did you/your partner make the other afraid when this was done?

3. Did you/your partner smash property when annoyed/angry?

4. If yes, was it the other's property?

5. When angry, did you/your partner vent anger on household pets?

Emotional. Each measure of the use of emotional abuse is the mean of five items with a 5-point response format ranging from 1 (never) to 9 (always). The items were as follows:

1. Did you/your partner put the other down when they felt the other was getting "too big for their boots"?

2. If yes, did you/your partner put the other down in front of others (friends, family, children)?

3. Did you/your partner try to humiliate the other in front of others?

4. Did you/your partner tell the other that he/she was going crazy? 
5. Did you/your partner call the other unpleasant names?

Isolation. Each measure of the use of isolation is the mean of five items with a 5-point response format ranging from 1 (never) to 9 (always). The items were as follows:

1. Did you/your partner restrict the amount of time the other spent with friends and/or family?

2. If you/your partner went out, did the other want to know where the other went and who the other spoke to?

3. Did you/your partner limit the other's activities outside the relationship?

4. Did you/your partner feel suspicious and jealous of the other?

5. If yes, was this used as a reason to monitor and control the other's activities? 


\section{Appendix Q:}

Emotion Dysregulation

Difficulties in Emotion Regulation Scale (DERS; Gratz \& Roemer, 2004)

Please use the following scoring key to answer:

\begin{tabular}{lllllllll}
1 & 2 & 3 & 4 & 5 & 6 & 7 & 8 & 9 \\
& 1 & 1 & 1 & 1 & 1 & 1 & 1 & \\
\hline
\end{tabular}

$\begin{array}{llll}\text { Never } & \text { Sometimes } & \text { Frequently } & \text { Almost Always }\end{array}$

Nonacceptance of Emotional Responses (NONACCEPTANCE)

1. When I'm upset, I feel guilty for feeling that way.

2. When I'm upset, I feel ashamed with myself for feeling that way.

3. When I'm upset, I become embarrassed for feeling that way.

4. When I'm upset, I become angry with myself for feeling that way.

5. When I'm upset, I become irritated with myself for feeling that way.

6. When I'm upset, I feel like I am weak.

\section{Difficulties Engaging in Goal-Directed Behavior (GOALS)}

1. When I'm upset, I have difficulty concentrating.

2. When I'm upset, I have difficulty focusing on other things.

3. When I'm upset, I have difficulty getting work done.

4. When I'm upset, I have difficulty thinking about anything else.

5. When I'm upset, I can still get things done.

Impulse Control Difficulties (IMPULSE)

1. When I'm upset, I lose control over my behaviors.

2. When I'm upset, I have difficulty controlling my behaviors.

3. When I'm upset, I become out of control.

4. When I'm upset, I feel out of control.

5. I experience my emotions as overwhelming and out of control.

6. When I'm upset, I feel like I can remain in control of my behaviors.

Lack of Emotional Awareness (AWARENESS)

1. I am attentive to my feelings.

2. I pay attention to how I feel. 
3. When I'm upset, I acknowledge my emotions.

4. When I'm upset, I believe that my feelings are valid and important.

5. I care about what I am feeling.

6. When I'm upset, I take time to figure out what I'm really feeling. (r)

Limited Access to Emotion Regulation Strategies (STRATEGIES)

1. When I'm upset, I believe that I'll end up feeling very depressed.

2. When I'm upset, I believe that I will remain that way for a long time.

3. When I'm upset, I believe that wallowing in it is all I can do.

4. When I'm upset, it takes me a long time to feel better.

5. When I'm upset, I believe that there is nothing I can do to make myself feel better.

6. When I'm upset, I know that I can find a way to eventually feel better. (r)

7. When I'm upset, my emotions feel overwhelming.

8. When I'm upset, I start to feel very bad about myself.

Lack of Emotional Clarity (CLARITY)

1. I have difficulty making sense out of my feelings.

2. I have no idea how I am feeling.

3. I am confused about how I feel.

4. I know exactly how I am feeling.

5. I am clear about my feelings. 


\section{Appendix R:}

Hypergender Ideology

Hypergender Ideology Scale (Hamburger, Hogben, McGowen, \& Dawson, 1996)

$1=$ extremely disagree, $2=$ strongly disagree, $3=$ disagree, $4=$ slightly disagree, $5=$ neither disagree or agree, $6=$ slightly agree, $7=$ agree, $8=$ strongly agree, $9=$ extremely agree

1. A true man knows how to command others.

2. The only thing a lesbian needs is a good, stiff cock.

3. Men should be ready to take any risk, if the payoff is large enough.

4. No wife is obliged to provide sex for anybody, even her husband.

5. Women should break dates with female friends when guys ask them out.

6. Men have to expect that most women will be something of a prick-tease.

7. A real man can get any woman to have sex with him.

8. Women instinctively try to manipulate men.

9. Get a woman drunk, high, or hot and she'll let you do whatever you want.

10. Men should be in charge during sex.

11. It's okay for a man to be a little forceful to get sex.

12. Women don't mind a little force in sex sometimes because they know it means they must be attractive.

13. Homosexuals can be just as good at parenting as heterosexuals.

14. Gays and lesbians are generally just like everybody else.

15. Pickups should expect to put out.

16. If men pay for a date, they deserve something in return.

17. Effeminate men deserve to be ridiculed.

18. Any man who is a man needs to have sex regularly.

19. I believe some women lead happy lives without having male partners. 


\section{$\underline{\text { Appendix S: }}$}

Investment Model Scale

Investment Model Scale (IMS; Rusbult et al., 1998)

(9-point scale; $1=$ Do not agree at all, $9=$ agree completely)

Satisfaction:

1. Please indicate the degree to which you agree with each of the following statements regarding your current relationship (circle an answer for each item).

a. My partner fulfills my needs for intimacy (sharing personal thoughts, secrets, etc.).

b. My partner fulfills my needs for companionship (doing things together, enjoying each other's company, etc.).

c. My partner fulfills my sexual needs (holding hands, kissing, etc.).

d. My partner fulfills my needs for security (feeling trusting, comfortable in a stable relationship, etc.).

2. My partner fulfills my needs for emotional involvement (feeling emotionally attached, feeling good when another feels good, etc.).

3. I feel satisfied with our relationship

4. My relationship is much better than others' relationships

5. My relationship is close to ideal.

6. Our relationship makes me very happy.

7. Our relationship does a good job of fulfilling my needs for intimacy, companionship, etc.

Quality of Alternatives:

1. Please indicate the degree to which you agree with each statement regarding the fulfillment of each need in alternative relationships (e.g., by another dating partner, friends, family).

a. My needs for intimacy (sharing personal thoughts, secrets, etc.) could be fulfilled in alternative relationships.

b. My needs for companionship (doing things together, enjoying each other's company, etc.) could be fulfilled in alternative relationships.

c. My sexual needs (holding hands, kissing, etc.) could be fulfilled in alternative relationships.

d. My needs for security (feeling trusting, comfortable in a stable relationship, etc.) could be fulfilled in alternative relationships.

e. My needs for emotional involvement (feeling emotionally attached, feeling good when another feels good, etc.) could be fulfilled in alternative relationships.

2. The people other than my partner with whom I might become involved are very appealing.

3. My alternatives to our relationship are close to ideal (dating another, spending time with friends or on my own, etc.). 
4. If I weren't dating my partner, I would do fine-I would find another appealing person to date.

5. My alternatives are attractive to me (dating another, spending time with friends or on my own, etc.).

6. My needs for intimacy, companionship, etc., could easily be fulfilled in an alternative relationship.

Investment Size:

1. Please indicate the degree to which you agree with each of the following statements regarding your current relationship.

a. I have invested a great deal of time in our relationship.

b. I have told my partner many private things about myself (I disclose secrets to him/her).

c. My partner and I have an intellectual life together that would be difficult to replace.

d. My sense of personal identity (who I am) is linked to my partner and our relationship.

e. My partner and I share many memories.

2. I have put a great deal into our relationship that I would lose if the relationship were to end.

3. Many aspects of my life have become linked to my partner (recreational activities, etc.), and I would lose all of this if we were to break up.

4. I feel very involved in our relationship-like I have put a great deal into it.

5. My relationships with friends and family members would be complicated if my partner and I were to break up (e.g., partner is friends with people I care about).

6. Compared to other people I know, I have invested a great deal in my relationship with my partner.

Commitment:

1. I want our relationship to last for a very long time.

2. I am committed to maintaining my relationship with my partner.

3. I would not feel very upset if our relationship were to end in the near future.

4. It is likely that I will date someone other than my partner within the next year.

5. I feel very attached to our relationship-very strongly linked to my partner.

6. I want our relationship to last forever.

7. I am oriented toward the long-term future of my relationship (for example, I imagine being with my partner several years from now). 


\section{Appendix T:}

Propensity and Perceived Partner Propensity for future IPA (Author-Created Scale)

DIRECTIONS: Please indicate how likely it is that you and your partner will do each of these things in the future.

How likely is this to happen in the future? $(1=$ extremely unlikely; $9=$ extremely likely $)$

1. I will be physically aggressive (e.g., push my partner, slap my partner).

2. I will be sexually aggressive (e.g., verbally pressure my partner for sex)

3. I will be psychologically aggressive (e.g., insult my partner, swear at my partner, threaten to date someone else).

4. I will be controlling (e.g., use looks, actions, and/or gestures to change my partner's behavior).

5. My partner will be physically aggressive (e.g., push me, slap me).

6. My partner will be sexually aggressive (e.g., verbally pressure me partner for sex).

7. My partner will be psychologically aggressive (e.g., insult me, swear at me, threaten to date someone else).

8. My partner will be controlling (e.g., use looks, actions, and/or gestures to change my behavior). 


\section{Appendix U:}

\section{Self-Esteem}

\section{Rosenberg Self-Esteem Scale (Rosenberg, 1965)}

Instructions: Below is a list of statements dealing with your general feelings about yourself. Circle the answer that best corresponds with how you feel about the question.

1 = extremely disagree, 2 = strongly disagree, $3=$ disagree, $4=$ slightly disagree, $5=$ neither disagree or agree, $6=$ slightly agree, $7=$ agree, $8=$ strongly agree, $9=$ extremely agree

1. On the whole, I am satisfied with myself.

2. At times, I think I am no good at all.

3. I feel that I have a number of good qualities.

4. I am able to do things as well as most other people.

5. I feel I do not have much to be proud of.

6. I certainly feel useless at times.

7. I feel that I'm a person of worth, at least on an equal plane with others.

8. I wish I could have more respect for myself.

9. All in all, I am inclined to feel that I am a failure.

10. I take a positive attitude toward myself.

Scoring: $\mathrm{SA}=3, \mathrm{~A}=2, \mathrm{D}=1, \mathrm{SD}=0$. Items with asterisk reverse scored $(\mathrm{SA}=0, \mathrm{~A}=1, \mathrm{D}=2, \mathrm{SD}=3$ ). Sum scores for the 10 items. The higher the score, the higher the self-esteem. Scores below 15 suggest low self-esteem. 